Det här verket har digitaliserats vid Göteborgs universitetsbibliotek. Alla tryckta texter är OCRtolkade till maskinläsbar text. Det betyder att du kan söka och kopiera texten från dokumentet. Vissa äldre dokument med dåligt tryck kan vara svåra att OCR-tolka korrekt vilket medför att den OCR-tolkade texten kan innehålla fel och därför bör man visuellt jämföra med verkets bilder för att avgöra vad som är riktigt.

This work has been digitized at Gothenburg University Library. All printed texts have been OCR-processed and converted to machine readable text. This means that you can search and copy text from the document. Some early printed books are hard to OCR-process correctly and the text may contain errors, so one should always visually compare it with the images to determine what is correct. 


\section{SOLVENT-ASSISTED DYEING OF WOOL}

BX

MARIANNE KARRHOLM

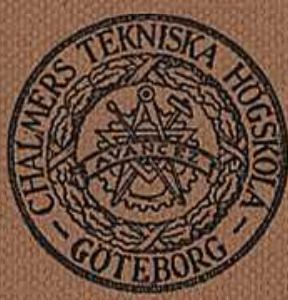

GÖTEBORG 1960

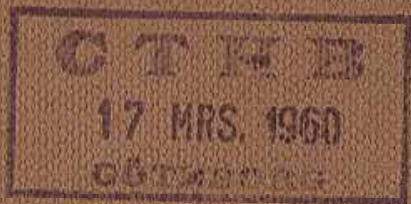


1.

4.

-

(6)

2.

3)

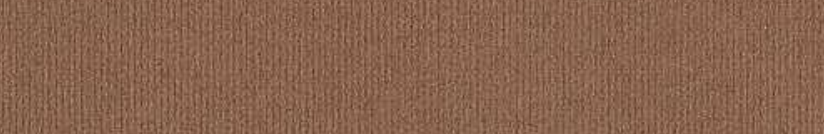

6. 


\title{
SOLVENT-ASSISTED DYEING OF WOOL
}

BY

\author{
MARIANNE K ÄRRHOLM
}

\begin{abstract}
AKADEMISK AVHANDLING
som med tillstånd av Chalmers Tekniska Högskola för teknologie doktorsgrads vinnande till offentlig granskning framlägges å föreläsningssalen för fysik, Gibraltargatan 5 B, Göteborg, lördagen den 2 april $1960 \mathrm{kl}$. 10.
\end{abstract}




\section{?}




\section{SOLVENT-ASSISTED DYEING OF WOOL \\ BY}

MARIANNE KÄRRHOLM 
TO MY MOTHER

TO MY HUSBAND 


\section{ERRATA}

\section{to the paper SOLVENT-ASSISTED DYEING OF WOOL by Marianne Kärrholm}

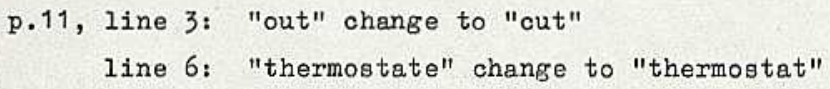

line 3 from the bottom: "conficence" change to "confidence" p.32, abscissa: "millimol/l" change to "millimol/100 ml"

p.33, The formula should be:<smiles>C=C(/C=C\C(=O)Br)CC1CCCCC1S(=O)(=O)O</smiles>

p.40, line 8 from the bottom: "increases" change to "increased"

p. 43, line 3: "chapter 4.3" change to "chapter 3.3"

line 16: "previous" change to "previously"

line 3 from the bottom: "is" change to "are"

p.45, table 8, column 4, line 14 from the bottom: "0.061" change to "0.614" p.60, line 8 from the bottom: "percentages" change to "percent" p.62, line 4: "in" change to "for" p.70, line 11: "Courmonts" change to "Courmont" p.77, line 6 from the bottom: "conslusions" change to "conclusions" p.90, line 11: "wool" change to "Wool"

To the Bibliography should be added:

Moncrieff, R.W. - Wool Shrinkage and its Prevention. London 1953. Whewell, C.S. and Selim, A. - The Action of Halogens on Wool. Part I. J. Soc.Chem. Ind. (London) 63 (1944), p. 121. 


$$
\text { . }
$$





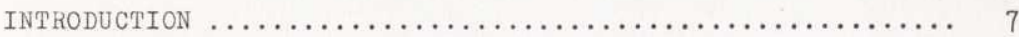

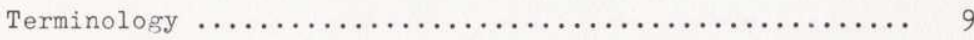

1. PRELININARY INVESTIGATIONS $\ldots \ldots \ldots \ldots \ldots \ldots \ldots \ldots \ldots \ldots \ldots \ldots \ldots \ldots \ldots \ldots$

1.1 Degree of sulphonation of dye $\ldots \ldots \ldots \ldots \ldots \ldots \ldots \ldots \ldots$

1.2 "Extraction" effect of solvent $\ldots \ldots \ldots \ldots \ldots \ldots \ldots \ldots 13$

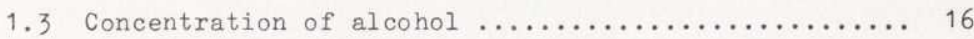

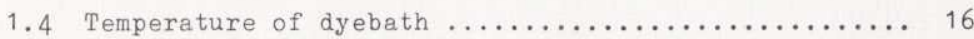

1.5 Surface-treatment of wool $\ldots \ldots \ldots \ldots \ldots \ldots \ldots \ldots \ldots \ldots \ldots \ldots$

1.6 Dye distribution between different fibres ......... 17

2. INVESTIGATION OF SOME FACTORS OF IMPORTANCE TO THE

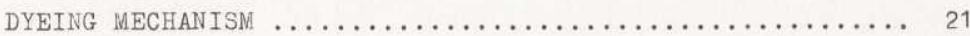

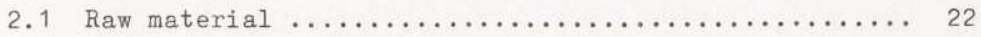

2.2 Adsorption of alcohol and dyestuff on wool from

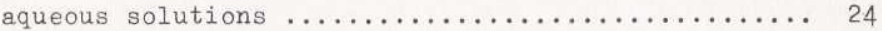

2.3 Dyeing at different $\mathrm{pH}-\mathrm{values} \ldots \ldots \ldots \ldots \ldots \ldots \ldots \ldots$

2.4 Dyeing of surface-treated wool $\ldots \ldots \ldots \ldots \ldots \ldots \ldots \ldots .43$

2.5 Influence of solvents on stress relaxation and

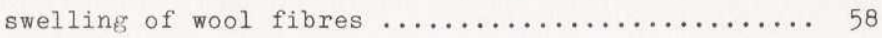

3. GENERAL DISCUSSION OF THE MECHANISM OF SOLVENT-ASSISTED

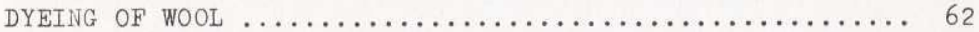

3.1 The effect of a solvent layer $\ldots \ldots \ldots \ldots \ldots \ldots \ldots \ldots \ldots$

3.2 Loosening of the fibre structure $\ldots \ldots \ldots \ldots \ldots \ldots \ldots .70$

3.3 Diffusion of dye in the adsorbed solvent $\ldots \ldots \ldots \ldots .72$

4. INDUSTRIAL EXPERTMENTS ON LOOSE WOOL DYEING $\ldots \ldots \ldots \ldots \ldots 75$

4.1 Performance of the experiments $\ldots \ldots \ldots \ldots \ldots \ldots \ldots \ldots$

4.2 Results and conclusions $\ldots \ldots \ldots \ldots \ldots \ldots \ldots \ldots \ldots \ldots \ldots$

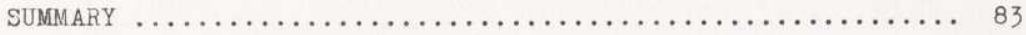

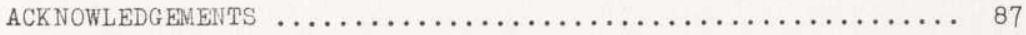







\section{INTRODUCTION}

The main difficulties in open width continuous dyeing of wool fabrics arise from the low rate of dyeing and the selectivity of the wool fibre surface towards many dyestuffs, resulting in uneven dyeing. The dyeing rate may be increased either by changing the properties of the wool fibre surface by chlorination or alkaline treatments, or by using dye assistants in the dyebath. The selectivity of the wool fibre surface may be decreased by chemical treatments (Barritt, Elsworth, 1948, and Lindberg, 1953), or by using special dyestuffs (Schetty, 1955). In 1956 Peters and Stevens showed that the introduction of small amounts of an organic solvent may increase the dyeing rate of wool to an appreciable extent. Since then, a few papers on this subject have been published. Gokhale, Peters and Stevens, 1958, have used the technique for dyeing acetate fibres. The Delaware Valley Section of AATCC, 1958, has investigated the influence of different solvents in increasing the dyeing rate of hydrophilic fibres such as wool and cotton. Delmenico, 1957, has applied the method for vigoreux printing of wool, finding benzyl alcohol to be the best solvent for technical purposes.

At the beginning of this investigation in 1955, this method was an alternative to surface-modification of wool by alkali or chlorine treatments in order to increase the rate of dyeing. At that time it was known (from unpublished observations by L. Peters) only that some organic compounds, with limited solubility in water, e.g. butanol, might increase the dyeing rate of some dyes on wool. Therefore, it was considered essential to obtain some general understanding of the conditions under which the method could be used. For this purpose a preliminary investigation was made. Some of the results from this research have already been published very briefly as a letter to the Editor (Kärrholm, Lindberg, 1956), but as they are of interest for the following industrial and laboratory 
experiments, they are included in this paper (chapter 1).

After the preliminary work had shown it was possible to obtain a considerable increase in the dyeing rate of technically important dyes, and at the same time a uniform distribution of the dye between different fibres, the next step was to try the method in industry. Experiments were made on loose wool dyeing, as this kind of dyeing was very easily carried out. These industrial experiments are briefly described in chapter 4, and the results show that a superior dyeing, compared with conventional methods, might be obtained. It was therefore considered justified to make a further investigation of solvent-assisted dyeings in order to obtain some understanding of the dyeing mechanism. It has been shown, both at this laboratory and by others (see e.g. the paper by Gokhale et al, 1958), that there is an adsorption of solvent by wool, and it might be assumed that this adsorption has an influence on the rate of dyeing. A special apparatus was designed to measure this adsorption quantitatively and also the increase in dyeing rate of a dye, non-aggregated in dilute solutions. These experiments, and further investigations of factors influencing the dyeing rate, are described in chapter 2 .

Possible dyeing mechanisms of solvent-assisted dyeings are discussed in chapter 3 , taking into consideration the results obtained from the different parts of this investigation. 


\section{Terminology}

The term "solvent-assisted" dyeing, used in this investigation, means that the dyeing rate of a dye in aqueous solution is increased by the addition of an organic compound to the dyebath. The compounds found to have this effect are usually organic solvents which are sparingly soluble in water. The solvents investigated are some alcohols and one amine. The general term alcohol, when not otherwise stated, means alcohols of limited solubility in water (butanol or higher homologues). The expressions butanol, amyl alcohol, hexanol, octyl alcohol etc. without further notation refer to primary normal alcohols.

All dyes used are commercial samples without further purification. The alcohols used were obtained from Theodor Schuchardt, München, or Fluka AG, Buchs, and were of the highest grade obtainable (usually "reinst"). 


\section{PRELIMINARY INVESTIGATIONS}

As mentioned in the Introduction these experiments were performed to obtain some general understanding of solvent-assisted dyeing of wool. The change in dyeing rate obtained with different dyestuffs and at different concentrations of alcohol in the solution was investigated. The influence of surface treatments and the dye distribution between different fibres was also studied.

\subsection{Degree of sulphonation of dye}

Experiments have been performed with a series of acid dyes differing only in the degree of sulphonation. The dyes used were Naphthalene Red J (CI Acid Red 88), Naphthalene Red EA (CI Acid Red 13) and Naphthalene Scarlet 4 R (CI Acid Red 18) with the following constitution:
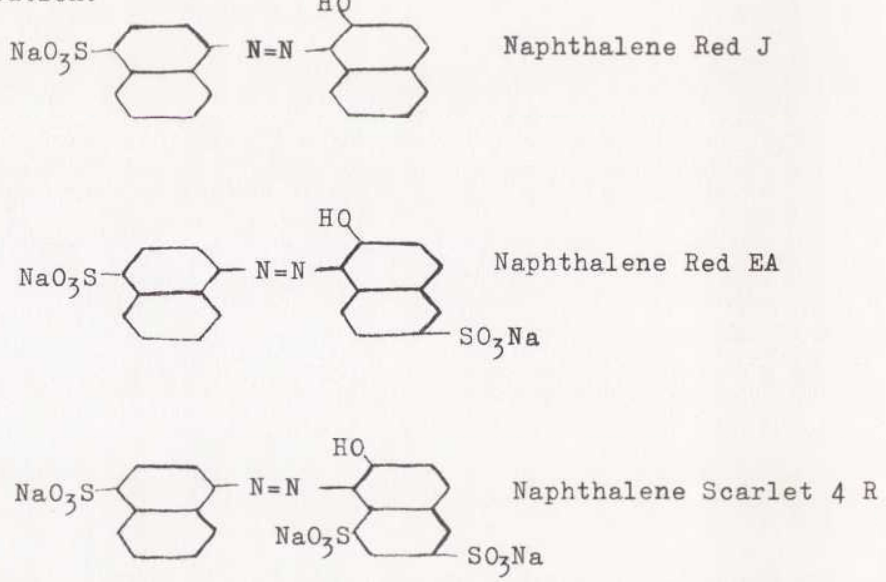

As these dyes have about the same equilibrium exhaustion, which is only affected to a small degree by the alcohols used (at concentrations below or not much greater than the saturation concentration of the alcohols in water), the time of half-dyeing can be used as a measure of the dyeing rate (Vickerstaff, 1954, p.147). The rate of sorption of dye by the wool fibres was determined by measuring the concentration of dye in the dyebath 
after different times. The dyeing experiments were performed in a $400 \mathrm{ml}$ glass beaker using a high liquor ratio (250:1), pH 2.6 and a temperature of $60^{\circ} \mathrm{C}$. One gram of wool top, out into pieces of $2 \mathrm{~mm}$ in length, was immersed into a small piece of glass tubing in a blank solution and brought to the test temperature in a water bath controlled by a thermostate. The fibres were then very quickly pushed through the tubing in to the dye liquor, circulated with a glass stirrer at about $1000 \mathrm{r} \cdot \mathrm{p} \cdot \mathrm{m}$. Small samples of the dye liquor were withdrawn at definite times and the concentration of dye determined, using a Beckman DU Spectrophotometer. By the addition of $3 \%(v / v)$ amyl alcohol to the dye liquor, the dyeing rate was increased ten times (i.e. the time of half-dyeing was decreased to the same extent) for the monosulphonated dye, Naphthalene Red J. For the disulphonated dye, Naphthalene Red EA, the increase in dyeing rate was about four times, while the trisulphonated dye, Naphthalene Scarlet $4 \mathrm{R}$, was unaffected by this alcohol.

When determining the partition ratio for these dyes between water and amyl alcohol, the monosulphonated dye was completely absorbed by the alcohol phase, the trisulphonated remained in the water phase and the disulphonated was soluble in both water and alcohol (in a partition ratio of $4: 1$ ). Apparently the degree of sulphonation determines the solubility of the dye in the alcohol, and this solubility, at least to some extent, seems to be a necessary condition to obtain an increased dyeing rate.

The partition ratio for a dye between water and solvent will be discussed later in connection with dyeing experiments using bromphenol blue at different $\mathrm{pH}$ values.

A new group of wool dyes, known as 1:2 chrom-complex dyes, has been developed to obtain dyes with reduced hydrophilic character, but still soluble in water (Schetty, 1955). These dyes do not contain any sulphonic acid groups and should be dyed from neutral solutions. The effect of amyl alcohol on the dyeing rate of these dyes is much greater than with the monosulphonated acid dyes. In Fig. 1 are shown 
some exhaustion-time curves for a dye of this type (Cibalanblau BL) with various concentrations of octyl alcohol or amyl alcohol in the dye liquor. The experiments were performed as described above, but at $\mathrm{pH}$ 6.4, using a phosphate buffer. The dyeing rate was increased with a factor of one hundred by the addition of $3 \%$ $(\mathrm{v} / \mathrm{v})$ amyl alcohol. In figure 1 an exhaustion-time curve refering to $5 \%(\mathrm{v} / \mathrm{v})$ of butanol in the dyebath is included for comparison with amyl alcohol. These alcohols are used in the industrial experiments, described in chapter 4.

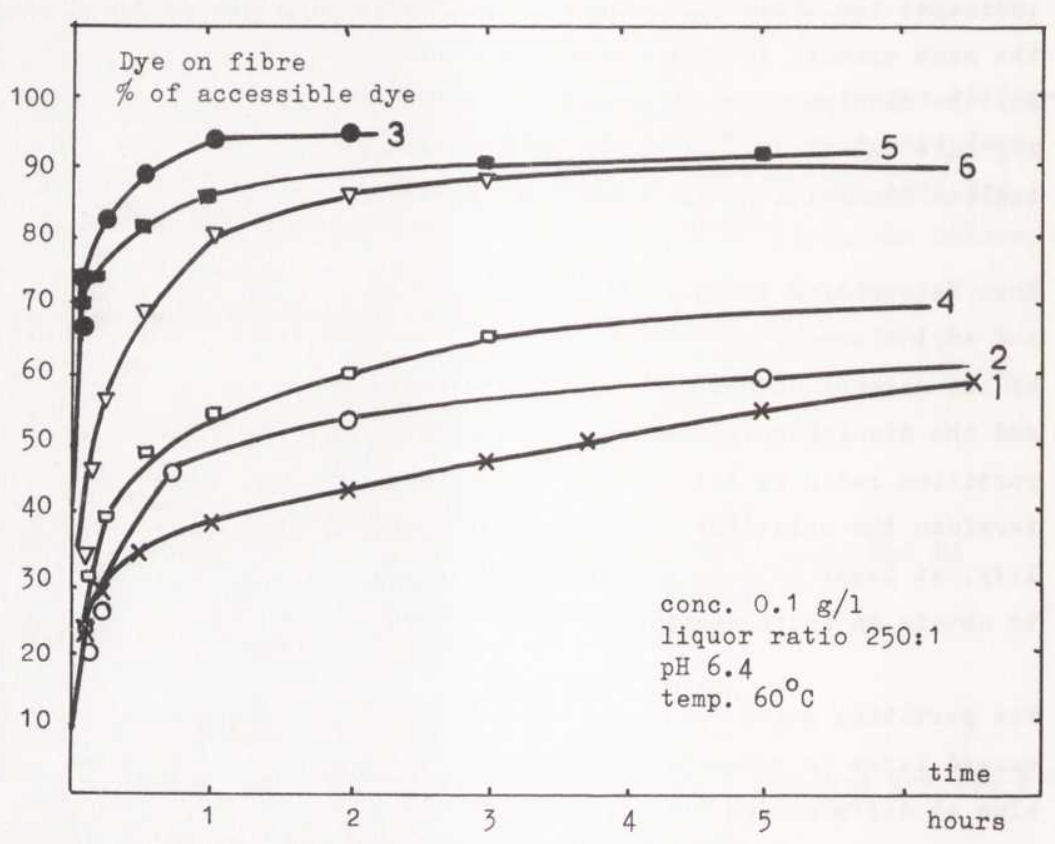
1) without addition
2) $1 \%$ amyl alcohol
3) $3 \%$ amyl alcohol

4) $0.2 \%$ octyl alcohol

All percentages as $\mathrm{v} / \mathrm{v}$

5) $1 \%$ octyl alcohol

6) $5 \%$ butanol

Fig. 1 - Dyeing rate of Cibalanblau BL on wool at different concentrations of alcohols in the bath. 


\section{2 "Extraction effect" of solvent}

A 60's Australian wool top was used for these experiments. It was kerosene-extracted in a mill, and the only other treatment was with ethyl ether at room temperature. However, it is known that the dyeing rate of wool is increased by extraction with solvents (Lindberg, 1953). The presence of a solvent in the dyebath might then increase the dyeing rate by this "extraction effect". To determine the extent to which this occurs, the ether-extracted wool top was treated with water containing $3 \%$ by volume of amyl alcohol for one hour at $60^{\circ} \mathrm{C}$. The wool was then rinsed in water, dried and cut

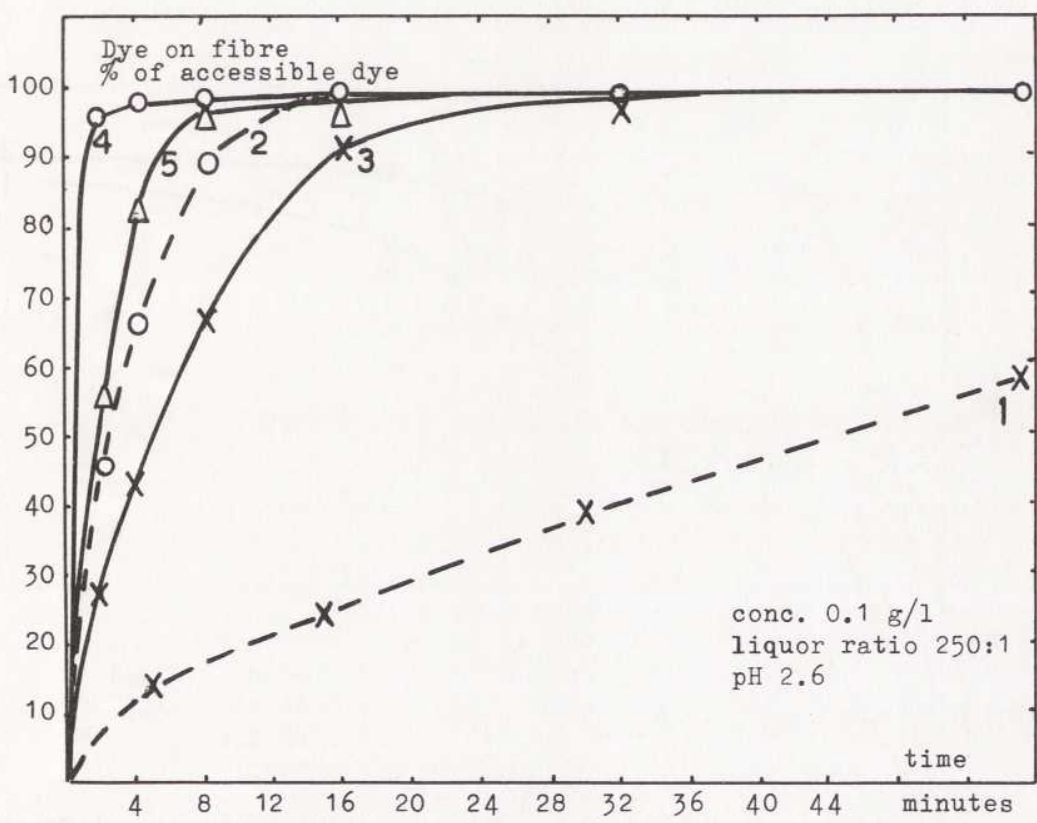

1) untreated wool, without addition, at $40^{\circ} \mathrm{C}$

2) " ", $3 \%$ amyl alcohol, at $40^{\circ} \mathrm{C}$

3) " ", without addition, at $60^{\circ} \mathrm{C}$

4) untreated or AAT-wool, $3 \%$ amyl alcohol, at $60^{\circ} \mathrm{C}$

5) AAT-wool, without addition, at $60^{\circ} \mathrm{C}$

Fig. 2 - Dyeing rate of Naphthalene Red $\mathrm{J}$ on wool at different conditions. 
into pieces of $2 \mathrm{~mm}$ length. This wool will be referred to as amyl alcohol-treated wool (AAT-wool). The time of half-dyeing was determined for AAT-wool with and without amyl alcohol in the dye liquor, using the dyes and dyeing technique described above. For all the sulphonated dyes, the dyeing rate was increased on AATwool compared with the ether-extracted wool.

An addition of amyl alcohol to the dye liquor further increased the dyeing rate of the monosulphonated dye on AAT-wool to the same value as that obtained on ether-extracted wool (see fig. 2). This was also true for the disulphonated dye, although the "extraction

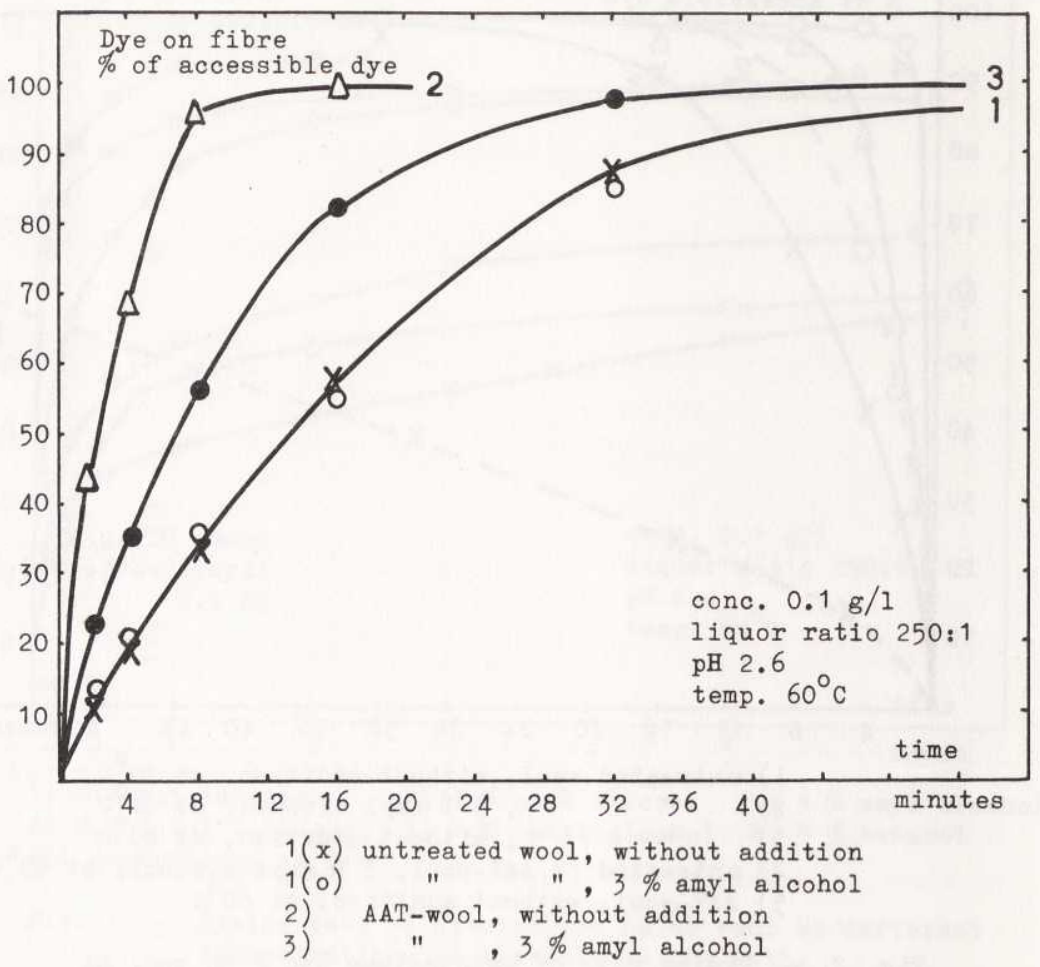

Fig. 3 - Dyeing rate of Naphthalene Scarlet $4 \mathrm{R}$ on wool at different conditions. 
effect" is relatively larger for this type of dye. For the trisulphonated dye, however, the reverse effect was obtained; the addition of amyl alcohol to AAT-wool decreased the rate of dyeing (see Fig. 3). The net effect on the dyeing rate, when a solvent in which the dye is insoluble, is added to the dyebath, is therefore dependent on whether an increase due to the "extraction effect" is obtained that is larger than a retardation due to the presence of the solvent.

In fig. 4 is seen that the same exhaustion-time curves were obtained on the AAT-wool and ether extracted wool both with and without the

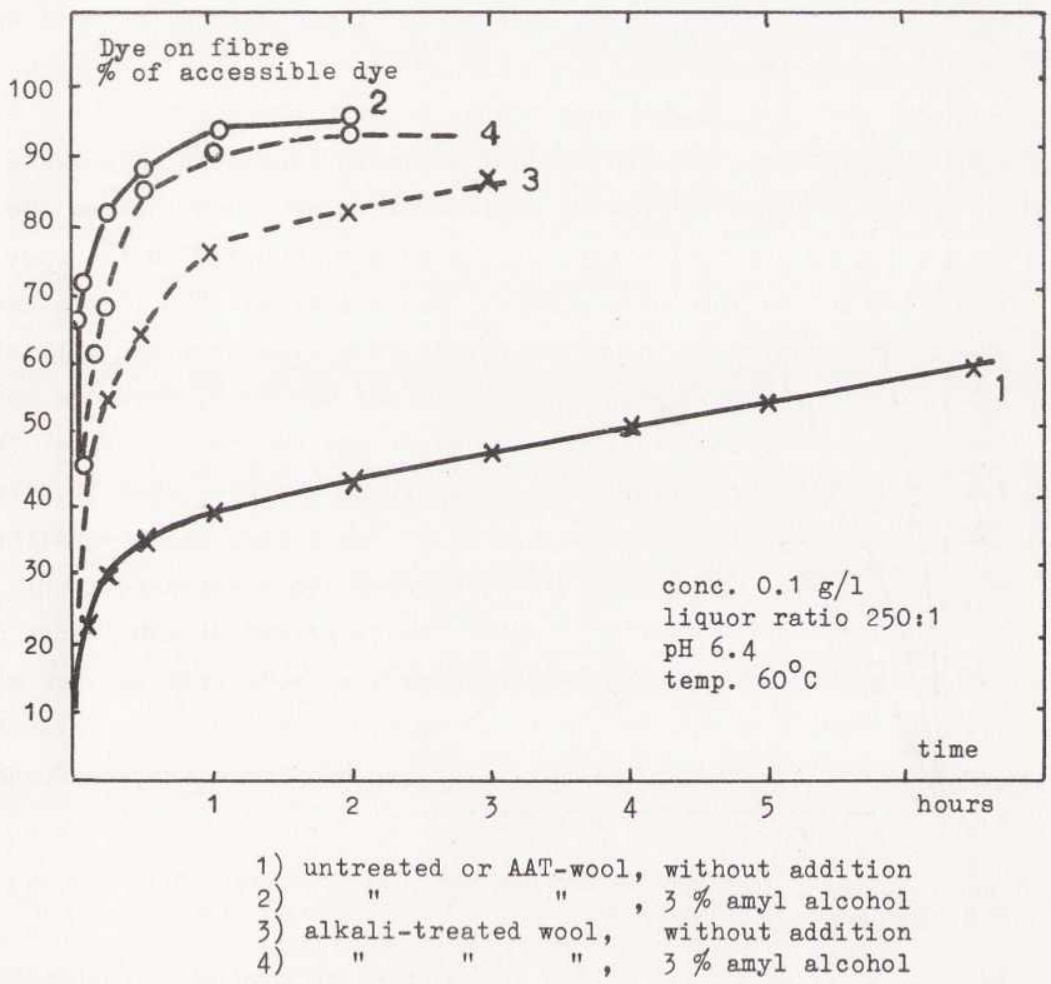

Fig. 4 - Dyeing rate of Cibalanblau BL on wool at different conditions. 
addition of amyl alcohol to the dye liquor for the 1:2 chrom-complex dye (Cibalanblau BL). With this type of dye, however, the largest increase in the dyeing rate was obtained by the addition of an alcohol to the dye liquor. It must be concluded, therefore, that the "extraction" effect" of an added alcohol may increase the dyeing rate in some cases, but this effect is unimportant in the mechanism of solvent-assisted dyeings.

\subsection{Concentration of alcohol}

In fig. 1 is shown the large effect of the concentration of alcohol in the dye liquor, the increase in dyeing rate being much greater near the saturation concentration of the alcohol. This is later shown to be dependent on the adsorption of the alcohol on wool and is considered in chapter 2 .

Referring to dye - alcohol systems where an appreciable increase in dyeing rate is obtained, a concentration of alcohol above the saturation concentration will cause smaller increase in the dyeing rate, as has also been shown by Gokhale et al 1958 in the dyeing of triacetate fibres. The equilibrium concentration will also be influenced, more dye will remain in the dye bath, when the concentration of alcohol is increased above its saturation value. Thus dyeings carried out from a bath, containing the dye, dissolved in an alcohol, saturated with water, will show a very small equilibrium exhaustion of dye on the fibre. Dyeing ether-extracted wool with Cibalanblau BL $(0.3 \mathrm{~g} / \mathrm{l})$ under the experimental conditions described gives a dye uptake of $20 \mathrm{mg}$ per $\mathrm{g}$ of wool from aqueous solution after 24 hours, but only $1.8 \mathrm{mg}$ per $g$ of wool from butanol saturated with water. Fibre swelling has been measured and found to be the same in the two systems.

\subsection{Temperature of dyebath}

In fig. 2 are shown two curves which refer to dyeing of Naphthalene Red $\mathrm{J}$ at $40^{\circ} \mathrm{C}$. It is obvious that the increase in dyeing rate caused by amyl alcohol is greater at $40^{\circ} \mathrm{C}$ than at $60^{\circ} \mathrm{C}$. The investiga- 
tion of solvent-assisted dyeings of hydrophilic fibres by the Delaware Valley Section of AATCC, 1958, has shown this to be generally true, the increase in dyeing rate brought about by solvent being greater at lower than at higher temperatures.

\subsection{Surface treatment of wool}

At an early stage of this investigation, it was considered probable that the surface properties of the wool fibres might play an important role in solvent-assisted dyeings. In order to test this, wool top was treated with sodium hydroxide in butanol-kerosene to change the hydrophobic wool surface into a hydrophilic one and to make the epicuticle easier to penetrate (Wikström et al, 1955). The surface-treated wool was then dyed with Cibalanblau BL, and the influence of amyl alcohol on the dyeing rate was compared with that obtained on untreated wool. The results are shown in fig. 4, and it is seen that the alcohols gives a lower increase in the dyeing rate of surface-treated wool than with untreated wool. No further discussion will be made at this stage as the influence of surface treatments on solvent-assisted dyeings will be discussed later in a separate chapter.

\subsection{Dye distribution between different fibres}

At the beginning of the dyeing period the dye is usually unevenly distributed between different fibres and also between different parts of the same fibre. Lindberg, 1953, has reported that the uneveness is greater for a disulphonated dye than for a monosulphonated one of the same constitution. This has also been found to be true for the three acid dyes mentioned above, the uneveness being greatest for the trisulphonated and least for the monosulphonated dye. It is, however, of both practical and theoretical interest to know, how the dye distribution will be influenced by the addition of a solvent to the dye liquor. For this purpose fibre samples were taken from the dyebath at different times and examined under the microscope. One hundred fibres were classified into four groups; undyed, spot dyed, lightly dyed and heavily dyed. The results shown in table 1 are for 
Table 1

Dye distribution after dyeing with Naphthalene Red J. $\mathrm{pH} 2.6$; temp. $60^{\circ} \mathrm{C}$; conc. $0.1 \mathrm{~g} / 1$; liquor ratio $250: 1$

\begin{tabular}{|c|c|c|c|c|c|c|}
\hline \multirow{2}{*}{$\begin{array}{l}\text { Time } \\
\text { of } \\
\text { dyeing } \\
\text { min. }\end{array}$} & \multirow{2}{*}{$\begin{array}{l}\text { Addi- } \\
\text { tion } \\
\text { to } \\
\text { dyebath }\end{array}$} & \multirow{2}{*}{$\begin{array}{l}\text { Dye on } \\
\text { fibre } \\
\% \text { of avail- } \\
\text { able dye }\end{array}$} & \multicolumn{4}{|c|}{$\%$ of total fibres belonging to } \\
\hline & & & $\begin{array}{l}\text { Un- } \\
\text { dyed } \\
\text { fibres }\end{array}$ & $\begin{array}{l}\text { Spot- } \\
\text { dyed } \\
\text { fibres }\end{array}$ & $\begin{array}{l}\text { Lightly } \\
\text { dyed } \\
\text { fibres }\end{array}$ & $\begin{array}{l}\text { Heavily } \\
\text { dyed } \\
\text { fibres }\end{array}$ \\
\hline 2 & & 28 & 48 & 19 & 27 & 6 \\
\hline 10 & none & 75 & 9 & 20 & 48 & 23 \\
\hline 40 & & 99 & 0 & 10 & 40 & 50 \\
\hline 2 & $3 \%$ amyl & 95 & 0 & 0 & 73 & 27 \\
\hline 20 & alcohol & 99 & 0 & 0 & 22 & 78 \\
\hline
\end{tabular}

the monosulphonated dye, Naphthalene Red J, on ether-extracted wool with and without the addition of amyl alcohol to the dyebath. The figures given are the mean values of four samples tested by two different persons. When amyl alcohol was present in the dye liquor, about $70 \%$ of the fibres were classed as "lightly dyed" after only 2 minutes dyeing, and after 20 minutes about $80 \%$ were "heavily dyed". Without the addition of an alcohol, $50 \%$ of the fibres were "undyed" after 2 minutes and the remainder were distributed among the other three groups. After 40 minutes there were still some "spot-dyed" fibres, but the majority were "lightly" and "heavily" dyed.

For the disulphonated dye an equal change in the distribution of dye between the fibres was obtained by the addition of amyl alcohol, although the change was not as great as for the monosulphonated dye. Dyeing with the trisulphonated dye resulted in the most uneven dyeing; the group of "spot-dyed" fibres was particularly large. As would be expected, there was no appreciable change in the dye distribution after the addition of amyl alcohol, because, as mentioned earlier, no change in the dyeing rate was ob- 
served with this dye.

In table 1 the dye distribution after a fixed time of dyeing is compared for dyeings with and without the addition of amyl alcohol. It would also be of interest to make a similar comparison for dyeings in which the same amount of dye was present on the wool in each case. However, the dyeing rate of Naphthalene Red $\mathrm{J}$ is too large at $\mathrm{pH}$ 2.6 so a test series was made at $\mathrm{pH} 4.3$. The results are given in tabie 2. For the same amount of dye on the fibre, the distribution was also more uniform when the dyeing was made in the presence of amyl alcohol, although the effect was less marked than when the comparison was made after equal dyeing times.

\section{Table 2}

Dye distribution after dyeing with Naphthalene Red J. $\mathrm{pH} 4.3$; temp. $60^{\circ} \mathrm{C}$; conc. $0.1 \mathrm{~g} / 1$; liquor ratio $250: 1$

\begin{tabular}{|c|c|c|c|c|c|c|}
\hline \multirow{2}{*}{$\begin{array}{l}\text { Time } \\
\text { of } \\
\text { dyeing } \\
\text { min. }\end{array}$} & \multirow{2}{*}{$\begin{array}{l}\text { Addi- } \\
\text { tion } \\
\text { to } \\
\text { dyebath }\end{array}$} & \multirow{2}{*}{$\begin{array}{l}\text { Dye on } \\
\text { fibre } \\
\% \text { of avail- } \\
\text { able dye }\end{array}$} & \multicolumn{4}{|c|}{$\%$ of total fibres belonging to } \\
\hline & & & $\begin{array}{l}\text { Un- } \\
\text { dyed } \\
\text { fibres }\end{array}$ & $\begin{array}{l}\text { Spot- } \\
\text { dyed } \\
\text { fibres }\end{array}$ & $\begin{array}{l}\text { Lightly } \\
\text { dyed } \\
\text { fibres }\end{array}$ & $\begin{array}{l}\text { Heavily } \\
\text { dyed } \\
\text { fibres }\end{array}$ \\
\hline 10 & & 63 & 18 & 12 & 68 & 2 \\
\hline 18 & none & 83 & 4 & 8 & 76 & 12 \\
\hline 40 & & 96 & 5 & 9 & 18 & 68 \\
\hline 2 & $3 \%$ & 62 & 1 & 10 & 73 & 16 \\
\hline 4 & amyl & 83 & 0 & 1 & 30 & 69 \\
\hline 10 & alcohol & 96 & 0 & 3 & 17 & 80 \\
\hline
\end{tabular}

The results indicate that if the dyeing rate of wool is increased by a solvent, the distribution of dye will be more uniform between different fibres and between different parts of the same fibre. This kind of uneveness is considered to be due to a variation in 
surface properties of the wool; the outermost layer (the epicuticle) being intact or not modified on some fibres or some parts of the same fibre, and thus offering resistance to the dye molecules. The addition to the dyebath of an alcohol, which is adsorbed by the wool (as shown later) and in which the dye is soluble, would then give the entire fibre, and different fibres, the same permeability to the dye. 


\section{CHAPTER 2}

\section{INVESTIGATION OF SOME FACTORS OF IMPORTANCE TO}

\section{THE DYEING MECHANISM}

The preliminary investigation described in the previous chapter showed that a great increase in the dyeing rate could be obtained by addition of butanol or one of its higher homologues to the dyebath. Furthermore, the dye distribution between different fibres and different parts of the same fibre became more uniform. Further experiments are, however, necessary to obtain some understanding of the dyeing mechanism.

Soon after the discovery of solvent-assisted dyeing, it was found that the alcohols are adsorbed by the wool fibres (Stevens and Peters, 1956). It was of interest therefore to measure this adsorption quantitatively and determine if there is any simple relation between the dyeing rate and the amount of adsorption.

This adsorption, however, cannot be the only factor of importance, as the dyeing rate of many dyes is unaffected by solvents. The partition ratio of the dye between solvent and water seems to be another important factor. This factor has been studied for an indicator dye at different pH-values. A change of the surface properties of wool will also influence the dyeing rate in the presence of solvents, as shown by the preliminary investigation. This might be of importance for the dyeing mechanism and further experiments have been performed on this subject.

Valuable information concerning the dyeing mechanism might also be obtained from changes in physical properties brought about by the solvents used. The stress-relaxation properties and the swelling of single wool fibres have been investigated for this purpose. 


\subsection{Raw material}

\section{Ether-alcohol-water extracted wool}

Australian wool tops from $60^{\circ}$ s wool was used as the raw material. It is important that, as far as possible, the wool fibres are uniform as regards dyeing rate, and that the surface layer of the wool fibres is intact. Preliminary experiments showed, that the dyeing rate may be influenced to an appreciable extent by extraction with organic solvents or water solutions and even by different methods of drying. For these reasons, a wool top was chosen which had been scoured in kerosene in a Swedish textile mill and had never been in contact with water since it left the sheep. The top was further cleaned by extraction with ethyl ether, ethanol and water. The top was cut into pieces of about $12 \mathrm{~g}$ each, with a thread knotted round each end to keep the fibres in position during the treatments. The thread was also used to mark the samples. Each piece was immersed in $500 \mathrm{ml}$ of the solvent in separate beakers for $10 \mathrm{~min}$, and was then pressed between filter papers. Three baths of each solvent were used, and after the final water treatment, the wool was dried at $50^{\circ} \mathrm{C}$ overnight and then conditioned at $65 \%$ relative humidity and $20^{\circ} \mathrm{C}$. All wool used was taken from the same top, and all extractions made by the same person within the shortest possible time. In all, about 200 pieces of wool top were extracted. About 6 pieces could be treated at the same time, and these were marked in the same way. Furthermore, the marking was made in such a way, that the position of the piece in the original top could be identified, as well as the number of the extraction series.

When chemical treatments were to be made, the pieces of top could then be selected so, that different treatments could be performed on pieces with the same marking. Furthermore, all investigations, where dyeing rates are compared, were made on small samples of cut wool fibres taken from the same large, general sample. An investigation of the alcohol adsorption of extracted wool, however, showed that the wool is rather uniform in this respect. 
Wool top, extracted as above, is referred to as EAW-wool, but when being compared with chemically treated wool, is sometimes also referred to as untreated wool.

\section{Chlorine treatments}

The surface properties of wool fibres were modified to different degrees by dry chlorination. A degree of modification was desired which only affected the cuticular layers of the wool, leaving the cortex unchanged. This can be obtained approximately by treatment with chlorine in a solvent, e.g. carbon tetrachloride (Moncrieff, 1953). Lindberg has followed the effect of chlorination on the frictional properties of wool fibres (Lindberg, Gralén, 1949). Whewell and Selim, 1944, have also shown, that the degree of penetration of the chlorine is dependent on the amount of water present in the system. Using Lindberg's data, reaction conditions were chosen to obtain 3 different degrees of modification.

A) $8 \times 12 \mathrm{~g}$ of EAW-wool was dried at $105^{\circ} \mathrm{C}$ for $1 \mathrm{hr}$ and treated with $0.3 \mathrm{~m} \mathrm{Cl}_{2}$ in dried carbon tetrachloride for $10 \mathrm{~min}$ at a liquor ratio of $25: 1$. The samples were rinsed once with carbon tetrachloride, twice with ethanol, twice with distilled water, once with buffer solution of $\mathrm{pH} 7.7$ and finally four times with distilled water using a fresh bath for each rinse. A treatment such as this increases the coefficient of friction without affecting the resistance to mechanical abrasion of the scales of the wool fibres.

B) The same treatment as A), but the EAW-wool was conditioned at $65 \%$ relative humidity and thus contained about $13 \%$ by weight of water. The carbon tetrachloride was not dried. This treatment increases the coefficient of friction, but also decreases the resistance to mechanical abrasion of the scales of the wool fibres.

C) The same treatment as B, but extended to $60 \mathrm{~min}$. The whole cuticular layer was then removed by treatment with papain after the chlorination (Patent specification BP 546.915, 1941). For this purpose a solution of a $0.025 \%$ commercial papain in an acetate buffer, containing $0.25 \%$ sodium bisulphite at $\mathrm{pH} 5.0$ was used. The wool tops were treated in this bath for 2 hours at $65^{\circ} \mathrm{C}$. The samples 
were rinsed in the usual way after chlorination, but the papain solution replaced the buffer solution of $\mathrm{pH} 7.7$. After the papain treatment, the samples were rinsed in distilled water, treated with buffer of $\mathrm{pH} 7.7$, rinsed again and dried overnight at $50^{\circ} \mathrm{C}$.

Microscopic examination of the treated wool revealed only small changes in the appearance after treatment A) and B) but an almost completely descaled wool after treatment $C$ ). The weight loss was less than $1 \%$ after treatment $\mathrm{A}$ and $\mathrm{B}$ but $20 \%$ after treatment $\mathrm{C}$.

The wettability of the wool samples was tested according to the method by Schuyten et al, 1949, and was found to be 72 dynes/cm, i.e. all three methods of chlorination resulted in a wool, the surface of which was wet by water.

The wool, treated as above, will be referred to as wool A, wool B and wool $\mathrm{C}$.

\subsection{Adsorption of alcohols and dyestuff on wool from aqueous}

\section{solutions.}

Preliminary experiments showed that alcohols were selectively adsorbed from aqueous solutions by wool. In order to measure the amount of adsorption, an apparatus was designed at the Institute. This apparatus could be used for dyeing experiments as well, thus making it possible to determine the amount of adsorption of alcohol and of dyestuff from the same experiment.

\section{Apparatus}

The apparatus consists of a glass cylinder about $22 \mathrm{~mm}$ in diameter, which is surrounded by a glass mantle for circulating water (See fig. 5 a and b).

The cylinder is grooved in both ends and can be tightly closed with teflon stoppers. A stainless steel shaft passes through the stopp- 

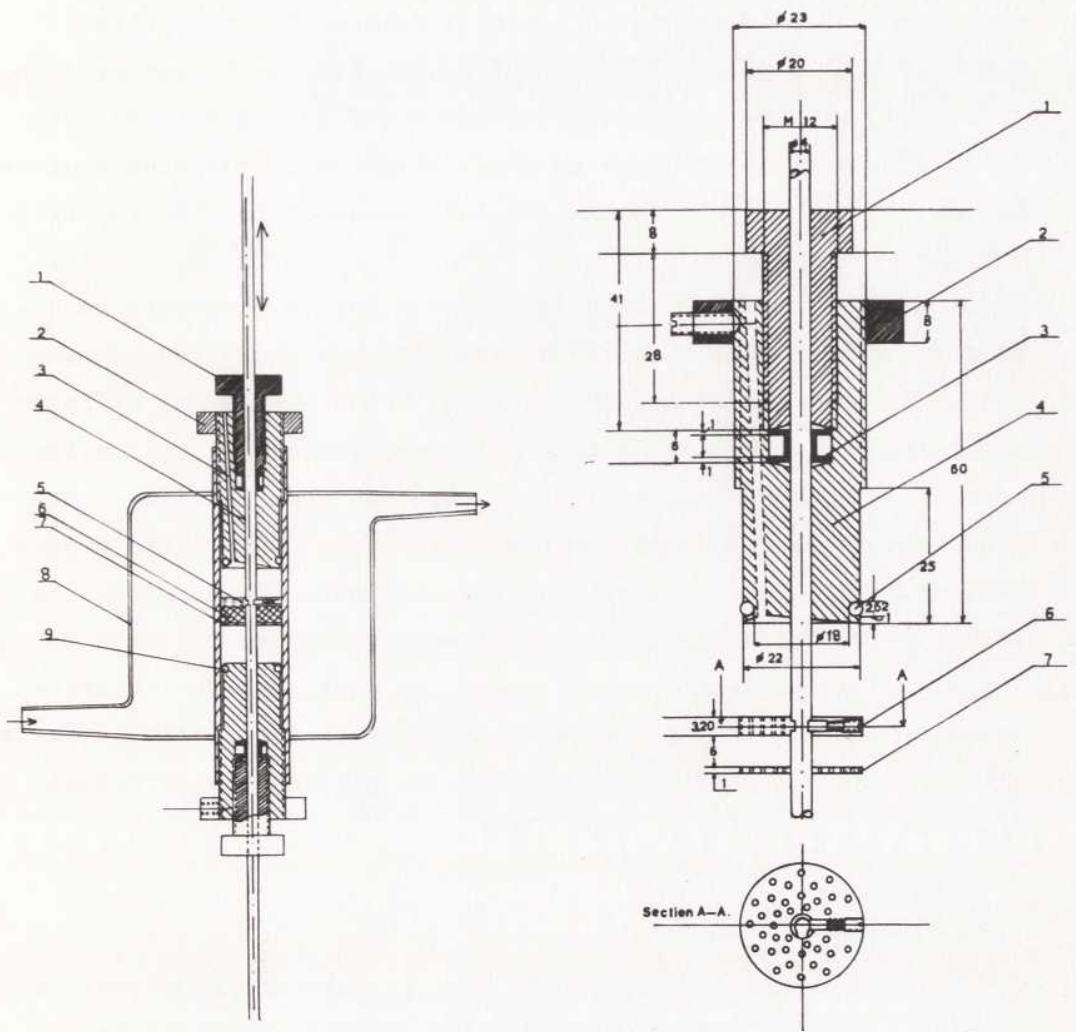

1) Teflon gland

2) Plastic ring

3) Bored hole in the teflon stopper

4) Stainless steel shaft

5) Upper disc.

6) Fibre sample

7) Lower disc, fixed to the shaft

8) Glass mantle

9) Rubber packing

Fig. 5 a

Apparatus for measurement of adsorption and dyeing rate.
1) Gland consisting of a teflon screw (1) and teflon packing (3)

2) Plastic ring

4) Teflon stopper

5) Rubber packing

6) Upper disc.

7) Lower disc.
Fig. 5 b

Details of teflon stopper and dises. 
ers. The fibres to be tested are held between two perforated discs of stainless steel. The lower disc is firmly connected to the shaft, but the upper disc is free and fixed to the shaft by means of a spring, which is released when the disc passes a groove in the rod. The $\varepsilon$ aft is connected to an eccentric, driven by a gear speed reducer motor. Thus the shaft is moving up and down through the stoppers. Teflon was chosen for the stoppers to obtain low friction against the shaft. After a short time, however, the motion of the shaft enlarged the holes in the stoppers and leakage occurred. A special gland was designed, consisting of small packing pieces of teflon, which were expanded against the shaft by means of a screw (See fig. 5 b). When these pieces were worn out, they were replaced by new ones. By changing the amount of wool and the distance between the discs, the bath ratio could be changed at a constant degree of packing. The distance between the discs was varied most simply by using different shafts, where the groove for the upper plate was placed at a different distance from the fixed lower plate.

\section{Test procedure}

The shaft carrying the lower disc, was put through the lower teflon stopper, and $15 \mathrm{ml}$ of the test solution placed in the inner cylinder. Water of desired temperature was circulated in the outer cylinder, and the temperature of the water measured on both sides of the apparatus. The rate of flow was adjusted to give the same temperature within $0.3^{\circ} \mathrm{C}$ on the incoming and outgoing water. Under these conditions the temperature of the outer cylinder was also obtained in the inner cylinder. For the adsorption experiments, a weighed amount of wool, cut in $2 \mathrm{~mm}$ pieces, was placed in the solution, and the upper disc put in position. The distance between the discs was chosen to correspond to a degree of packing of the wool of 0.2 (Degree of packing = volume of wet fibres/total volume). After the wool had been placed between the discs, the upper teflon stopper was screwed into position, the air escaping through a narrow hole, bored in the stopper. If the experiment was not 
carried out at room temperature, the final adjustment of the stopper was made when the solution had obtained test temperature. For dyeing or adsorption experiments, where the time is also measured, the test solution was first brought to the desired temperature, and the wool then entered into the solution, the stopper closed, and the shaft connected to the motor. The time elapsing from when the wool was brought into contact with the solution until the stirring could be commenced was about 22 seconds. By this procedure, experiments could be done with good reproducibility for times exceeding 2 minutes.

The test solution was forced through the plug of wool fibres as the plug was moving up and down in the closed space between the teflon stoppers. The shaft moved at a rate of 21 cycles per minute, which corresponds to a flow of liquid through the plug of about $200 \mathrm{ml}$ per min. and $\mathrm{cm}^{2}$ at a bath ratio of $30: 1$. After an experiment was finished, the upper stopper and the shaft with the fiber plug were removed, and the solution collected in a test tube. This procedure could be done within a few seconds.

To obtain a rate curve experimentally it is thus necessary to make a separate experiment for each time interval.

\section{Methods for determination of alcohol concentration}

Refractive index method

The amount of adsorption of alcohol or dyestuff was calculated from the difference in concentration of the test solution before and after the adsorption.

It is rather difficult to determine quantitatively the concentration of an aliphatic alcohol in aqueous solution by chemical methods. A colorimetric method using ammonium cerium nitrate was tried (Reid, Truelove, 1952), but found less accurate than a physical method, using the refractive index of a solution as a measure of concentration. This determination is simple, but a necessary condition 
is that the concentration of all other substances is constant. For our purpose this limits the applicability to solutions consisting of only one solute, as other solutes may well be adsorbed by the wool at the same time, also causing a change in refractive index. For the experiments a Zeiss dipping refractometer was used. The temperature was carefully controlled by circulating the bath surrounding the samples through a thermostat. All measurements were performed at $25.0^{\circ} \mathrm{C}$. The refractive index of the stock solution was measured at the same time as that of the test solution, and directly after each other, to minimize errors depending on time. Generally two adsorption experiments were carried out at each concentration of the alcohol. Calibration curves were established by measurements with known solutions. The measurement of refractive index was repeated three times on each solution.

Distilled water will dissolve some substance out of the wool. This continues for very long times, resulting in an increasing refractive index of the solution. It was, however, easy to correct for this, by making separate experiments, using distilled water, at the same time as the adsorption experiment. These corrections are highly reproducible. Alcohol solutions may remove solids from wool to a different degree than distilled water, thereby making the correction inaccurate. For benzyl alcohol this effect can be determined experimentally, and is found to be negligible, as seen from table 5, by comparison of coloumn 2 and 3 .

To test the whole procedure, especially losses due to evaporation, adsorption tests should be made on fibres with zero adsorption. Polyacrylics were suitable, as both polyamides and polyesters showed a selective adsorption of alcohols.

It was possible to carry out the adsorption experinents using a $4 \%$ solution of butanol and polyacrylic fibres, without any change in refractive index of the solution at $60^{\circ} \mathrm{C}$ or $70^{\circ} \mathrm{C}$. At $70^{\circ} \mathrm{C}$ it was necessary to introduce the fibres at room temperature, and 
then increase the temperature, but at $60^{\circ} \mathrm{C}$ the fibres can be introduced at the test temperature. Evaporation losses from the closed apparatus were also investigated, by stirring the alcohol solutions without fibres. For times up to 1 hour at $60^{\circ} \mathrm{C}$ no correction has to be made, but for longer times a correction is necessary.

The $95 \%$ confidence limits for the mean value of the refractive indices for two separate experiments have been calculated from a great number of experiments and found to be $\pm 1.3 \times 10^{-5}$. This is somewhat less than the correction introduced for the extraction of soluble compounds out of the wool fibres.

\section{Spectrophotometric method}

Some aromatic alcohols show a maximum for light absorption in the ultraviolet region, and this can be used for the determination of their concentration. Benzyl alcohol, for example, shows an absorption maximum at $257 \mathrm{m \mu}$. This method has the advantage of being applicable also when other solutes are present in the solution. If the determination is made in the presence of other aromatic compounds, showing a light absorption at the wavelength used, a correction must be made for this.

The spectrophotometric method has been applied to solutions of benzyl alcohol in the presence of a dyestuff. Instead of using a blank solution of zero concentration of benzyl alcohol at the spectrophotometric determination of the concentration, the test solution (obtained after the adsorption experiment) was used as a blank and measured against the stock solution (the alcohol solution before the adsorption). In this way, the desired concentration difference was obtained, and the reading errors minimized. It was necessary to dilute the benzyl alcohol solution before measurement to get a measurable optical density. Three dilutions were made of the test solution and three of the stock solution. These solutions were then measured against each other in random order, using a Beckman DU Spectrophotometer. The mean value of these three determinations was used for calculation of 
the adsorption. Two separate experiments were performed at each concentration of benzyl alcohol. The confidence limits for the mean value of the adsorption of benzyl alcohol according to above procedure was found to be $\pm 1,2 \mathrm{mg} / \mathrm{g}$ wool and is rather independent of the magnitude of the adsorption.

$\underline{\text { Results }}$

Adsorption of aliphatic alcohols from solutions in distilled water

The amount of adsorption was measured for various aliphatic alcohols from solutions in distilled water, using the refractive index as a measurement of concentration. In fig. 6 and table 3 some results are shown at a liquor ratio of 30:1 and a temperature of $60^{\circ} \mathrm{C}$ and a time of $30 \mathrm{~min}$. At this temperature only a slight increase in adsorption is obtained at times longer than $30 \mathrm{~min}$, but the values may not be treated as true thermodynamic equilibrium values. From these results it is seen that adsorption of alcohols will increase with the number of carbon atoms in the chain at the same concentration in the bath. For the different isomers of the same alcohols the adsorption increases with decreasing solubility.

Adsorption of alcohol and dyestuff from buffer solutions

Benzyl al cohol

The main difficulty in investigating the influence of adsorption of an alcohol on the dyeing rate is to find a suitable dyestuff. Dyestuffs are affected to different degrees by alcohols, i.e. depending on the degree of sulphonation of the dyestuff. Many sulphonic acid groups in the molecule result in high solubility in water, but usually a low solubility in alcohols, whereas other solubilizing groups (as in the 1:2 chrome complex dyes) may give the dyestuff the reverse solubility properties. The dyeing rate of the last group is most influenced by alcohols. However, these dyes are highly aggregated in aqueous solutions up to temperatures of about $90^{\circ} \mathrm{C}$ and therefore less suitable for comparisons of dye- 
$\underline{\text { Table } 3}$

Adsorption of alcohols on wool temp. $60^{\circ} \mathrm{C}$; time $30 \mathrm{~min}$; liquor ratio $30: 1$

\begin{tabular}{|c|c|c|c|c|}
\hline \multirow{2}{*}{ Alcohol } & \multicolumn{2}{|c|}{$\begin{array}{l}\text { Conc. in solution } \\
\text { in millimol/1 }\end{array}$} & \multicolumn{2}{|c|}{ Adsorption } \\
\hline & $\begin{array}{l}\text { before ad- } \\
\text { sorption }\end{array}$ & $\begin{array}{l}\text { after ad- } \\
\text { sorption }\end{array}$ & $\mathrm{mg} / \mathrm{g}$ wool & $\begin{array}{l}\text { millimol/g } \\
\text { wool }\end{array}$ \\
\hline $\begin{array}{l}\text { butyl alcohol (n) } \\
\mathrm{CH}_{3}\left(\mathrm{CH}_{2}\right)_{2} \mathrm{CH}_{2} \mathrm{OH}\end{array}$ & $\begin{array}{l}13.5 \\
27.6 \\
54.4 \\
81.9\end{array}$ & $\begin{array}{l}13.2 \\
25.8 \\
50.8 \\
75.2\end{array}$ & $\begin{array}{r}5.1 \\
26.3 \\
54.5 \\
99.6\end{array}$ & $\begin{array}{l}0.07 \\
0.36 \\
0.74 \\
1.34\end{array}$ \\
\hline $\begin{array}{l}\text { butyl alcohol (iso) } \\
\mathrm{CH}_{3}>\mathrm{CH} \mathrm{CH}_{2} \mathrm{OH} \\
\mathrm{CH}_{3}\end{array}$ & $\begin{array}{l}13.3 \\
40.3 \\
67.1 \\
93.2\end{array}$ & $\begin{array}{l}13.0 \\
38.9 \\
64.1 \\
88.0\end{array}$ & $\begin{array}{r}6.1 \\
31.2 \\
65.7 \\
116\end{array}$ & $\begin{array}{l}0.08 \\
0.42 \\
0.89 \\
1.57\end{array}$ \\
\hline $\begin{array}{l}\text { butyl alcohol (sec) } \\
\mathrm{CH}_{3} \mathrm{CH}(\mathrm{OH}) \mathrm{C}_{2} \mathrm{H}_{5}\end{array}$ & $\begin{array}{r}13.2 \\
40.4 \\
94.2 \\
135.2\end{array}$ & $\begin{array}{r}12.8 \\
39.2 \\
91.9 \\
132.8\end{array}$ & $\begin{array}{r}7 \cdot 5 \\
27.2 \\
50.8 \\
52.6\end{array}$ & $\begin{array}{l}0.10 \\
0.37 \\
0.69 \\
0.71\end{array}$ \\
\hline $\begin{array}{l}\text { amyl alcohol (n) } \\
\mathrm{CH}_{3}\left(\mathrm{CH}_{2}\right)_{3} \mathrm{CH}_{2} \mathrm{OH}\end{array}$ & $\begin{array}{r}5.8 \\
11.6 \\
17.3 \\
22.1\end{array}$ & $\begin{array}{r}5.6 \\
11.3 \\
16.1 \\
19.9\end{array}$ & $\begin{array}{r}4.7 \\
8.5 \\
31.7 \\
58.7\end{array}$ & $\begin{array}{l}0.05 \\
0.10 \\
0.36 \\
0.67\end{array}$ \\
\hline $\begin{array}{l}\text { amyl alcohol } \\
\text { (prim.iso) } \\
\mathrm{CH}_{3}>\mathrm{CHCH}_{2} \mathrm{CH}_{2} \mathrm{OH} \\
\mathrm{CH}_{3}\end{array}$ & $\begin{array}{r}5.7 \\
11.5 \\
17.1 \\
23.0\end{array}$ & $\begin{array}{r}5.5 \\
11.1 \\
16.5 \\
21.7\end{array}$ & $\begin{array}{r}5.9 \\
11.1 \\
16.2 \\
33.1\end{array}$ & $\begin{array}{l}0.07 \\
0.13 \\
0.18 \\
0.38\end{array}$ \\
\hline $\begin{array}{l}\text { amyl alcohol } \\
\text { (sec.n) } \\
\mathrm{C}_{2} \mathrm{H}_{5} \mathrm{CH}_{2} \mathrm{CH}(\mathrm{OH}) \mathrm{CH}_{3}\end{array}$ & $\begin{array}{r}5.7 \\
22.8 \\
39.8 \\
46.7\end{array}$ & $\begin{array}{r}5.6 \\
22.1 \\
35.0 \\
36.3\end{array}$ & $\begin{array}{r}2.2 \\
19.5 \\
125 \\
276\end{array}$ & $\begin{array}{l}0.02 \\
0.22 \\
1.42 \\
3.13\end{array}$ \\
\hline $\begin{array}{l}\text { hexyl alcohol } \\
4 \text {-methyl pentanol-2 } \\
\mathrm{CH}_{3}>\mathrm{CHCH}_{2} \mathrm{CH}(\mathrm{OH}) \mathrm{CH}_{3} \\
\mathrm{CH}_{3}\end{array}$ & $\begin{array}{r}2.9 \\
5.9 \\
9.9 \\
14.5\end{array}$ & $\begin{array}{r}2.7 \\
5.5 \\
9.1 \\
11.8\end{array}$ & $\begin{array}{r}5.6 \\
13.0 \\
22.8 \\
81.8\end{array}$ & $\begin{array}{l}0.05 \\
0.13 \\
0.22 \\
0.80\end{array}$ \\
\hline
\end{tabular}

The $95 \%$ conficence limits for the adsorption values are obtained by adding to the values in the table $\pm 3.3 \mathrm{mg} / \mathrm{g}$ wool or $\pm 0.04 \mathrm{millimol} / \mathrm{s}$ wool. 


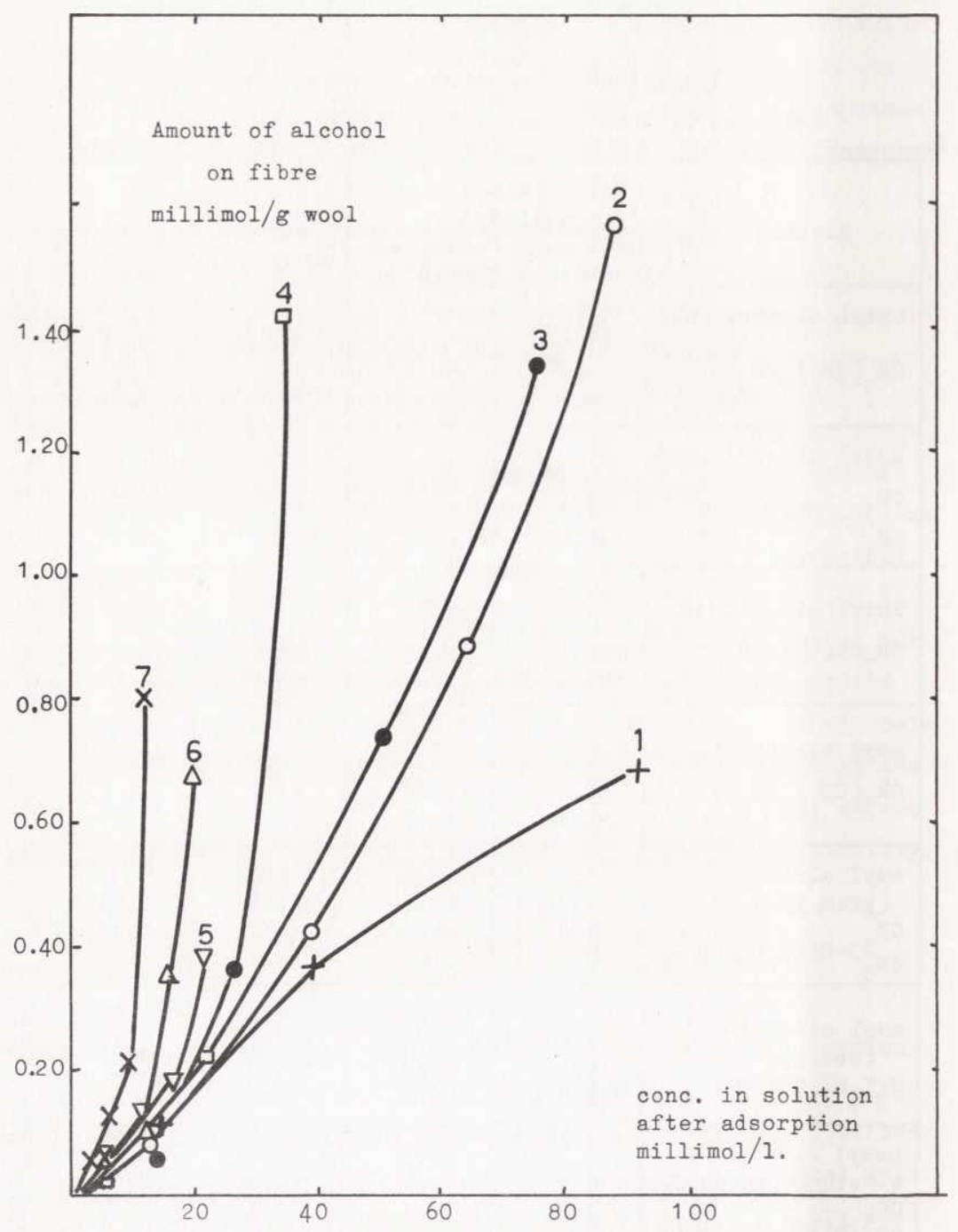

1) butyl alcohol (sec), 2) butyl alcohol (iso), 3) butyl alcohol (n), 4) amyl alcohol ( $(\mathrm{ec}-\mathrm{n})$, 5) amyl alcohol (iso), 6) amyl alcohol ( $\mathrm{n}$ ), 7) hexyl alcohol (4-methyl pentanol-2).

(The formulas are given in table 3 ).

Fig. 6 - Adsorption of aliphatic alcohols on wool fibres as a function of their final collcentration in solution. 
ing rate and adsorption at temperature below $90^{\circ} \mathrm{C}$. It is, however, possible to find a dyestuff, which has affinity for wool, is monomolecular in solution and the dyeing rate of which is influenced by alcohols. This dyestuff, tetrabromphenol sulphonphthalein, (an indicator dye known as bromphenol blue, see below), is not normally used for wool dyeing. The light absorption at different wave lengths of this dye in aqueous solutions varies with the $\mathrm{pH}$ of the solution in a simple way (Luck, 1958). At $\mathrm{pH} 1.2$ the dye is almost completely converted to its acid modification, which is yellow, whereas at $\mathrm{pH}$ about 7.8 it exists in its basic modification, which is blue.

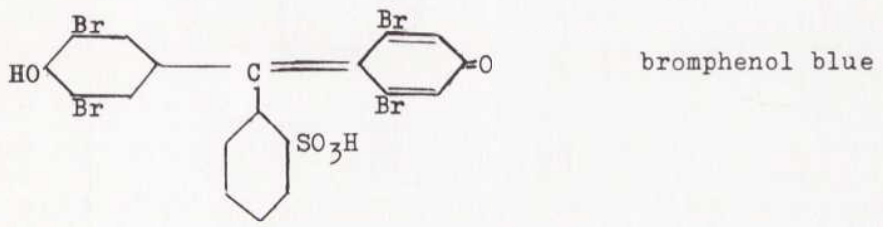

As the concentration of benzyl alcohol can be determined spectrophotometrically, the adsorption of this alcohol on wool has been measured from solutions containing bromphenol blue at $\mathrm{pH} 1.2$. The adsorption of dye by the wool was measured in the same experiment, using the apparatus described before. As the dyeing rate is very high at $\mathrm{pH} 1.2$, a temperature as low as $2.5^{\circ} \mathrm{C}$ was necessary. This temperature could be obtained by circulating ice-water through the outer mantle of the apparatus. Dye solutions of constant dye concentration, but containing different amounts of benzyl alcohol, were prepared by dissolving a weighed amount of benzyl alcohol in a buffer


bromphenol blue in the same buffer solution, and finally adjusting the volume with the buffer solution. Four different concentrations of benzyl alcohol were used at dyeing times of $2.5 \mathrm{~min}, 5 \mathrm{~min}, 10 \mathrm{~min}$, $30 \mathrm{~min}, 90 \mathrm{~min}$, and $180 \mathrm{~min}$. The experiments were repeated twice. The dye concentration was determined spectrophotometrically at a wavelength of $437 \mathrm{~m} \mu$. The same solution was then diluted, and the concentration of benzyl alcohol determined at $257 \mathrm{~m} \mu$ as described above. The results are given in table 4, and some values illustrated in fig. 7 a. Fig. $7 \mathrm{~b}$ gives the amount of adsorption of bromphenol blue as 


\section{Table 4}

Adsorption of benzyl alcohol and bromphenol blue on wool

$$
\mathrm{pH}=1.2 \text {; initial dye conc. }=0.02 \mathrm{~g} / 1 \text {; }
$$

temp. $=2.5^{\circ} \mathrm{C} ;$ liquor ratio $30: 1$

\begin{tabular}{|c|c|c|c|c|}
\hline $\begin{array}{l}\text { Conc. of } \\
\text { benzyl } \\
\text { alcohol } \\
\mathrm{g} / 100 \mathrm{ml}\end{array}$ & $\begin{array}{l}\text { Adsorption } \\
\text { of dye 1) } \\
\text { optical den- } \\
\text { sity at } 437 \\
\text { m } \mu\end{array}$ & $\begin{array}{c}\text { Adsorption } \\
\text { of alcohol } \\
\mathrm{mg} / \mathrm{g} \text { wool }\end{array}$ & $\begin{array}{c}\text { Time of } \\
\text { adsorption } \\
\text { min. }\end{array}$ & $\begin{array}{c}\text { Adsorption } \\
\text { of alcohol } \\
\text { millimol/g } \\
\text { wool }\end{array}$ \\
\hline $\begin{array}{c}0 \\
2.00 \\
3.00 \\
4.00\end{array}$ & $\begin{array}{l}0.235 \\
0.262 \\
0.312 \\
0.365\end{array}$ & $\begin{array}{r}- \\
6.5 \\
29.0 \\
47.9\end{array}$ & 2.5 & $\begin{array}{c}-\overline{0} \\
0.060 \\
0.268 \\
0.443\end{array}$ \\
\hline $\begin{array}{c}0 \\
1.00 \\
2.00 \\
3.00 \\
4.00\end{array}$ & $\begin{array}{l}0.320 \\
0.329 \\
0.336 \\
0.386 \\
0.412\end{array}$ & $\begin{array}{r}- \\
4.4 \\
10.7 \\
42.4 \\
60.1\end{array}$ & 5 & $\begin{array}{c}- \\
0.041 \\
0.099 \\
0.392 \\
0.555\end{array}$ \\
\hline $\begin{array}{c}0 \\
2.00 \\
4.00\end{array}$ & $\begin{array}{l}0.395 \\
0.405 \\
0.433\end{array}$ & $\begin{array}{l}- \\
13.7 \\
70.2\end{array}$ & 10 & $\begin{array}{c}- \\
0.126 \\
0.649\end{array}$ \\
\hline $\begin{array}{c}0 \\
2.00 \\
4.00\end{array}$ & $\begin{array}{l}0.438 \\
0.446 \\
0.461\end{array}$ & $\begin{array}{l}- \\
16.8 \\
81.1\end{array}$ & 30 & $\begin{array}{c}- \\
0.155 \\
0.750\end{array}$ \\
\hline $\begin{array}{c}0 \\
2.00 \\
4.00\end{array}$ & $\begin{array}{l}0.465 \\
0.469 \\
0.465\end{array}$ & $\begin{array}{l}- \\
21.8 \\
90.7\end{array}$ & 90 & $\begin{array}{c}- \\
0.202 \\
0.839\end{array}$ \\
\hline $\begin{array}{c}0 \\
4.00\end{array}$ & $\begin{array}{l}0.465 \\
0.465\end{array}$ & 102.5 & 180 & $0 . \overline{948}$ \\
\hline
\end{tabular}

1) The numbers represent the difference in optical density of dye solution before and after dyeing. Optical density of initial conc. $=0.500$; optical density of equilibrium conc. $=$ 0.035 .

The $95 \%$ confidence limits for the adsorption of benzyl alcohol is obtained by adding to the values in the table \pm 1.2 $\mathrm{mg} / \mathrm{g}$ or $\pm 0.01 \mathrm{millimol} / \mathrm{g}$. 


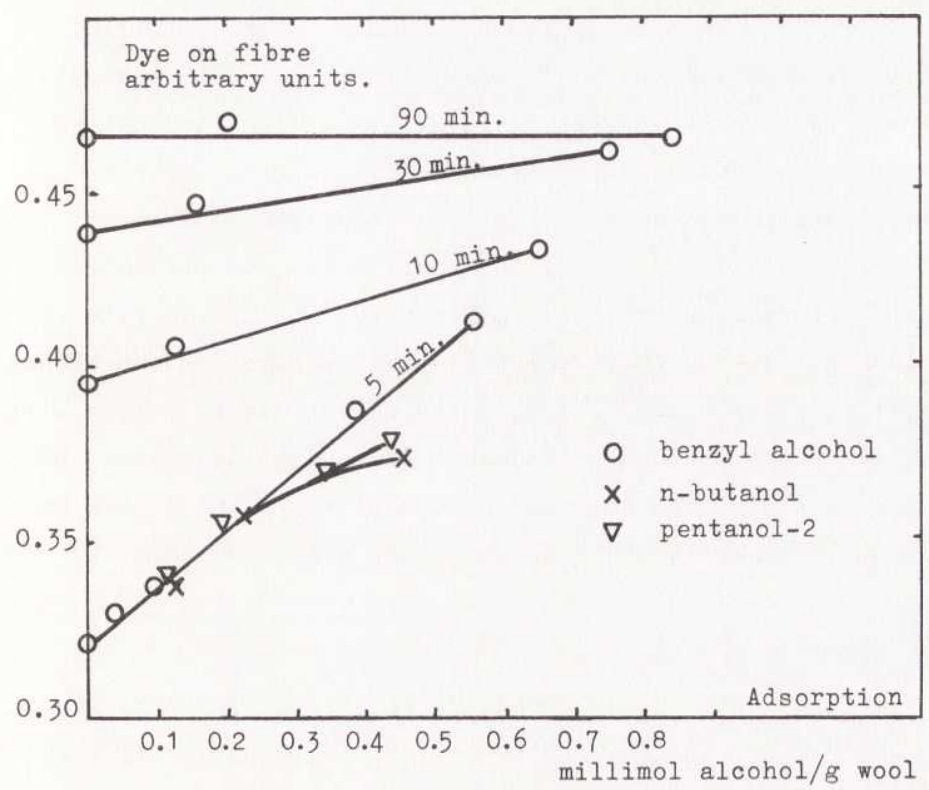

Fig. 7 a - Amount of bromphenol blue on wool after a fixed time at $\mathrm{pH} 1.2$ as a function of the adsorbed amount of different alcohols (see Table 4).

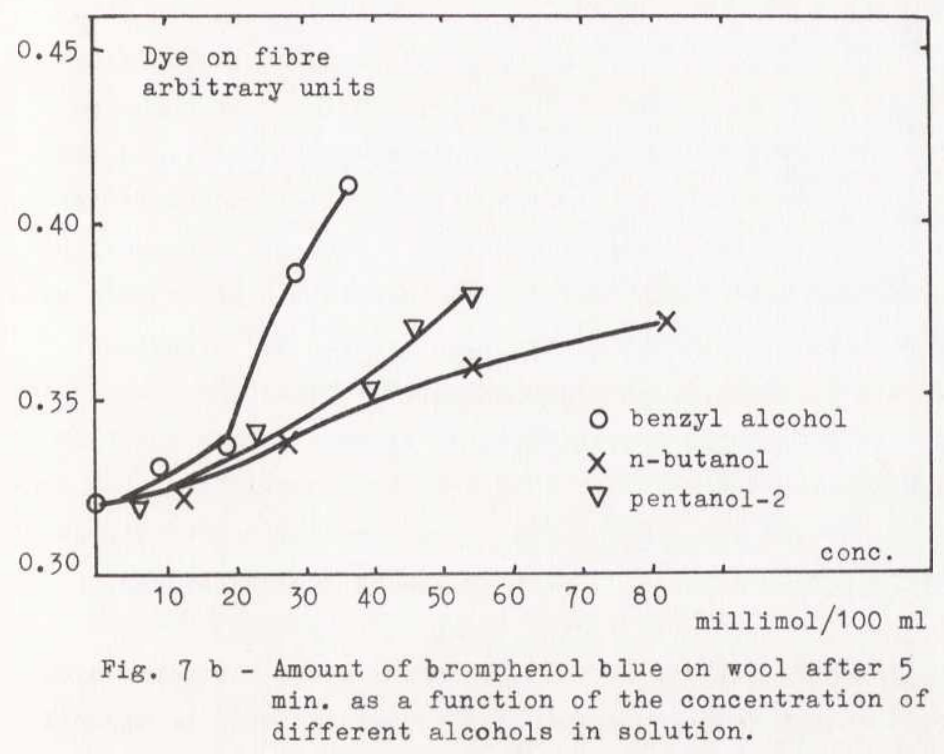


a function of concentration of benzyl aicohol in the solution. These adsorption values are much lower than the equilibrium values, due to the rate of adsorption being low at the low testing temperature. The amount of dye taken up by the wool after a fixed time, used as ordinate in fig. 7 a and b can be used as a measure of the dyeing rate, as the equilibrium adsorption of dye is noi influenced by the benzyl alcohol. The dyeing rate for this alcohol is therefore a rectilinear function of the amount of adsorption of the alcohol. The slope of the curves varies with the time of dyeing; the nearer to equilibrium dye adsorption, of course, the less will the alcohol influence the amount of dye on the fibre and the smaller will be the slope of the curve.

\section{Aliphatic alcohols}

It is of interest to find out if simple relationships between dyeing rate and adsorption also exists for other alcohols. As mentioned previously, the concentration of these alcohols must be determined by refractive index measurements, which means, that the adsorption of alcohol and dyestuff must be determined from separate experiments. The alcohol adsorption was measured from a solution in distilled water, whereas the dye adsorption was measured from buffer of $\mathrm{pH} 1.2$. As benzyl alcohol could be determined both by refractive index and spectrophotometric measurements, a comparison of these two methods could be made, and also the difference in adsorption from distilled water and buffer solutions with and without dyestuff in the solution. The results are shown in table 5. All differences between the adsorption values lie within the $95 \%$ confidence limits (with one exception). Thus for benzyl alcohol, the adsorption by wool is the same if the alcohol is dissolved in distilled water or in a buffer solution of $\mathrm{pH} 1.2$, or this buffer solution contains bromphenol blue at a concentration of $0.02 \mathrm{~g} / \mathrm{l}$. Furthermore, the two different methods of determining the concentration give values in good agreement.

Assuming these results to be valid also for other alcohols, dyeing experiments have been performed with solutions of bromphenol 
Table 5

Adsorption of benzyl alcohol on wool from different solutions and determined by different methods temp. $2.5^{\circ} \mathrm{C}$; time $5 \mathrm{~min}$; 1iquor ratio $30: 1$

\begin{tabular}{|c|c||c|c|c|}
\hline \multirow{2}{*}{$\begin{array}{c}\text { Conc. of } \\
\text { benzyl } \\
\text { alcohol }\end{array}$} & \multicolumn{4}{|c|}{ Adsorption in mg/g wool measured by } \\
\cline { 2 - 5 } g/100 ml & refractive index & light absorption at wavelength $257 \mathrm{m \mu}$ \\
& solution & water & buffer & dye in \\
& sH $\sim 6$ & pH $\sim 6$ & pH 1.2 & pH 1.2 \\
\hline 1.0 & 3.8 & 4.6 & 4.4 & 4.4 \\
2.0 & 11.5 & 10.5 & 11.3 & 10.5 \\
3.0 & 37.9 & 43.7 & 43.7 & 42.8 \\
4.0 & 62.3 & 61.3 & 62.2 & 61.5 \\
\hline
\end{tabular}

The $95 \%$ confidence limits for the adsorption values are obtained by adding to the values in the table $\pm 2.0 \mathrm{mg} / \mathrm{g}$ wool (refractive index method) or $\pm 1.2 \mathrm{mg} / \mathrm{g}$ wool (spectrophotometric method).

blue containing different amounts of n-butanol or pentanol-2. The results are given in fig. $7 \mathrm{a}$ and $\mathrm{b}$ and refer to a time of dyeing of 5 minutes. The dyeing rate at the same adsorption are very similar for the two alcohols and agree with the values obtained for benzyl alcohol at low adsorption values. At higher adsorption values the dyeing rate is increased more by benzyl alcohol than by these alcohols.

\subsection{Dyeing at different $\mathrm{pH}$-values}

Dyeing experiments have shown that not only the acid form of bromphenol blue but also the basic form, has an affinity for wool, although the dyeing rate is much less at higher $\mathrm{pH}$ values. For this reason dyeing experiments were carried out at $60^{\circ} \mathrm{C}$ and $\mathrm{pH} 7.7$ with the same apparatus as described before and at the same concentration of dyestuff in the solution. The results are given in table 6. The dyeing rate is slightly increased by butanol but unaffected 
by the presence of benzyl alcohol. This is not due to changes in the adsorption of benzyl alcohol on wool, as is shown in the table. In fact, nearly the same amount of benzyl alcohol is adsorbed as in the dyeing experiments at $\mathrm{pH} 1.2$. It is thus found that two modifications of the same dye react in different ways to the same alcohol. The dyeing rate of one form is increased, while the dyeing rate of the other is unaffected. The reason for this might be of utmost interest to explain the mechanism of solvent-assisted dyeing of wool. For this reason, further investigations have been carried out with bromphenol blue at different $\mathrm{pH}$ values.

\section{Table 6}

Dyeing rate of the basic form of bromphenol blue in the presence of butanol, benzyl alcohol or hexylamine

initial dye conc. $=0.02 \mathrm{~g} / 1$; temp. $=60^{\circ} \mathrm{C}$; liquor ratio $30: 1$

\begin{tabular}{|c|c|c|c|c|c|c|}
\hline \multicolumn{4}{|c|}{ D y e solution } & \multirow{2}{*}{$\begin{array}{l}\text { Dye- } \\
\text { ing } \\
\text { time } \\
\text { min. }\end{array}$} & \multirow{2}{*}{$\begin{array}{l}\text { Amount of dye } \\
\text { on fibre } 1)^{\text {on }} \\
\text { optical den- } \\
\text { sity at } 590 \\
\text { m } \mu\end{array}$} & \multirow{2}{*}{$\begin{array}{l}\text { Adsorption } \\
\text { of } \\
\text { solvent } \\
\text { mg/g } \\
\text { wool }\end{array}$} \\
\hline & Solvent & $\begin{array}{c}\text { Solvent } \\
\text { conc. } \\
\mathrm{g} / 100 \mathrm{ml}\end{array}$ & $\mathrm{pH}$ & & & \\
\hline $\begin{array}{l}\text { phosphate } \\
\text { buffer }\end{array}$ & - & $\begin{array}{l}- \\
-\end{array}$ & $\begin{array}{l}7.7 \\
" 1\end{array}$ & $\begin{array}{r}5 \\
30\end{array}$ & $\begin{array}{l}0.19 \\
0.70\end{array}$ & \\
\hline$n$ & $\begin{array}{l}\text { benzyl } \\
\text { alcohol }\end{array}$ & $\begin{array}{c}3.0 \\
" 1\end{array}$ & $\begin{array}{l}7.7 \\
" 1\end{array}$ & $\begin{array}{r}5 \\
30\end{array}$ & $\begin{array}{l}0.20 \\
0.67\end{array}$ & $\begin{array}{l}42 \\
51\end{array}$ \\
\hline$"$ & $\begin{array}{l}\text { butanol } \\
\text { " }\end{array}$ & 6.0 & $\begin{array}{l}7.7 \\
" 1\end{array}$ & $\begin{array}{r}5 \\
30\end{array}$ & $\begin{array}{l}0.29 \\
0.87\end{array}$ & \\
\hline $\begin{array}{l}\text { borate } \\
\text { buffer }\end{array}$ & - & - & $\begin{array}{r}7.8 \\
10.2\end{array}$ & $\begin{array}{l}5 \\
5\end{array}$ & $\begin{array}{l}0.19 \\
0.18\end{array}$ & \\
\hline $\begin{array}{l}\text { phosphate } \\
\text { buffer }\end{array}$ & $\begin{array}{l}\text { hexyl- } \\
\text { amine }\end{array}$ & 0.74 & $\begin{array}{l}10.2 \\
10.2\end{array}$ & $\begin{array}{r}5 \\
30\end{array}$ & $\begin{array}{l}1.21 \\
1.82\end{array}$ & 48 \\
\hline
\end{tabular}

1) The numbers represent the difference in optical density of the dye solution before and after dyeing. Optical density corresponding to initial concentration $=2.32$ (at $590 \mathrm{~m} \mu$ ) and corresponding to equilibrium concentration $=0.20$. The amount of dye on the wool at equilibrium $=2.12$ in the units used. 


\section{Partition ratios of bromphenol blue between solvents and}

\section{water solutions of different $\mathrm{pH}$}

Bromphenol blue may be considered an indicator acid HI, ionizing according to the formula:

$\mathrm{HI}+\mathrm{B} \rightleftarrows \mathrm{HB}^{+}+\mathrm{I}^{-}$

where $\mathrm{H} \mathrm{I}$ is yellow and $\mathrm{I}^{-}$is blue. ( $\mathrm{In}$ the $\mathrm{pH}$ range investigated, H I might have one negative charge, then the ion I has two negative charges. This is, however, of minor importance for the following discussion). As is known the addition of alcohols to aqueous solutions of indicator acids will shift the colour of the solution towards the acid side (Kolthoff, Rosenblum, 1937, p.203 f). If butanol or benzyl alcohol, in concentrations below the saturation point, is added to an aqueous solution of bromphenol blue, this shift is very small. However, by shaking an aqueous solution of bromphenol blue with butanol or benzyl alcohol, the solvent phase will contain a higher proportion of the unionized acid form than the water phase. Comparing butanol and benzyl alcohol solutions, saturated with water, the shift towards the acid side is larger in benzyl alcohol. Experiments have been made to determine the partition ratios of the two forms of bromphenol blue between butanol or benzyl alcohol and buffer solutions at different $\mathrm{pH}$. When the same volume of buffer and alcohol are used at pH 1.2, the composition of the alcohol phase will be about the same as the original buffer phase, i.e. the dye exists almost entirely in its acid form. Making the same experiment at $\mathrm{pH} 7.7$, when the dye is in its basic form to the greatest extent, will result in alcohol phases containing mainly the basic form. In the benzyl alcohol phase there is an increase in concentration of the acidic form and a decrease of the basic form compared with the original buffer solution, but still the concentration of the basic form is about 6 times as high as that of the acidic.

Remembering that the amount of adsorption of alcohol on wool is related to the dyeing rate, and assuming that the adsorbed alcohol is able to dissolve the dye out of the solution surrounding the wool 
fibres, it should be of interest to study the partition ratios at liquor ratios which are related to the dyeing experiments. If we take the results from the adsorption measurements, about $0.06 \mathrm{~g}$ benzyl alcohol is adsorbed per $g$ wool at a liquor ratio of $30: 1$ from an aqueous solution containing $4 \%$ benzyl alcohol. If we regard the adsorbed amount of alcohol as one separate phase, and the dye solution as the other phase, the distribution of dye should be studied at liquor ratios of $30: 0.06=500: 1$.

Such a distribution study has been made, both for butanol and benzyl alcohol, in equilibrium with buffer solutions of bromphenol blue at $\mathrm{pH} 1.2$ and 7.7 and the same concentration as used in the dyeing experiments. For experimental convenience the determination was made at a liquor ratio of $200: 1$. Some tests were also made at a ratio of $400: 1$ but this did not change the principal conclusions that could be drawn. The results are given in table 7 and may be summarized as follows.

At $\mathrm{pH} 1.2$ when wool is dyed with the acidic form of bromphenol blue under the experimental conditions used, the partition ratio for this form in benzyl alcohol and buffer solution is about 470, i.e. the concentration in the benzyl alcohol is 470 times that in the buffer solution. For butanol the same partition ratio is obtained. At $\mathrm{pH} 7.7$ wool is dyed by the basic form of bromphenol blue. The partition ratio for this form at the same experimental conditions will be 0.9 for benzyl alcohol and about 3 for butanol. The fact that the dyeing rate of bromphenol blue will be increases by the alcohols at $\mathrm{pH} 1.2$ but almost unaffected at $\mathrm{pH} 7.7$, makes it reasonable to believe, that there is a connection between the rate of dyeing and the partition ratios determined at high liquor ratios.

It should be valuable to test this hypothesis by trying to find a solvent giving a high partition ratio for the basic form of bromphenol blue and investigate the influence of this solvent on the dyeing rate of the basic form. 


\section{Table 7}

Partition of bromphenol blue between alcohol and buffer solutions

initial dye conc. $0.02 \mathrm{~g} / 1$

\begin{tabular}{|c|c|c|c|c|c|c|}
\hline Solution 1) & $\mathrm{pH}^{2)}$ & $\begin{array}{l}\text { Optical } \\
437^{3)} \\
m \mu\end{array}$ & $\begin{array}{l}\text { ensity } \\
590^{4)} \\
m \mu\end{array}$ & $\begin{array}{c}\text { Volume } \\
\text { of } \\
\text { phase } \\
\text { ml }\end{array}$ & $\begin{array}{l}\mathrm{R}_{437}{ }^{5)} \\
\frac{\mathrm{c}_{\text {alc }}}{\mathrm{c}_{\text {buff. }}}\end{array}$ & $\begin{array}{l}\mathrm{R}_{590} \\
\frac{\mathrm{c}_{\text {alc }}}{\mathrm{c}_{\text {buff. }}}\end{array}$ \\
\hline $\begin{array}{l}\text { initial solution } \\
\text { benzyl alcohol phase } \\
\text { buffer phase }\end{array}$ & 1.2 & $\begin{array}{l}0.695 \\
98.6 \\
0.208\end{array}$ & 0.02 & $\begin{array}{r}2000 \\
10 \\
2000\end{array}$ & 474 & \\
\hline $\begin{array}{l}\text { initial solution } \\
\text { butanol phase } \\
\text { buffer phase }\end{array}$ & 1.2 & $\begin{array}{l}0.768 \\
107.5 \\
0.227\end{array}$ & 0.02 & $\begin{array}{r}2000 \\
10 \\
2000\end{array}$ & 474 & \\
\hline $\begin{array}{l}\text { initial solution } \\
\text { benzyl alcohol phase } \\
\text { buffer phase }\end{array}$ & 7.7 & $\begin{array}{l}0.048 \\
0.985 \\
0.040\end{array}$ & $\begin{array}{l}2.13 \\
1.88 \\
2.12\end{array}$ & $\begin{array}{r}2000 \\
10 \\
2000\end{array}$ & & 0.9 \\
\hline $\begin{array}{l}\text { initial solution } \\
\text { butanol phase } \\
\text { buffer phase }\end{array}$ & 7.7 & $\begin{array}{l}0.029 \\
0.670 \\
0.025\end{array}$ & $\begin{array}{l}2.30 \\
6.9 \\
2.27\end{array}$ & $\begin{array}{r}2000 \\
10 \\
2000\end{array}$ & & 3 \\
\hline
\end{tabular}

1) the dye and alcohol solutions were mutually saturated with each other before the experiment

2) $\mathrm{pH} 1.2$ was obtained with a sodium citrate-hydrogen chloride buffer solution, $\mathrm{pH} 7.7$ with a phosphate buffer solution

3) wavelength at maximum extinction for the acidic form of bromphenol blue

4) wavelength at maximum extinction for the basic form of bromphenol blue

5) $R=$ partition ratio. 
Benzyl alcohol and butanol are weaker bases than water and rather bad solvents for the basic form of bromphenol blue. In looking for a good solvent for the latter, it was thought reasonable to try substances which are stronger bases than water, and which thus convert the acidic form of bromphenol blue to the basic. Many amines have these properties and we therefore tried hexylamine, the simplest aliphatic amine, which is partly soluble in water. The partition ratio for the basic form of bromphenol blue between hexylamine and a buffer solution of $\mathrm{pH} 7.7$ is above 1000 at the same liquor ratio $(200: 1)$ and the same dye concentration as in the experiments with butanol and benzyl alcohol. Hexylamine is thus a good solvent for the basic form of bromphenol blue. Further experiments were made to determine if hexylamine was adsorbed by wool from aqueous solutions. Using the refractive index for determination of concentration, it was found that $1 \mathrm{~g}$ wool adsorb about $48 \mathrm{mg}$ hexylamine after $5 \mathrm{~min}$. at $60^{\circ} \mathrm{C}$ at a liquor ratio of $30: 1$ from an aqueous solution containing $0.74 \mathrm{~g}$ hexylamine $/ 100 \mathrm{ml}$ (a.lmost saturated). Dyeing experiments have been made under the same conditions as used for the determination of influence of benzyl alcohol and butanol, and the results are found in the same tabIe $(T a b l e ~ 6)$. It is seen that the dyeing rate is very much increased by the addition of hexylamine to the basic form of bromphenol blue. As hexylamine is strongly basic, there will be an increase in $\mathrm{pH}$ of the buffer solution to about 10 by its addition to the dyebath. However, this will not affect the dyeing rate in this special case, as has been shown by dyeing from a borate buffer at $\mathrm{pH}$ 10.2. The experiments with hexylamine thus support the conclusions drawn from the dyeings with alcohols present in the dyebath.

Adsorption of the solvent onto wool, together with high solubility of the dye in the solvent used, is thus found to be of importance for obtaining an increase in the dyeing rate with this solvent. (It might also be possible to obtain an increase in the dyeing rate for dyes insoluble in the solvent, due to the "extraction" effect discussed in chapter 1.2. This latter effect is, 
however, separate from the main mechanism).

The results may be used for formulating a hypothesis on the mechanism of solvent-assisted dyeings of wool given in chapter 4.3 .

\subsection{Dyeing of surface-treated wool}

Experiments made at an early stage of this work have shown that the increase in dyeing rate by the addition of solvents is less for surface-treated wool than for untreated wool (see fig. 4). It was therefore considered of interest to investigate in what way the surface properties of wool fibres are connected with the mechanism of solvent-assisted dyeings. For this purpose, the properties of the wool surface were changed, as described earlier (chapter 2.1). The wools, chlorinated to different degrees, were dyed with bromphenol blue at $\mathrm{pH} 1.2$ and 7.8 using benzyl alcohol or hexylamine as solvents. The experiments were carried out in the same apparatus used for the adsorption of alcohols and described previous in this chapter. As the dyeing rate of bromphenol blue on untreated wool is large at $\mathrm{pH} 1.2$ and is further increased by the use of surface-treated wool, a high liquor ratio $(150: 1)$ and a low temperature of dyeing $\left(2.5^{\circ} \mathrm{C}\right)$ were used, to make it possible to follow the change in concentration of the solution with time. A preliminary test series was performed on chlorinated wools B and C, i.e. on dry chlorinated moist wool and on the completely descaled wool. Dyeing experiments at $\mathrm{pH} 1.2$ gave the same rate of dyeing on both types of wool (expressed as diffusion constants) if allowance was made for the difference in mean diameter. At $\mathrm{pH} 7.8$, however, a difference in dyeing rate was obtained for wools $B$ and $C$. Wool $C$ was therefore included in the main experimental series at $\mathrm{pH} 7.8$ but not at $\mathrm{pH} 1.2$. The dyeing rate of bromphenol blue at $\mathrm{pH} 7.8$ is much slower than at $\mathrm{pH}$ 1.2. For this reason, a temperature of $60^{\circ} \mathrm{C}$ was used, and a $1 i-$ quor ratio of $30: 1$. At higher liquor ratios the dyeing times is inconveniently long, and the equilibrium values are particularly difficult to obtain. 
The experimental results are given in table 8 and 9 . The concentration in the dye liquor, $c_{t}$, divided by the initial concentration, $c_{0}$, at different times, and also the amount of dye on the fibre at time $t, M_{t}$, divided by the amount at equilibrium, $M_{\infty}$, are given. Fig. 8 and 9 show the values of $M_{t} / M_{\infty}$ as a function of time. All curves approach unity as time increases to that necessary for obtaining equilibrium. Firstly, it is interesting to note that all three chlorine treatments cause an increase in the dyeing rate of the basic form of bromphenol blue (fig. 9), whereas the dyeing rate of the acid form (fig. 8) is decreased for wool A (dry chlorinated dry wool), but increased for the others. Changing the hydrophobic wool surface into a hydrophilic one seems to make it repellent to the acid form of the dye. The same effect was found when determining the rate of adsorption of benzyl alcohol on wool, the rate of adsorption being less on wool A than on untreated wool (see fig. $10 \mathrm{a}$ and $\mathrm{b}$ ).

The increase in dyeing rate brought about by solvents as seen in fig. 8 and 9 appears to be less for the surface-treated wool than for the untreated wool. There is, however, still an appreciable effect of the solvent on descaled wool fibres.

\section{Calculation of diffusion constants}

It would be of great interest to obtain a quantitative measure of the dyeing rate, in order to compare the influence of solvents on untreated and surface-treated wool. Vickerstaff (1954 p. 147) has given a summary of different methods for describing dyeing rates. The only method suitable for the experiments described in this paper is a calculation of the diffusion constant, where it must be assumed, that the fibres have a number of sites for fixation of the dye and that only the free concentration contributes to the diffusion. Furthermore, the experiments were made from a finite dyebath, the concentration of which rapidly decreased with time. Olofsson, 1956, has worked out an approximate method for the calculation of the diffusion constant for this case, if the diffusing 
Table 8

Dyeing of wool with bromphenol blue

pH 1.2; temp. $2.5^{\circ} \mathrm{C}$; initial conc. $=0.02 \mathrm{~g} / \mathrm{l}$;

liquor ratio $=150: 1$

\begin{tabular}{|c|c|c|c|c|}
\hline Kind of wool. & $\begin{array}{c}\text { Addition } \\
\text { to } \\
\text { dyebath }\end{array}$ & $\begin{array}{l}\text { Time } \\
\text { min. }\end{array}$ & $\left.c_{t} / c_{0} 1\right)$ & $M_{t} / M^{2)}$ \\
\hline \multirow{2}{*}{ (ether alcohol-water } & none & $\begin{array}{c}2.5 \\
5 \\
15 \\
30 \\
60 \\
180 \\
\infty\end{array}$ & $\begin{array}{l}0.820 \\
0.728 \\
0.509 \\
0.295 \\
0.228 \\
0.160 \\
0.020\end{array}$ & $\begin{array}{l}0.184 \\
0.278 \\
0.501 \\
0.719 \\
0.788 \\
0.858\end{array}$ \\
\hline & $\begin{array}{l}\text { benzyl } \\
\text { alcohol } \\
4 \%(\mathrm{w} / \mathrm{v})\end{array}$ & $\begin{array}{c}2.5 \\
5 \\
15 \\
30 \\
60 \\
180 \\
\infty\end{array}$ & $\begin{array}{l}0.527 \\
0.330 \\
0.188 \\
0.113 \\
0.065 \\
0.056 \\
0.020\end{array}$ & $\begin{array}{l}0.482 \\
0.684 \\
0.829 \\
0.906 \\
0.955 \\
0.964\end{array}$ \\
\hline \multirow[t]{2}{*}{$\begin{array}{l}\text { Chlorinated } \\
\text { wool A }\end{array}$} & none & $\begin{array}{c}2.5 \\
5 \\
15 \\
30 \\
60 \\
180 \\
\infty\end{array}$ & $\begin{array}{l}0.814 \\
0.763 \\
0.550 \\
0.341 \\
0.234 \\
0.164 \\
0.020\end{array}$ & $\begin{array}{l}0.190 \\
0.242 \\
0.460 \\
0.672 \\
0.782 \\
0.853\end{array}$ \\
\hline & $\begin{array}{l}\text { benzyl } \\
\text { alcohol } \\
4 \%(w / v)\end{array}$ & $\begin{array}{c}2.5 \\
5 \\
15 \\
30 \\
60 \\
180 \\
\infty\end{array}$ & $\begin{array}{l}0.061 \\
0.473 \\
0.261 \\
0.182 \\
0.163 \\
0.124 \\
0.020\end{array}$ & $\begin{array}{l}0.394 \\
0.538 \\
0.755 \\
0.835 \\
0.854 \\
0.894\end{array}$ \\
\hline $\begin{array}{c}\text { Chlorinated } \\
\text { wool B } \\
\text { (dry chlorinated } \\
\text { moist wool) }\end{array}$ & none & $\begin{array}{c}2.5 \\
5 \\
15 \\
30 \\
60 \\
180 \\
\infty\end{array}$ & $\begin{array}{l}0.508 \\
0.371 \\
0.205 \\
0.098 \\
0.077 \\
0.055 \\
0.020\end{array}$ & $\begin{array}{l}0.502 \\
0.642 \\
0.811 \\
0.920 \\
0.949 \\
0.965\end{array}$ \\
\hline
\end{tabular}

1) concentration in solution/initial concentration

2) dye on fibre at time $t / d y e$ on fibre at equilibrium 
Table 8 (continued)

\begin{tabular}{|c|l|c|c|c|}
\hline Kind of wool & $\begin{array}{c}\text { Addition } \\
\text { to } \\
\text { dyebath }\end{array}$ & Time & $c_{t} / c_{0}{ }^{1)}$ & $\mathrm{M}_{t} / \mathrm{M}_{\infty}{ }^{2)}$ \\
\hline min. & & 2.5 & 0.289 & 0.726 \\
wool B & benzyl & 5 & 0.200 & 0.817 \\
(dry chlorinated & alcohol & 15 & 0.106 & 0.912 \\
moist wool) & & 60 & 0.068 & 0.951 \\
& & 180 & 0.033 & 0.987 \\
& & $\infty$ & 0.020 & 1.000 \\
\hline
\end{tabular}

$\mathrm{S}_{\mathrm{m}}=147$ for all test series. $\mathrm{S}_{\mathrm{m}}=\begin{aligned} & \text { number of sites for fixation of dye divided by initial bath } \\ & \text { concentration, } c_{0} \text {. }\end{aligned}$

All values given are calculated from mean values of two determinations.

Table 9

Dyeing of wool with bromphenol blue

pH 7.8 ; temp. $60^{\circ} \mathrm{C}$; initial conc. $=0.02 \mathrm{~g} / \mathrm{l}$;

liquor ratio $30: 1$

\begin{tabular}{|c|c|c|c|c|c|}
\hline Kind of wool & $\begin{array}{l}\text { Addition } \\
\text { to } \\
\text { dyebath }\end{array}$ & $\begin{array}{l}\text { Time } \\
\text { min. }\end{array}$ & $\left.t^{/ c_{0}} 1\right)$ & $\mathrm{s}_{\mathrm{m}}{ }^{3)}$ & $M_{t} / M_{\infty}^{2)}$ \\
\hline \multirow{2}{*}{$\begin{array}{c}\text { (ether alcohol- } \\
\text {-water } \\
\text { extracted) }\end{array}$} & none & $\begin{array}{r}5 \\
30 \\
60 \\
120 \\
300 \\
\infty\end{array}$ & $\begin{array}{l}0.921 \\
0.710 \\
0.527 \\
0.390 \\
0.224 \\
0.107\end{array}$ & 26.7 & $\begin{array}{l}0.088 \\
0.326 \\
0.530 \\
0.684 \\
0.870\end{array}$ \\
\hline & $\begin{array}{l}\text { hexyl- } \\
\text { amine } \\
1 \%(\mathrm{v} / \mathrm{v})\end{array}$ & $\begin{array}{r}5 \\
15 \\
30 \\
60 \\
300 \\
\infty\end{array}$ & $\begin{array}{l}0.485 \\
0.300 \\
0.226 \\
0.166 \\
0.128 \\
0.069\end{array}$ & 27.9 & $\begin{array}{l}0.553 \\
0.753 \\
0.831 \\
0.895 \\
0.936\end{array}$ \\
\hline $\begin{array}{c}\text { Chlorinated } \\
\text { wool A } \\
\text { (ary chlorinated } \\
\text { dry wool) }\end{array}$ & none & $\begin{array}{r}5 \\
30 \\
60 \\
120 \\
\infty\end{array}$ & $\begin{array}{l}0.851 \\
0.558 \\
0.415 \\
0.266 \\
0.107\end{array}$ & 26.7 & $\begin{array}{l}0.167 \\
0.495 \\
0.656 \\
0.823\end{array}$ \\
\hline
\end{tabular}


Table 9 (continued)

\begin{tabular}{|c|c|c|c|c|c|}
\hline Kind of wool & $\begin{array}{c}\text { Addition } \\
\text { to } \\
\text { dyebath }\end{array}$ & $\begin{array}{l}\text { Time } \\
\text { min. }\end{array}$ & $\left./ c_{0} 1\right)$ & $\mathrm{S}_{\mathrm{m}}$ 3) & $M_{t} / M_{\infty}^{2)}$ \\
\hline $\begin{array}{c}\text { Chlorinated } \\
\text { wool A } \\
\text { (dry chlorinated } \\
\text { dry wool) }\end{array}$ & $\begin{array}{l}\text { hexyl- } \\
\text { amine } \\
1 \%(v / v)\end{array}$ & $\begin{array}{r}5 \\
15 \\
30 \\
60 \\
150 \\
\infty 0\end{array}$ & $\begin{array}{l}0.532 \\
0.255 \\
0.194 \\
0.132 \\
0.123 \\
0.069\end{array}$ & 27.9 & $\begin{array}{l}0.502 \\
0.785 \\
0.863 \\
0.922 \\
0.941\end{array}$ \\
\hline \multirow[b]{2}{*}{$\begin{array}{l}\text { (dry chlorinated } \\
\text { moist wool) }\end{array}$} & none & $\begin{array}{r}5 \\
15 \\
30 \\
60 \\
120 \\
300\end{array}$ & $\begin{array}{l}0.674 \\
0.502 \\
0.407 \\
0.307 \\
0.207 \\
0.158 \\
0.107\end{array}$ & 26.7 & $\begin{array}{l}0.365 \\
0.549 \\
0.665 \\
0.777 \\
0.888 \\
0.944\end{array}$ \\
\hline & $\begin{array}{l}\text { hexyl- } \\
\text { amine } \\
1 \%(\mathrm{v} / \mathrm{v})\end{array}$ & $\begin{array}{r}5 \\
15 \\
30 \\
60 \\
120 \\
\infty\end{array}$ & $\begin{array}{l}0.421 \\
0.247 \\
0.179 \\
0.132 \\
0.132 \\
0.069\end{array}$ & 27.9 & $\begin{array}{l}0.621 \\
0.808 \\
0.881 \\
0.932 \\
0.932\end{array}$ \\
\hline \multirow[t]{2}{*}{$\begin{array}{c}\text { Chlorinated } \\
\text { wool C } \\
\text { (dry chlorinated }\end{array}$} & none & $\begin{array}{r}5 \\
15 \\
30 \\
60 \\
120 \\
300 \\
\infty\end{array}$ & $\begin{array}{l}0.693 \\
0.523 \\
0.436 \\
0.340 \\
0.264 \\
0.199 \\
0.162\end{array}$ & 25.0 & $\begin{array}{l}0.366 \\
0.569 \\
0.673 \\
0.787 \\
0.876 \\
0.955\end{array}$ \\
\hline & $\begin{array}{l}\text { hexyl- } \\
\text { amine } \\
1 \%(v / v)\end{array}$ & $\begin{array}{r}5 \\
15 \\
30 \\
60 \\
135 \\
300\end{array}$ & $\begin{array}{l}0.379 \\
0.226 \\
0.183 \\
0.132 \\
0.120 \\
0.120 \\
0.120\end{array}$ & 26.3 & $\begin{array}{l}0.705 \\
0.879 \\
0.928 \\
0.985 \\
1.000\end{array}$ \\
\hline
\end{tabular}

All values given are calculated from mean values of two determinations.

1) concentration in solution/initial concentration

2) dye on fibre at time $t / d y e$ on fibre at equilibrium

3) $\mathrm{S}_{\mathrm{m}}=$ number of sites for fixation of dye divided by initial bath concentration $c_{0}$. 


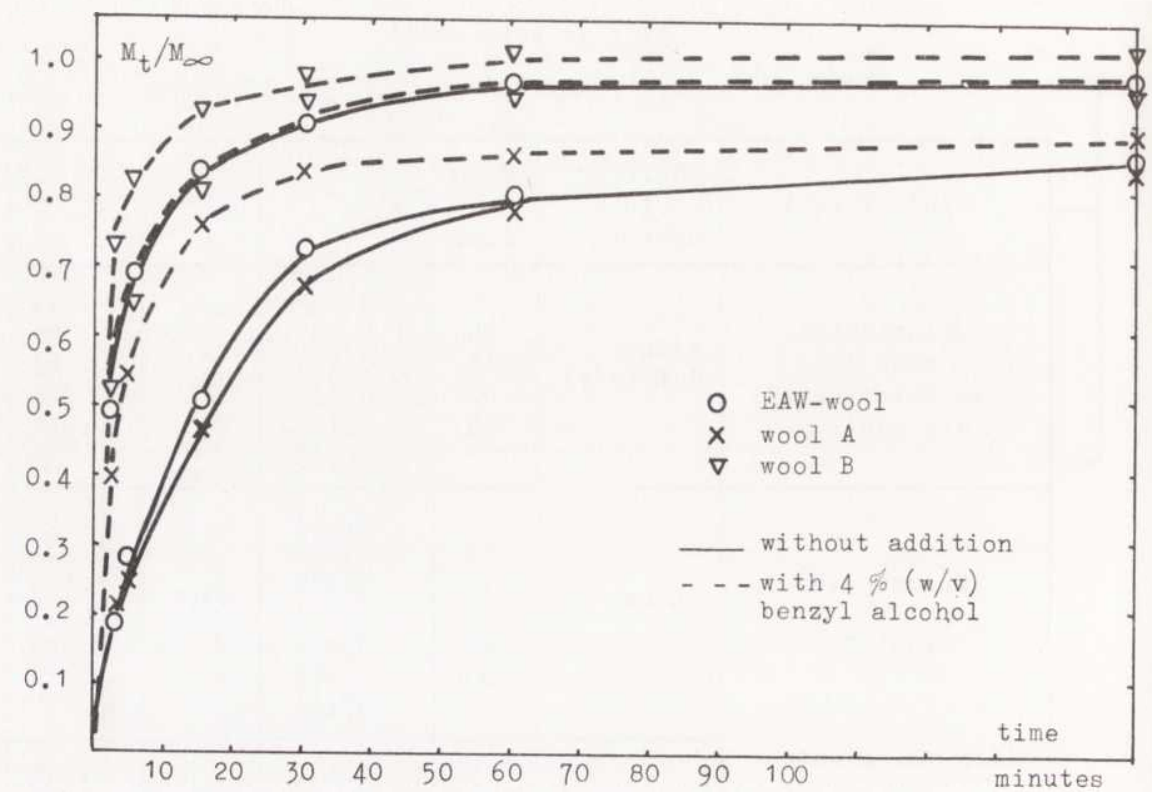

Fig. $8-M_{t} / M_{\infty}$ as a function of time, at dyeing of untreated and chlorinated wool at $\mathrm{pH} 1.2$.

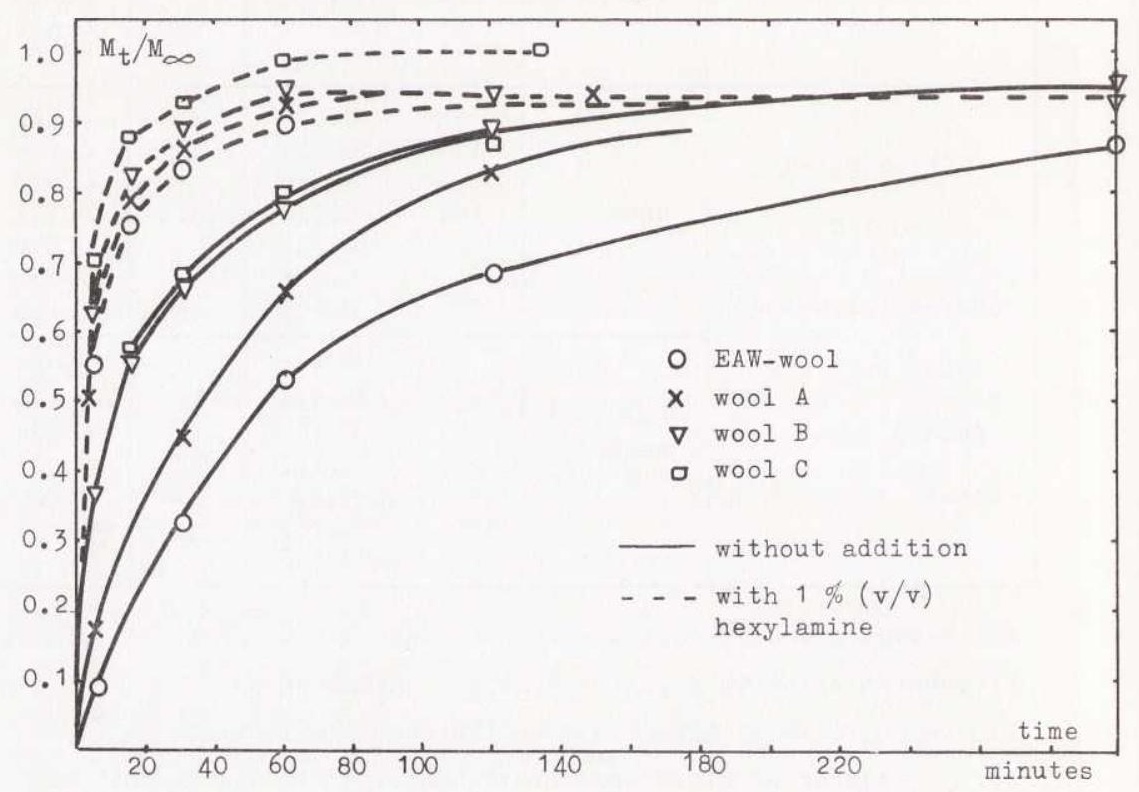

Fig. $9-\mathbb{M}_{t} / \mathbb{M}_{\infty}$ as a function of time, at dyeing of untreated and chlorinated wool at $\mathrm{pH} 7.8$. 


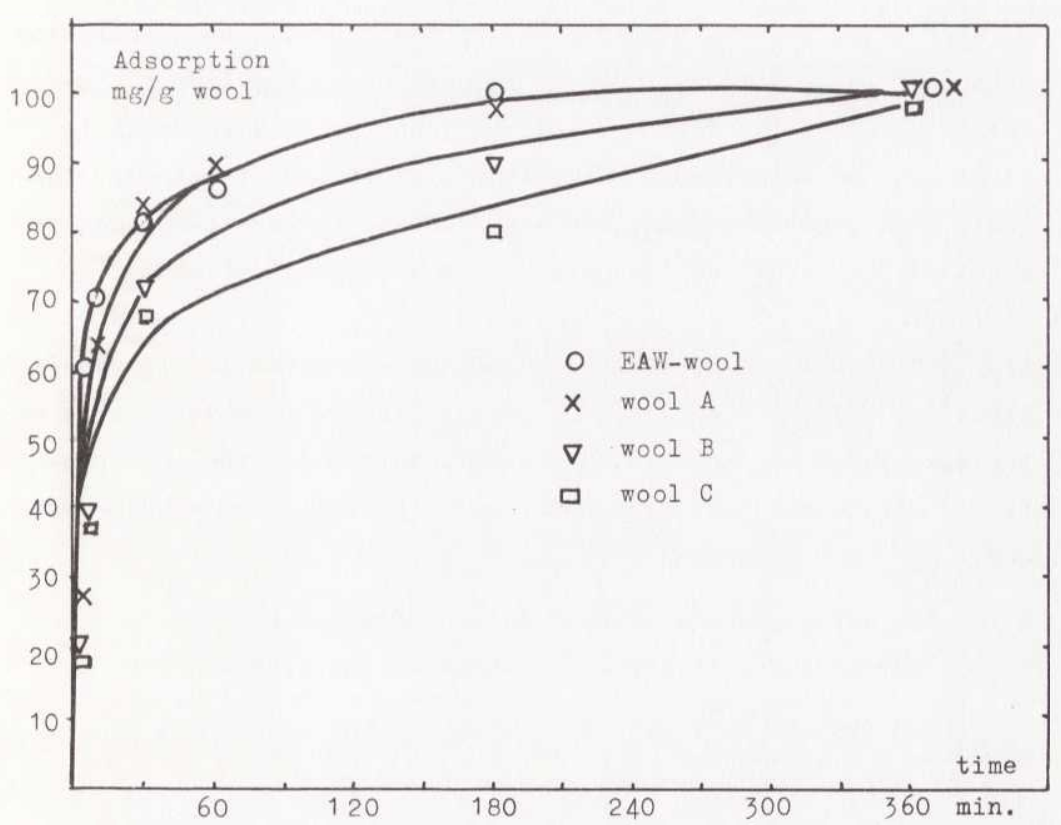

Fig. 10 a - Adsorption of benzyl alcohol as a function of time on untreated and chlorinated wool at $\mathrm{pH} \mathrm{1.2,}$ liquor ratio $30: 1$, initial conc. $4 \mathrm{~g} / 100 \mathrm{ml}$, temp. $2.5^{\circ} \mathrm{C}$.



Fig. $10 \mathrm{~b}$

First part of fig. 10 a 
substance is irreversibly adsorbed by the fibre. The calculation method given by Wilson, 1948, is founded on a rectilinear, reversible adsorption isotherm and was found to be less suitable for the above experimental data than was 0lofsson's method. The latter was used therefore, and was found to be less laborious in practice than might be considered from a theoretical study.

Detailed directions for the calculations are given in Olofsson's paper (p. T470) and will not be repeated here. However, parts of the calculation method, which are of interest for the interpretation of the results, are described. The following symbols are used:

$B=A / \pi a^{2}=$ volume of bath/volume of moist fibres

$c_{0}=$ concentration of dye in solution at the time $t=0$

$c_{t}=$ concentration of dye in solution at the time $t=t$

$c_{\rho=1}=c_{t} / c_{0}$

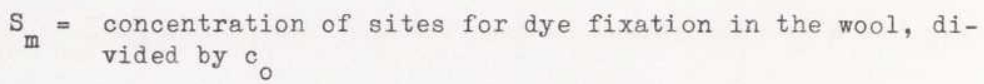

1 = position of moving boundary (see fig. 11)

$\mathrm{a}=$ fibre radius $=12.1 \times 10^{-4} \mathrm{~cm}$ for EAW-wool, wool $\mathrm{A}$, and wool $\mathrm{B}$ $=9.7 \times 10^{-4} \mathrm{~cm}$ for wool $\mathrm{C}$

$\lambda=1 / \mathrm{a}$

$D=$ diffusion constant

Firstly, from the experimental data $c_{t} / c_{0}$ is plotted against the time $t$.

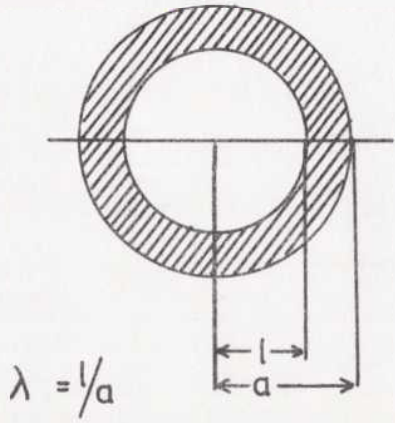

Fig. 11
A series of values of $\lambda$ (see fig. 11) is chosen arbitrarily (in this case $1.00,0.95,0.90,0.85 \ldots$.$) and the$ corresponding values of $\mathrm{C}_{f=1}$ are calculated from eq (20) p. T471 in Olofsson's paper. From the experimental curves, corresponding $t$ - values are obtained and mean values of $\Delta t$ are calculated for a fixed difference 
in the position of the moving boundary at time steps immediately before and immediately after time $t$. Two values of $\mathrm{D} / \mathrm{a}^{2}$ are then calculated according to eqs (21) and (22) respectively and a mean value of $\mathrm{D} / \mathrm{a}^{2}$ according to eq $\left(28^{\prime}\right)$ is obtained as the final result. The numbers of the equations refer to Olofsson's paper.

From the experiments of interest in this case, the graphs of $c_{t} / c_{0}$ against $t$, obtained from the values in table 8 , are given in fig. 12 and $13 \mathrm{a}$ and $\mathrm{b}$. The chosen values of $\lambda$, the calculated values of $\mathrm{C}_{\rho=1}$, and $\Delta \mathrm{tm}$ obtained from the experimental curves are given in tables 10 and 11 together with the final values of $D / a^{2}$. As the fibre radius, a, is constant, the variation obtained in $\mathrm{D} / \mathrm{a}^{2}$ is due to a variation in the diffusion constant, D. For some curves, D is fairly constant whilst for others it varies considerably. (When the dyeing rate is large, the first part of the curve has been drawn as a straight line, giving values of $D$ which are too small at the beginning and too large at the end of the rectilinear portion). For

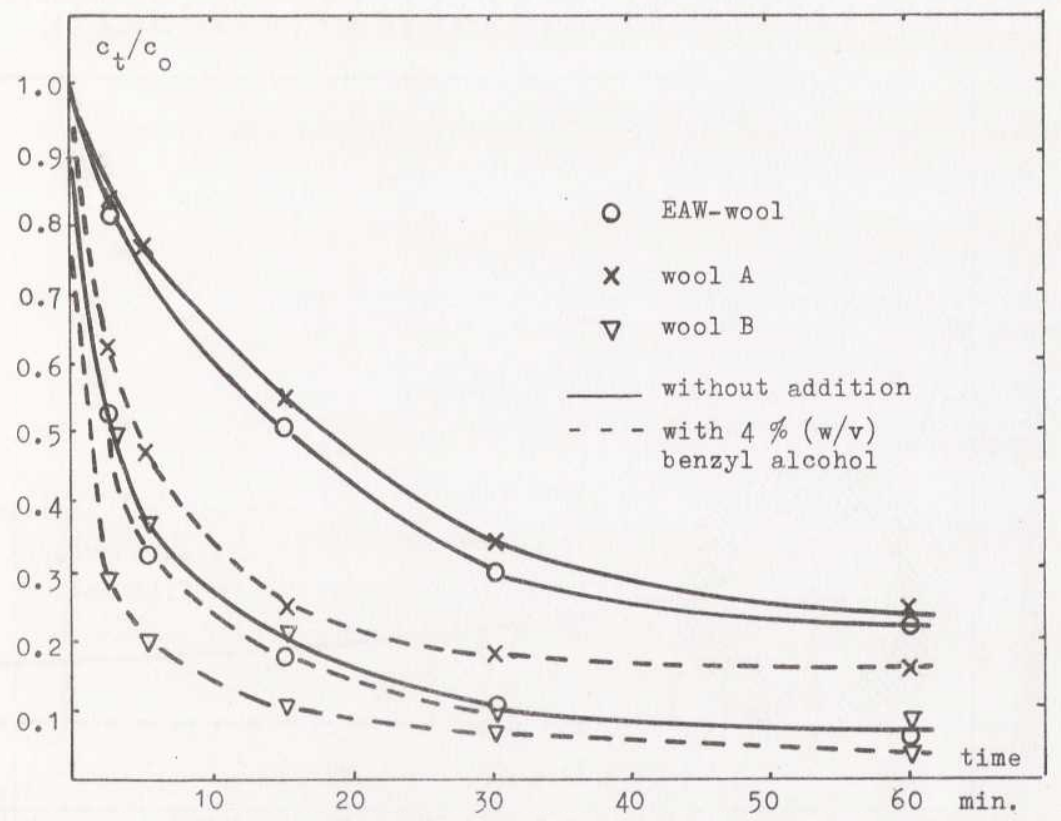

Fig. $12-c_{t} / c_{0}$ as a function of time, at dyeing of untreated and chlorinated wool at $\mathrm{pH} 1.2$ (see table 8 ). 


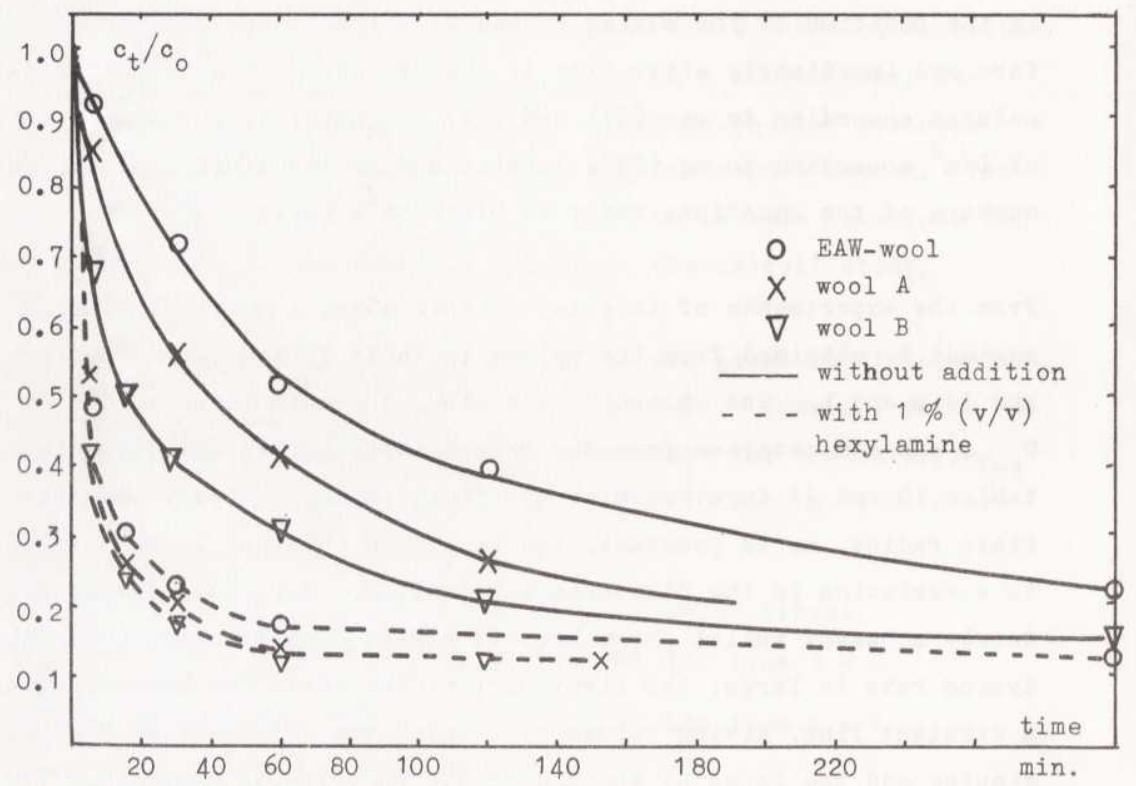

Fig. 13 a $-c_{t} / c_{0}$ as a function of time, at dyeing of untreated and chlorinated wool at $\mathrm{pH} 7.8$ (see table 9).

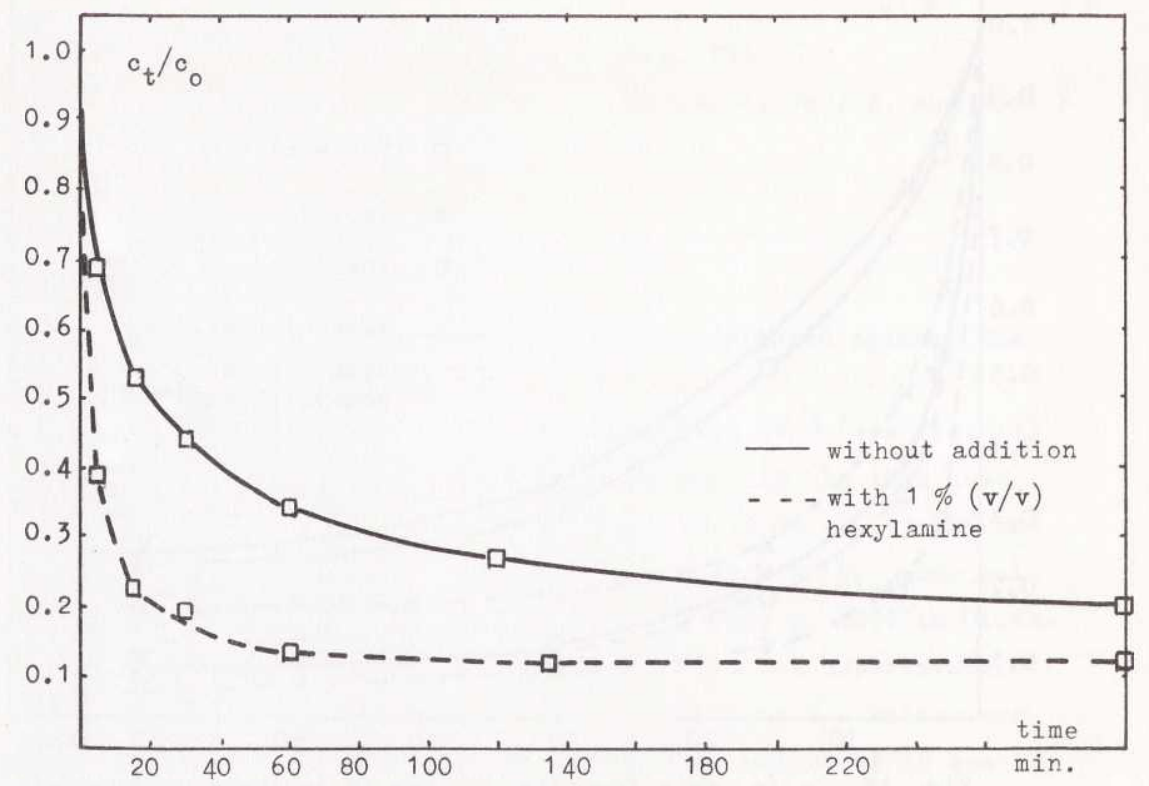

Fig. $13 \mathrm{~b}-\mathrm{c}_{\mathrm{t}} / \mathrm{c}_{0}$ as a function of time, at dyeing of descaled
wool (wool c) at $\mathrm{pH} 7.8$ (see table 9 ). 


\section{Table 10}

Values of $\mathrm{D} / \mathrm{a}^{2}$ at different values of $/$ calculated from the experimental series in table 8

$\Delta t_{m}$ is given in min., $\mathrm{D} / \mathrm{a}^{2}$ in min. ${ }^{-1}$

\begin{tabular}{|c|c|c|c|c|c|c|c|c|c|}
\hline \multirow[t]{2}{*}{$\lambda$} & \multirow{2}{*}{${ }^{C} \rho=1$} & \multicolumn{2}{|c|}{ EAW-wool } & \multicolumn{2}{|c|}{$\begin{array}{l}\text { EAVI-wool and } \\
\text { benzyl alcohol }\end{array}$} & \multicolumn{2}{|c|}{$\begin{array}{l}\text { Chlorinated } \\
\text { wool A }\end{array}$} & \multicolumn{2}{|c|}{$\begin{array}{l}\text { Chlorinated } \\
\text { wool A and } \\
\text { benzyl alcohol }\end{array}$} \\
\hline & & $\Delta t_{m}$ & $D / a^{2}$ & $\Delta t_{m}$ & $D / a^{2}$ & $\Delta t_{m}$ & $D / a^{2}$ & $\Delta t_{m}$ & $D / a^{2}$ \\
\hline $\begin{array}{l}0.95 \\
0.90 \\
0.85 \\
0.80 \\
0.75 \\
0.70 \\
0.65 \\
0.60 \\
0.55 \\
0.50 \\
0.45 \\
0.40 \\
0.35\end{array}$ & $\begin{array}{l}0.904 \\
0.813 \\
0.727 \\
0.646 \\
0.570 \\
0.499 \\
0.433 \\
0.372 \\
0.316 \\
0.264 \\
0.218 \\
0.176 \\
0.140\end{array}$ & $\begin{array}{c}1.25 \\
1.85 \\
2.63 \\
3.08 \\
3.73 \\
3.93 \\
4.03 \\
4.38 \\
6.0 \\
17.8\end{array}$ & $\begin{array}{l}0.318 \\
0.465 \\
0.536 \\
0.665 \\
0.756 \\
0.956 \\
1.21 \\
1.44 \\
1.35 \\
0.59\end{array}$ & $\begin{array}{l}0.25 \\
0.50 \\
0.45 \\
0.40 \\
0.40 \\
0.40 \\
0.60 \\
1.38 \\
2.50 \\
3.25 \\
3.83 \\
4.93 \\
6.23\end{array}$ & $\begin{array}{l}1.59 \\
1.72 \\
3.12 \\
5.12 \\
5.76 \\
9.40 \\
8.14 \\
4.57 \\
3.25 \\
3.22 \\
3.52 \\
3.60 \\
3.69\end{array}$ & $\begin{array}{r}1.65 \\
2.20 \\
3.35 \\
3.68 \\
4.03 \\
4.20 \\
4.48 \\
5.35 \\
8.53 \\
26.0\end{array}$ & $\begin{array}{l}0.241 \\
0.391 \\
0.419 \\
0.556 \\
0.699 \\
0.896 \\
1.09 \\
1.18 \\
0.952 \\
0.401\end{array}$ & $\begin{array}{l}0.45 \\
0.55 \\
0.60 \\
0.85 \\
1.08 \\
1.68 \\
2.28 \\
2.48 \\
2.88 \\
4.28\end{array}$ & $\begin{array}{l}0.883 \\
1.56 \\
2.34 \\
2.41 \\
2.58 \\
2.24 \\
2.14 \\
2.54 \\
2.83 \\
2.44\end{array}$ \\
\hline
\end{tabular}

Table 10 (continued)

\begin{tabular}{|c|c|c|c|c|c|}
\hline \multirow[t]{2}{*}{$\lambda$} & \multirow{2}{*}{$\mathrm{C}_{\rho=1}$} & \multicolumn{2}{|c|}{ Chlorinated wool B } & \multicolumn{2}{|c|}{$\begin{array}{l}\text { Chlorinated wool B } \\
\text { and benzyl alcohol }\end{array}$} \\
\hline & & $\Delta t_{m}$ & $D / a^{2}$ & $\Delta t_{m}$ & $D / a^{2}$ \\
\hline $\begin{array}{l}0.95 \\
0.90 \\
0.85 \\
0.80 \\
0.75 \\
0.70 \\
0.65 \\
0.60 \\
0.55 \\
0.50 \\
0.45 \\
0.40 \\
0.35 \\
0.30\end{array}$ & $\begin{array}{l}0.904 \\
0.813 \\
0.727 \\
0.646 \\
0.570 \\
0.499 \\
0.433 \\
0.372 \\
0.316 \\
0.264 \\
0.218 \\
0.176 \\
0.140 \\
0.108\end{array}$ & $\begin{array}{l}0.35 \\
0.43 \\
0.40 \\
0.40 \\
0.60 \\
1.20 \\
1.38 \\
1.83 \\
? .70 \\
3.35 \\
3.93 \\
4.63 \\
5.73\end{array}$ & $\begin{array}{l}1.13 \\
2.00 \\
3.51 \\
5.12 \\
4.70 \\
3.13 \\
3.54 \\
3.45 \\
3.01 \\
3.11 \\
3.42 \\
3.79 \\
4.01\end{array}$ & $\begin{array}{l}0.13 \\
0.20 \\
0.28 \\
0.30 \\
0.33 \\
0.30 \\
0.40 \\
0.40 \\
0.63 \\
1.10 \\
1.90 \\
3.20 \\
4.20 \\
5.43\end{array}$ & $\begin{array}{c}3.06 \\
4.30 \\
5.01 \\
6.83 \\
8.55 \\
12.5 \\
12.2 \\
15.7 \\
12.9 \\
9.50 \\
7.07 \\
5.47 \\
5.48 \\
5.76\end{array}$ \\
\hline
\end{tabular}




\section{Table 11}

Values of $\mathrm{D} / \mathrm{a}^{2}$ at different value of $\lambda$ calculated from the experimental series in table 9

$\Delta t_{m}$ is given in min., $\mathrm{D} / \mathrm{a}^{2}$ in min. ${ }^{-1}$

\begin{tabular}{|c|c|c|c|c|c|c|c|}
\hline$\lambda$ & \multirow{2}{*}{$c_{\rho=1}$} & \multicolumn{2}{|c|}{ EAW - wool } & \multicolumn{2}{c|}{$\begin{array}{c}\text { Chlorinated } \\
\text { wool }\end{array}$} & \multicolumn{2}{c|}{$\begin{array}{c}\text { Chlorinated } \\
\text { wool }\end{array}$} \\
\cline { 3 - 8 } & & $\Delta t_{m}$ & $D / a^{2}$ & $\Delta t_{m}$ & $D / a^{2}$ & $\Delta t_{m}$ & $D / a^{2}$ \\
\hline 0.95 & 0.912 & 7.30 & 0.0099 & 3.0 & 0.0240 & 1.15 & 0.123 \\
0.90 & 0.828 & 9.20 & 0.0167 & 3.85 & 0.0400 & 1.20 & 0.128 \\
0.85 & 0.750 & 9.75 & 0.0254 & 4.95 & 0.0500 & 1.55 & 0.160 \\
0.80 & 0.676 & 10.30 & 0.0347 & 6.50 & 0.0550 & 1.90 & 0.188 \\
0.75 & 0.606 & 11.35 & 0.0426 & 8.0 & 0.0605 & 3.23 & 0.150 \\
0.70 & 0.542 & 13.35 & 0.0469 & 9.83 & 0.0637 & 5.25 & 0.119 \\
0.65 & 0.482 & 18.90 & 0.0423 & 11.95 & 0.0669 & 7.30 & 0.109 \\
0.60 & 0.426 & 27.78 & 0.0360 & 14.48 & 0.0690 & 9.95 & 0.100 \\
0.55 & 0.375 & 38.20 & 0.0325 & 17.53 & 0.0709 & 12.75 & 0.0975 \\
0.50 & 0.328 & 45.93 & 0.0333 & 20.9 & 0.0730 & 15.60 & 0.0979 \\
0.45 & 0.286 & 44.63 & 0.0409 & 26.0 & 0.0702 & 19.0 & 0.0961 \\
0.40 & 0.249 & 46.25 & 0.0469 & 38.1 & 0.0569 & 22.5 & 0.0964 \\
0.35 & 0.216 & & & & & 28.5 & 0.0915 \\
\hline
\end{tabular}

Table 11 (continued)

\begin{tabular}{|c|c|c|c|c|c|c|c|}
\hline$\lambda$ & \multirow{2}{*}{$\mathrm{c}_{\rho=1}$} & \multicolumn{2}{|c|}{$\begin{array}{c}\text { EAW - wool and } \\
\text { hexylamine }\end{array}$} & \multicolumn{2}{c|}{$\begin{array}{c}\text { Chlorinated } \\
\text { wool A and } \\
\text { hexylamine }\end{array}$} & \multicolumn{2}{c|}{$\begin{array}{c}\text { Chlorinated } \\
\text { wool B and } \\
\text { hexylamine }\end{array}$} \\
\cline { 3 - 8 } & & $\Delta t_{m}$ & $D / a^{2}$ & $\Delta t_{m}$ & $D / a^{2}$ & $\Delta t_{m}$ & $D / a^{2}$ \\
\hline 0.95 & 0.908 & 0.80 & 0.0942 & 0.60 & 0.126 & 0.25 & 0.295 \\
0.90 & 0.821 & 0.73 & 0.222 & 0.80 & 0.203 & 0.20 & 0.793 \\
0.85 & 0.739 & 0.78 & 0.336 & 0.70 & 0.375 & 0.20 & 1.28 \\
0.80 & 0.662 & 0.85 & 0.448 & 0.65 & 0.586 & 0.20 & 1.86 \\
0.75 & 0.589 & 0.83 & 0.624 & 0.78 & 0.664 & 0.30 & 1.69 \\
0.70 & 0.522 & 0.90 & 0.757 & 0.83 & 0.820 & 0.55 & 1.21 \\
0.65 & 0.459 & 1.65 & 0.533 & 1.20 & 0.735 & 0.85 & 1.01 \\
0.60 & 0.401 & 2.35 & 0.474 & 1.68 & 0.663 & 1.45 & 0.751 \\
0.55 & 0.348 & 3.60 & 0.388 & 2.43 & 0.575 & 2.40 & 0.566 \\
0.50 & 0.299 & 5.95 & 0.293 & 3.85 & 0.453 & 4.20 & 0.405 \\
0.45 & 0.256 & 9.20 & 0.236 & 6.30 & 0.345 & 6.40 & 0.329 \\
0.40 & 0.216 & 13.15 & 0.206 & 8.90 & 0.304 & 8.00 & 0.329 \\
0.35 & 0.182 & 19.80 & 0.169 & & & 10.15 & 0.320 \\
\hline
\end{tabular}


Table 11 (continued)

\begin{tabular}{|c|c|c|c|c|c|c|}
\hline \multirow{2}{*}{$\lambda$} & \multicolumn{3}{|c|}{ Chlorinated wool C } & \multicolumn{3}{c|}{$\begin{array}{c}\text { Chlorinated wool C } \\
\text { and hexylamine }\end{array}$} \\
\cline { 2 - 7 } & $C_{\rho=1}$ & $\Delta t_{m}$ & $D / a^{2}$ & $C_{\rho=1}$ & $\Delta_{m}$ & $D / a^{2}$ \\
\hline 0.95 & 0.917 & 0.80 & 0.0838 & 0.913 & 0.40 & 0.177 \\
0.90 & 0.839 & 0.85 & 0.168 & 0.831 & 0.35 & 0.433 \\
0.85 & 0.765 & 1.23 & 0.185 & 0.753 & 0.40 & 0.610 \\
0.80 & 0.696 & 1.95 & 0.167 & 0.680 & 0.40 & 0.872 \\
0.75 & 0.631 & 3.03 & 0.144 & 0.612 & 0.45 & 1.050 \\
0.70 & 0.570 & 4.53 & 0.124 & 0.548 & 0.50 & 1.223 \\
0.65 & 0.514 & 6.73 & 0.104 & 0.489 & 0.65 & 1.193 \\
0.60 & 0.462 & 9.93 & 0.0868 & 0.434 & 0.95 & 1.015 \\
0.55 & 0.414 & 12.28 & 0.0859 & 0.384 & 1.30 & 0.918 \\
0.50 & 0.370 & 13.80 & 0.0917 & 0.338 & 1.90 & 0.766 \\
0.45 & 0.331 & 18.33 & 0.0821 & 0.297 & 2.70 & 0.652 \\
0.40 & 0.296 & 26.30 & 0.0677 & 0.260 & 4.38 & 0.485 \\
0.35 & & & & 0.227 & 5.93 & 0.428 \\
0.30 & & & & 0.199 & 7.03 & 0.429 \\
0.25 & & & & 0.175 & 8.40 & 0.419 \\
\hline
\end{tabular}

comparison of diffusion constants, a mean value of $D$ should therefore be calculated. The main purpose of this investigation is to compare the change in the diffusion constants for dyeings performed on wool with different surface properties with and without the addition of solvents. It is therefore considered as most suitable to use mean values of the diffusion constant obtained over the same range of $\lambda$-values, i.e. the same depth of penetration of dye into the fibres. Olofsson (in the cited paper) points out that his approximate method of calculation is most accurate at the beginning of the diffusion and should not be used for $\lambda$-values lower than 0.35 to 0.30 . Therefore, mean values of $\mathrm{D} / \mathrm{a}^{2}$ have been calculated for $\lambda$-values from 0.95 to 0.50 and are summarized in table 12 and 13.

When the dyeing rate is high, the experimental accuracy will be low at the beginning of the dyeing period, and also rather small changes in the curve between $c_{t} / c_{0}=1, t=0$, and the first experimental point, will then give rise to different mean values. For the curves referring to dyeing of wool $B$ and wool $C$ in the presence of hexyl- 
$\underline{\text { Table } 12}$

Mean values of $\mathrm{D} / \mathrm{a}^{2}$ and values of $\mathrm{D}_{\mathrm{s}} / \mathrm{D}$ for bromphenol blue on different types of wool

ph 1.2; temp. $2.5^{\circ} \mathrm{C}$; liquor ratio $150: 1$

\begin{tabular}{|l|c|c|c|}
\hline Kind of wool & $\begin{array}{c}\text { Addition } \\
\text { to } \\
\text { dyebath }\end{array}$ & $\begin{array}{c}\text { D/a } \\
\text { mean value at } \\
\lambda 0.95-0.50\end{array}$ & $D_{s} / D^{1)}$ \\
\hline EAW-wool & $\begin{array}{c}- \\
\text { benzyl alcohol } \\
4 \%(w / v)\end{array}$ & 0.828 & 5.5 \\
\hline Wool A & $\begin{array}{c}\text { benzyl alcohol } \\
4 \%(w / v)\end{array}$ & 0.682 & 3.2 \\
\hline Wool B & $\begin{array}{c}2.20 \\
\text { benzyl alcohol } \\
4 \%(w / v)\end{array}$ & 3.27 & 2.8 \\
\hline
\end{tabular}

$a=12.1 \times 10^{-4} \mathrm{~cm}$

\section{Table 13}

Mean values of $\mathrm{D} / \mathrm{a}^{2}$ and values of $\mathrm{D}_{\mathrm{g}} / \mathrm{D}$ for bromphenol blue on different types of wool pH 7.8 ; temp. $60^{\circ} \mathrm{C}$; liquor ratio $30: 1$

\begin{tabular}{|c|c|c|c|}
\hline Kind of wool & $\begin{array}{c}\text { Addition } \\
\text { to } \\
\text { dyebath }\end{array}$ & $\begin{array}{c}\mathrm{D} / \mathrm{a}^{2} \\
\text { mean value at } \\
\lambda 0.95-0.50\end{array}$ & $D_{s} / D^{1)}$ \\
\hline EAW-wOOI & $\begin{array}{c}\text { hexylamine } \\
1 \%(v / v)\end{array}$ & $\begin{array}{l}0.0414 \\
0.384\end{array}$ & 9.3 \\
\hline Wool A & $\begin{array}{c}- \\
\text { hexylamine } \\
1 \%(\mathrm{v} / \mathrm{v})\end{array}$ & $\begin{array}{l}0.0583 \\
0.488\end{array}$ & 8.4 \\
\hline Wool B & $\begin{array}{c}\text { hexylamine } \\
1 \%(\mathrm{v} / \mathrm{v})\end{array}$ & $\begin{array}{c}0.122 \\
0.876 \\
(0.605)\end{array}$ & $\begin{array}{c}7.2 \\
(5.0)\end{array}$ \\
\hline Wool C & $\begin{array}{c}\text { hexylamine } \\
1 \%(\mathrm{v} / \mathrm{v})\end{array}$ & $\begin{array}{c}0.116 \\
0.783 \\
(0.814)\end{array}$ & $\begin{array}{c}6.8 \\
(7.0)\end{array}$ \\
\hline
\end{tabular}

1) $D_{s}=$ Diffusion constant in presence of solvent $a=12.1 \times 10^{-4}$ for EAW-wool, wool $\mathrm{A}$ and wool $\mathrm{B}$ $a=9.7 \times 10^{-4}$ for wool $\mathrm{C}$ 
amine, the diffusion constant has been calculated from alternative curves in this first region. The mean value of $\mathrm{D} / \mathrm{a}^{2}$ in table 13 is then changed and these alternative values are given within brackets.

The quotients between the $D / a^{2}$-values, $D_{S} / D$ i.e. the diffusion constants for dyeings with and without solvents on the same wool sample are also given in the tables 12 and 13 .

For bromphenol blue at $\mathrm{pH} 1.2$ the diffusion constant is increased 5.5 times by the addition of $4 \%$ benzyl alcohol to the dyebath when the dyeing is performed on untreated wool, but only 3.2 or 2.8 times on chlorinated wool.

The corresponding increase in diffusion constant for bromphenol blue at $\mathrm{pH} 7.8$ by the addition of $1 \%$ hexylamine is 9.3 times for untreated wool and decreases to 8.4 for wool A, 5.0-7.2 for wool B and $6.8-7.0$ for the descaled wool.

The absolute magnitude of these values refer to the investigated system and should not be considered representative for solventassisted dyeings in general. The relative values, however, i.e. the changes in $D_{s} / D$ due to surface treatments, should be valid for solvent-assisted dyeings performed on the same kind of surfacetreated wool as described.

The same general picture is thus obtained from the two dyeings made under different experimental conditions. For all surface-treated wool samples, the values of $D_{S} / D$ decrease compared with untreated wool. The decrease is larger for wool B and C than for wool A. Dyeing with the acid modification of bromphenol blue gives the same result on wool $B$ and $C$, but there might be a slight difference for the basic modification on these two chlorinated wools, depending on which mean value of $D$ is used.

Furthermore, it may be noted that the number of sites for dye fixation of the basic form of bromphenol blue (as expressed by the 
values of $\mathrm{S}_{\mathrm{m}}$ in table 9 is slightly less in descaled wool (wool C) than in untreated wool (EAW-wool). The number of these sites is increased by the addition of hexylamine to the dyebath. Thus hexylamine will cause a change in the equilibrium exhaustion of the dyebath both on untreated and chlorinated wool, and a difference in equilibrium exhaustion without the addition of hexylamine will also be obtained for wool C compared with the other kinds of wool.

Benzyl alcohol has no such effect on the acid form of bromphenol blue, and the number of sites available to this form of the dye is found to be equal on untreated and descaled wool.

Summarizing, it might be stated that the rate of adsorption of the solvent is dependent on the surface properties of wool, and that solvents cause smaller increase in the dyeing rate of chlorinated wool. The surface properties of wool are thus important in solventassisted dyeings, although the same mechanism of dye adsorption in such dyeings may apply with both untreated and surface-treated wool.

\subsection{Influence of solvents on stress relaxation and swelling of wool fibres}

Stress relaxation of wool fibres

In wool fibres break-down of cross linkages between the polypeptide chains, followed by a molecular rearrangement, has been proposed to account for stress relaxation (Speakman et al, 1941). The crosslinkages present in wool fibres include covalent disulphide bonds, salt linkages, hydrogen bonds and van der Waal's forces. If the alcohols used in solvent-assisted dyeings are able to break these cross-linkages to a much higher degree than water alone, this could increase the dyeing rate. It should be possible to determine the extent to which this occurs from stress-relaxation curves, as increased bond breaking would give rise to increased stress relaxation. The method of Katz and Tobolsky, 1950, has been used for this purpose. Wool fibres were extended $15 \%$ in water at $60^{\circ} \mathrm{C}$, using an Instron Textile Testing machine, and the decay of tension at constant 
temperature and extension was recorded. After one hour's relaxation of the fibre, amyl alcohol ( $3 \%$ by volume) or butanol ( $5 \%$ by volume) was added to the water and the decay of tension followed for several hours.

However, no change in the relaxation curve could be observed after the addition of one of these alcohols to the water. Break-down of cross-links and molecular rearrangement by these alcohols thus seem to be rather improbable.

\section{Swelling of wool fibres}

When wool is immersed in water there is a diffusion of water molecules into the fibres. Because of the presence of hydrophilic groups in the fibre this causes swelling.

An increase in the degree of swelling of a fibre would indicate breakdown of cross-linkages, with a consequent increased rate of diffusion of dyes. Atkinson et al, 1959, have observed a small increase in swelling of wool by an aqueous solution containing $45 \%$ propanol.

The change in swelling of wool fibres resulting from the addition of benzyl alcohol or hexylamine to an aqueous solution has therefore been determined from the change in fibre diameter. For this purpose, EAW-wool from the same piece of top, was divided into six parts. Five of these were immersed in the following solutions at room temperature for 48 hours: 1) distilled water $+0.075 \%$ of a nonionic wetting agent; 2) $4 \%(\mathrm{w} / \mathrm{v})$ benzyl alcohol in distilled water; 3) buffer solution at pH $7.8+0.075 \%$ of the above wetting agent; 4) buffer solution at $\mathrm{pH} 10.0+0.075 \%$ of the above wetting agent; 5) $1 \%(\mathrm{v} / \mathrm{v})$ of hexylamine (buffer solution of $\mathrm{pH} 7.8$ ). As shown previously, solution 5 has a $\mathrm{pH}$ of about 10 .

The sixth part was brought to equilibrium with an atmosphere of $65 \%$ relative humidity at room temperature. 
jection microscope, operating at a magnification of $500 x$ - the procedure is the technique standardized in the Swedish standard method SIS 6500 04. Eight samples were prepared from each of the six treatments and one hundred fibres were measured from each sample. The mean diameters of these hundred fibres are given in table 14. The $95 \%$ confidence interval for the difference between two mean values is calculated under table 14 and found to be $0.67 \mu$. This means that, by the technique used, a change in diameter of $2.8 \%$ (absolute) can be detected by this method. By increasing the pH to about 10 either by addition of hexylamine or by introducing a borate buffer of this pH the fibre diameter will increase by the above amount. It has, however, been shown earlier (see table 6) that hexylamine increases the rate of dyeing, but a mere change in $\mathrm{pH}$ by the addition of borate has no such effect. As wool fibres are already highly swollen in water $(13.3 \%$ increase in diameter over the air dry sample), this increase in swelling of a few percentages seems to be relatively unimportant to the rate of dyeing. The addition. of benzyl alcohol also seems to increase the fibre diameter to some extent (but less than the confidence interval). The increase in swelling is interesting, as it might indicate changes in the fibre due to the adsorption of benzyl alcohol or hexylamine, but it is rather improbable that this increase, as such, can affect the rate of dyeing to any great extent. 
Table 14

Swelling of wool fibres in different solutions

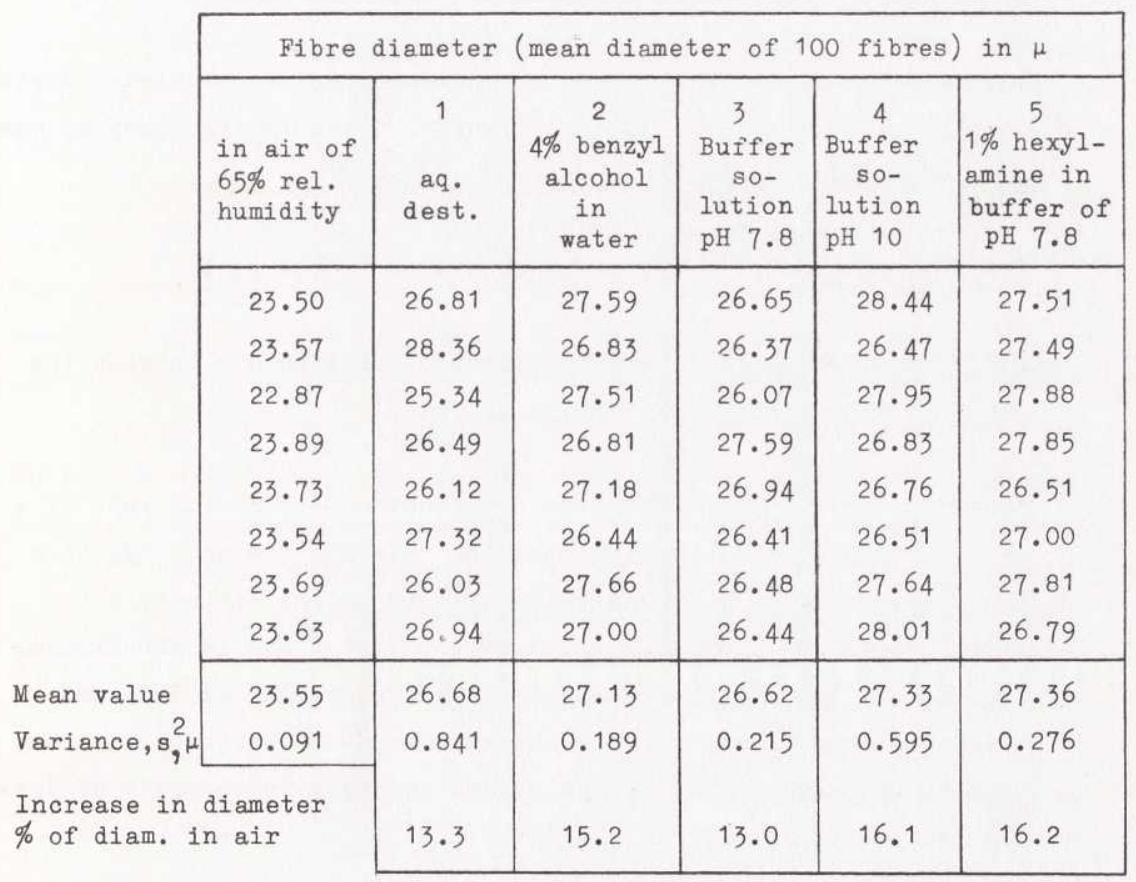

Mean value of $\mathrm{s}^{2}=0.368 \mu$

The $95 \%$ confidence interval, $\mathrm{d}$, for the difference between two mean values of fibre diameter $=t \cdot s \sqrt{\frac{1}{n_{1}}+\frac{1}{n_{2}}}$ where $t=2.2, s=\sqrt{s^{2}}=$ $=0.606, \mathrm{n}_{1}=\mathrm{n}_{2}=8$, which gives $\mathrm{d}=0.667 \mu$, which corresponds to $2.83 \%$ of the fibre diameter in air. 


\section{GENERAL DISCUSSION OF THE MECHANISN OF}

\section{SOLVEIT-ASSISTED DYEIIIG OF WOOL}

The results of interest in the mechanism of solvent-assisted dyeing, obtained from the foregoing experimental investigations may be summarized briefly as follows.

All solvents investigated are adsorbed on to the wool.

For some alcohols there exists a simple relationship between the amount of adsorption and the dyeing rate.

A particular alcohol might have no effect on the dyeing rate of a dye at a pH about 7 , but increase the rate for the same dye at a lower $\mathrm{pH}$, although the adsorption of this alcohol is nearly the same at both pH-values. The solubility of the dye in the alcohol is large at the low pH-value where the dyeing rate is affected, but low at the higher pH. By using an amine in which the dye has high solubility at this latter $\mathrm{pH}$, an increase in the rate of dyeing can be obtained.

Solvent-assisted dyeings of surface-treated wool show that solvents cause less increase in the dyeing rate in this case than with untreated wool, although an appreciable effect of solvents may be obtained with descaled wool.

The distribution of dye between different wool fibres and also between different parts of the same wool fibre becomes more uniform when dyeing is carried out in the presence of solvents.

The presence of alcohols in the dyebrth can increase the dyeing rate of some dyes by an "extraction" effect. The dyeing rate of $1: 2$ chrome-complex dyes are, however, unaffected by previous extraction with alcohols in aqueous solution. 
The solvents may cause some swelling of the wool fibres (less than $3 \%$ increase above the swelling in water).

No change in the stress-relaxation properties in water has been observed after the addition of an alcohol. The breaking tenacity and elongation at break are not changed by the presence of an alcohol in the dyebath.

For the same amount of dye on the wool, a higher percentage of fibres was penetrated by the dye in the presence of a solvent than in the normal aqueous system, even though the time of dyeing was much shorter.

The fastness properties of dyeings are about the same, whether solvents are used or not.

The three latter statements are obtained from results of the industrial experiments described in chapter 4 .

In discussing the mechanism of solvent-assisted dyeing of wool, it seems fairly reasonable to make comparisons with carrier dyeing of synthetic fibres. This was also done by Kärrholm and Lindberg, 1956, in the previously cited paper. In that paper, reference was made to Kramer, 1955, who proposed that the carrier is adsorbed on the fibre surface, and in this layer the dye concentration is higher than in the bath, thus giving rise to a higher concentration gradient, causing a higher diffusion rate into the fibre. The solvent-layer theory of carriers is also treated by other investigators, e.g. Choquette, 1954, supporting this theory, whereas the microdyeoscope studies published by Millson, 1955, might be used against the theory.

Another effect ascribed to the carrier is to open internal bonds, e.g. hydrogen bonds, thus facilitating penetration of the dye (Kramer, 1955, Fortess et al, 1958). The carrier acts on the fibre by both these mechanisms. It has, however, been proposed that the carrier might also act on the dye in the dyebath, decreasing the 
degree of aggregation and thus increasing the concentration of single dye molecules, thereby increasing the dyeing rate (see e.g. Zimmerman et al, 1955).

The latter mechanism may be rejected for solvent-assisted dyeing of wool, because solvents give an increased rate of dyeing with a dye which is monomolecular in solution. Even if there should be some aggregation of this dye, the concentration of single molecules should still be so large, that any increase by disaggregation could hardly account for the increase in dyeing rate.

It may be concluded therefore that the solvent will act on the wool fibre and not on the dye in the dyebath.

Three possible mechanisms for solvent-assisted dyeing are:

1) the effect of a solvent layer,

2) loosening of the fibre structure,

3) supplementing of normal diffusion in fibre by diffusion in the adsorbed solvent.

These alternatives are discussed below.

\subsection{The effect of a solvent layer}

According to this hypothesis the solvent is considered to be adsorbed on the wool as a surface layer. The high solubility of the dye in this layer gives a high concentration which should cause more dye molecules to diffuse into the fibre per unit time.

However, if this hypothesis is treated thermodynamically as a system in equilibrium then, for the reasons given below, no increase in the dyeing rate is to be expected.

\section{Equilibrium treatment}

It is assumed that a dye is dissolved in the solution with an activity $a_{c}$ and in the solvent layer with the activity $a_{s}$. The sol- 
vent layer is in equilibrium with the outer solution and has the same activity in all parts. Furthermore, it is assumed that the fibre in contact with the solvent layer has attained its equilibrium activity, $a_{f} \cdot$

The chemical potential of the dye in solution, $\mu_{c}$, in the solvent layer, $\mu_{s}$, and on fibre, $\mu_{f}$, is given by the following equations:

$$
\begin{aligned}
& \mu_{c}=\mu_{c}{ }^{0}+R T \ln a_{c} \\
& \mu_{s}=\mu_{s}{ }^{0}+R T \ln a_{s} \\
& \mu_{f}=\mu_{f}{ }^{0}+R T \ln a_{f}
\end{aligned}
$$

where $\mu^{\circ}$ is the standard chemical potential in the respective phase, $\mathrm{R}$ is the gas constant and $\mathrm{T}$ the absolute temperature.

At equilibrium, $\mu_{c}=\mu_{s}=\mu_{f}$

and thus, $\mu_{c}{ }^{\circ}-\mu_{f}{ }^{0}=R T \ln a_{f}-R T \ln a_{c}$.

For the same system without a solvent layer,

$$
\mu_{c}{ }^{0}-\mu_{f}{ }^{\circ}=R T \ln a_{f}{ }^{\prime}-R T \ln a^{\prime}{ }_{c}
$$

where $a^{\prime}{ }_{f}$ and $a^{\prime} c$ are the activities of dye on fibre and in solution in this case.

As the outer concentration is unaffected, or might be decreased, by the presence of a solvent layer

$a_{c} \leq a^{\prime}{ }_{c}$, which means that $a_{f} \leq a_{f}^{\prime} ;$

The activity of dye on the fibre when a solvent layer is present is thus equal to, or less than that in the absence of such a layer.

This treatment presupposes equilibrium conditions. However, as the rate of dyeing is being considered, a kinetic treatment would be more correct. 


\section{Kinetic treatment}

It is assumed that the fibre has a surface layer of different properties (e.g. an epicuticle on a wool fibre) and there is an outer solvent layer in contact with a dyebath. This is shown in fig. 14 .

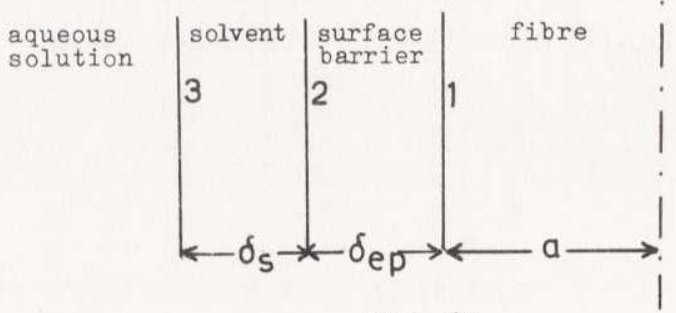

Fig. 14

From consideration of diffusional flow across the boundaries, the following expression has been deduced by B. Olofsson (unpublished).

$$
L=\frac{a}{D\left[\delta_{e p} / D_{e p} \cdot F_{e p}+\delta_{s} / D_{s} F\right]}
$$

where $a$ is the fibre radius, $D$ is the diffusion constant of dye in the fibre, $D_{e p}$ and $D_{S}$ are the diffusion constants in the surface barrier and solvent layer respectively. $F_{\text {ep }}$ and $F_{s}$ denote the partition constants of dye concentrations at equilibrium between the surface barrier and water, or solvent and water. $L$ is a dimensionless parameter, proportional to the combined permeability of the surface layers.

From the above expression, different L-values might be calculated for a fibre with and without epicuticle, and also with and without a solvent layer. Sorption and desorption curves for different L-values at infinite liquor ratio are given by Crank, 1956, and shown in fig. 15. From these curves, the influence of the parameters of interest on the uptake of dye might be obtained.

A quantitative treatment is questionable as many rather uncertain assumptions must be made, but the qualitative treatment below gives some valuable information. 


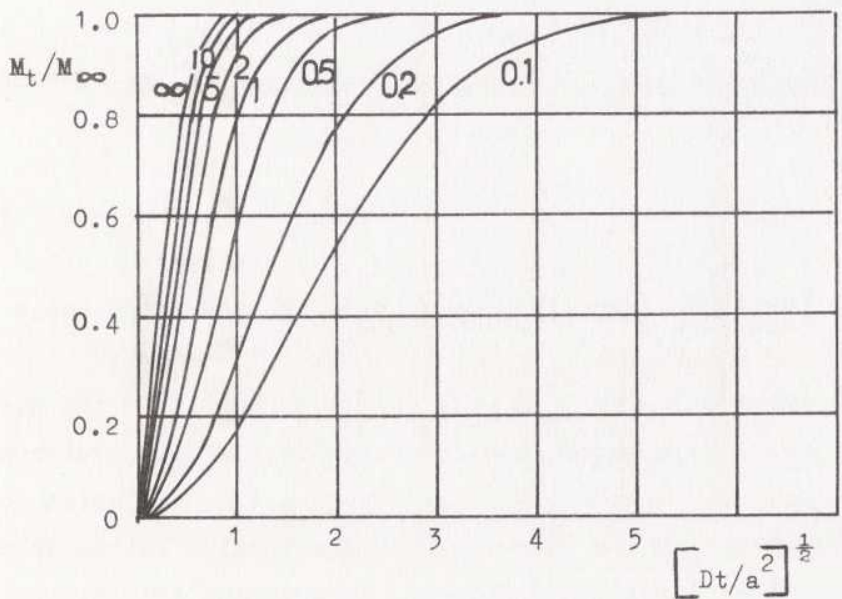

Fig. $15-M_{t} / M_{\infty}$ as a function of $\left[D t / a^{2}\right]^{\frac{1}{2}}$. Numbers on curves are values of L (from Crank, 1956, p. 74).

I. Fibre without surface barrier (epicuticle)

In this case $\delta_{\text {ep }}=0$ and the expression for $L$ becomes:

$$
L_{s}=\frac{a}{D \delta_{s} / D_{s} F_{s}}=\frac{D_{s} F}{D} \cdot \frac{a}{\delta_{s}}
$$

When calculating $L$ for fibres without a solvent layer, this layer is replaced by water of the same thickness:

$$
L_{w}=\frac{D_{w} \cdot F_{w} \cdot a}{D \cdot \delta_{w}}=\frac{D_{w}}{D} \cdot \frac{a}{\delta_{S}}
$$

as $F_{\mathrm{w}}=1$ and $\delta_{\mathrm{w}}=\delta_{\mathrm{s}} . \quad$ The quotient

$$
L_{S} / L_{w}=\frac{D_{S}}{D_{w}} \cdot F_{s}=F_{s}
$$

as $D_{s}$ may be assumed to have about the same value as $D_{w}$. 
The partition ratio of dye between solvent and water is usually high in solvent-assisted dyeings. If a value of $F_{s}=100$ is assumed then $\mathrm{L}_{\mathrm{S}}=100 \mathrm{~L}_{\mathrm{w}}$.

From fig. 15 it is seen that the effect of an increase of $L$ on the uptake of dye $\left(M_{t} / \mathbb{M}_{\infty}\right)$ is greater, the smaller the value of $L$. Therefore an attempt is made to find the lowest possible value of $\mathrm{L}_{\mathrm{w}}$.

The lowest value of $D_{w} / D$ will be 1 ; very probably the diffusion constant of dye in water is higher than in the fibre, although not necessarily much higher, as D denotes the true diffusion constant of the free dye in the fibre. The highest value of the thickness of the solvent layer $\delta_{\mathrm{g}}$ is obtained by assuming that all of the adsorbed solvent is on the surface of the wool. For an adsorption of $6 \%$ on the weight of the wool, a value of

$$
\delta_{s} / a=3 \times 10^{-2}
$$

is obtained.

Substitution in the above expression for $\mathrm{L}_{\mathrm{w}}$ gives $\mathrm{L}_{\mathrm{w}} \leq 33$.

From fig. 15 is seen that if $L=10$ an increase to $L=\infty$ will only give a low increase in the uptake of dye as a function of time.

\section{Fibre with surface barrier (epicuticle)}

\section{A) Without solvent layer}

The solvent layer is replaced by a water layer of the same thickness. If the epicuticle is assumed to have a thickness of about $0.1 \mu$, and the fibre radius, a, to be about $10 \mu$, then

$\delta_{\text {ep }} / \mathrm{a} \simeq 10^{-3} ; \quad \delta_{\mathrm{s}} / \mathrm{a}=3 \times 10^{-2} ; \quad \mathrm{F}_{\mathrm{s}}=1 ; \quad \mathrm{D}_{\mathrm{s}}=\mathrm{D}_{\mathrm{w}} ; \quad \mathrm{D} \leq \mathrm{D}_{\mathrm{w}}$.

The expression for $\mathrm{L}$ will be dependent on the nature of the surface barrier. It might be assumed that the affinity for the dye and also the diffusion constant are low. This means that $F_{\text {ep }} \leq 1$ and $D_{\text {ep }} \leqslant$ $\leq \mathrm{D}$. The value of $\mathrm{L}$ will then be less than 30. As seen from fig. 
15 a decrease of $L$ from this value might cause an appreciable decrease in the uptake of dye as a function of time. By assuming that $F_{e p}=$ 0.01 and $D_{e p}=D$, then $L=10$; for $F_{e p}=0.01$ and $D_{e p}=0.01 \mathrm{D}$, then $L=0.1$.

The retarding effect of a surface barrier upon the rate of dyeing is thus demonstrated by this treatment.

II B. With solvent layer

In the expression

$$
L=\frac{a}{D\left[\delta_{e p} / D_{e p} F_{e p}+\delta_{s} / D_{s} F_{s}\right]}
$$

the first term in the denominator referring to the surface barrier will increase with the efficiency of the barrier (decreasing $F_{e p}$ and $\left.D_{\text {ep }}\right)$. The second term in the denominator referring to the solvent layer will decrease with a higher concentration and higher diffusion constant of dye in the solvent layer (increasing $F_{S}$ and $D_{s}$ ). It is thus theoretically possible that the two expressions might balance each other, the decrease in dyeing rate caused by a surface barrier being counteracted by the increase caused by a solvent layer. However, by using the constants given above for this actual case, a rather small influence of the solvent layer is found. The value of $\delta_{\mathrm{s}} / \mathrm{D}_{\mathrm{s}} \mathrm{F}_{\mathrm{s}}$ will be small as $\mathrm{F}_{\mathrm{s}}$ increases compared with $\delta_{\text {ep }} / \mathrm{D}_{\mathrm{ep}} \mathrm{F}_{\mathrm{ep}}$, and the latter will determine the magnitude of $\mathrm{L}$.

The effect of a solvent layer in increasing the rate of dyeing when a surface barrier is present, can therefore be expected to be rather small.

The above kinetic treatment thus demonstrates that a solvent layer with high concentration of dye theoretically might cause some increase in the rate of dyeing, but this increase is small, and cannot account for the large increases in dyeing rate obtained experimentally with solvent-assisted dyeings. The effect of a surface 
barrier in decreasing the rate of dyeing is, however, demonstrated and this effect might be appreciable.

An experimental and theoretical treatment of the influence of a surface barrier on the dyeing rate of wool based on assumptions other than those above, has been published recently and shows a definite effect of a barrier in decreasing the rate of dyeing at the beginning of the dyeing period (Medley and Andrews, 1959).

The solvent layer theory as stated above is thus an unsatisfactory explanation of solvent-assisted dyeings of wool.

\subsection{Loosening of the fibre structure}

An investigation by Rochas and Courmonts, 1959, of the action of a carrier in dyeing polyester fibre with disperse dyes has shown that the carrier functions by loosening the fibre structure. After total elimination of the carrier by treatment with steam, the increase in dyeing rate remains, although not quite to the same extent. The Delaware Valley section of the AATCC in a previously cited publication also proposes that the carrier acts on the fibre, and rejects both the solvent layer theory and action on the dye in the dyebath.

An extensive investigation of accelerant dyeing of hydrophobic fibres, published by the Piedmont Section of the AATCC,1959, discusses nine mechanisms for carrier dyeing published to date and rejects them all for different reasons, with the exception of theories involving changes in the internal structure of the fibre. The carrier is considered to form"fibre-carrier" bonds, thereby breaking the "fibre-to-fibre" bonds. The "fibre-carrier"bonds, being looser bonds, give greater accessibility of the fibre.

The experimental data on solvent-assisted dyeing of wool do not contradict this theory, although it might be difficult to explain some results, if this theory alone is used. When wool is treated with a solution of amyl alcohol in water, and the alcohol washed out com- 
pletely, an increased dyeing rate is obtained for some dyes, as shown in chapter 1. This is called the "extraction effect" and corresponds to the effect of carriers on polyester fibres described by Rochas et al. However, no "extraction effect" was obtained with Cibalanblau BL as can be seen from fig. 4 and yet, with this dye, a large increase in the dyeing rate was caused by solvents.

As shown in chapter 2.5 the stress-relaxation curve in water was unchanged by the addition of solvents. This would indicate that breaking of cross-bonds did not occur to any large extent. It might be possible, however, that the number of cross-linkages that must be broken to obtain an increase in the rate of dyeing, is smaller than that necessary to cause a change in the stress-relaxation curve.

Furthermore, there is an increase in the swelling of wool by adsorption of benzyl alcohol or hexylamine from aqueous solutions, indicating a loosening of the fibre structure. However, the additional swelling is small (less than $3 \%$ ).

By assuming the above theory to be the only one valid, it is difficult to explain why benzyl alcohol should increase the dyeing rate of bromphenol blue at $\mathrm{pH} 1.2$ and not at $\mathrm{pH} 7.8$ as it is adsorbed to about the same extent at these two pH-values.

Furthermore, it is difficult to see why the same carrier could not be used for all dyes of about the same size, irrespective of their chemical constitution. Neither is the condition of high solubility of the dye in the solvent or carrier explained by assuming only a loosening of the fibre structure. These aspects of the theory are overlooked in the paper cited above (Piedmont Section of AATCC).

In conclusion it might be stated that, for the hydrophobic fibres with a very compact internal structure, loosening of the fibre structure seems to be the most important function of the carrier in increasing the dyeing rate. Hydrophilic fibres, such as wool, however, are already highly swollen in water, so that further loosen- 
ing of the structure by solvents might not be as important as with hydrophobic fibres. Furthermore, the theory cannot account for all the experimental data. For example, it does not explain why a high solubility of dye in solvent is necessary to obtain an increase in dyeing rate. If we accept the fact that solvents change the internal structure of the fibre, we still need another explanation for the dyeing mechanism.

\subsection{Diffusion of dye in the adsorbed solvent}

In this paper, it is shown that the solvent is adsorbed by the wool, and that this adsorption is one necessary condition for obtaining an increased dyeing rate. Another condition is, that the solubility of the dye in the solvent used must be high. As a first approximation we consider the solvent adsorbed on the wool as a separate phase. This phase is then small compared with the water phase. Under the experimental conditions used the ratio of the volume of the water phase to that of solvent phase is of the order of 500:1. Furthermore, it must be assumed that the dye molecules can be transported into the wool fibres in the adsorbed solvent phase at the same time as the normal dye transportation takes place by means of diffusion in the water-swollen fibre phase. If the dye concentration in the solvent phase is much higher than in the water phase, a large proportion of the dyestuff is transported by means of the solvent phase and an appreciable increase in dyeing rate is obtained. However, with about the same concentration in both phases there will only be small changes in the dyeing rate.

The difficulty with this hypothesis, however, is the assumption that the adsorbed solvent forms a separate phase. For dyes, the dyeing rate of which is increased by solvents, the affinity for the fibre from a solvent solution is low, as is also the partition ratio of dye between water and solvent, as shown in chapter 1. Although the dye might be transported in the solvent phase, it is not very probable that it will leave this phase and be adsorbed by the fibre. 
These difficulties might be overcome by a slight change in the hypothesis.

Diffusion of dye in a fibre is assumed to take place through a system of canals. Part of the dye is in aqueous solution, while the remainder is adsorbed on the walls of the canals. It is usually assumed that the adsorbed dye is so firmly held that surface diffusion along the walls of the pores can be considered negligible as compared with the diffusion in solution (Vickerstaff, 1954, p. 141). However, a theoretical treatment is given by Standing et al, 1947, for the case when diffusion along the walls of the pores is significant.

When a solvent is adsorbed on wool we might assume that the pore walls, to some extent, are covered with solvent molecules. Dye molecules, adsorbed on these solvated walls, may be assumed to have greater mobility than when adsorbed on the fibre molecules. Either a diffusion takes place along the solvated walls, or the concentration of "free" dye molecules in solution is increased by breaking the weak fibre-solvent bonds. In both cases an increase in the rate of diffusion is obtained. A high solubility of the dye in the solvent would then result in a high degree of adsorption of the dye molecules on the solvated walls. By this treatment we do not need to assume a separate solvent phase with a phase boundary at the fibre.

This theory is supported by the microscopical studies of cross-sections from the industrial dyeing experiments (see chapter 4). The ring-dyed fibres obtained after conventional dyeing give evidence of a strong attraction between fibre and dye. The dyeings in the presence of butanol show rapid penetration, pale in the beginning, but growing darker as the dyeing proceeds. This behaviour is also obtained by dyes with low affinity for the fibre.

According to the above theory the more uniform dye distribution obtained in the presence of solvents indicates that the adsorption of the solvents is also rather uniform. A change in dyeing conditions 
resulting in all parts of a fibre surface becoming accessible to the dye will, in itself, cause an increase in the dyeing rate. Such a uniform dye distrioution at the beginning of a dyeing can be obtained by surface-treatment of wool (Millson et al, 1950, Lindberg, 1953). Eowever, as surface-treated wool still shows an increase in dyeing rate in the presence of solvents, it is unlikely that the more uniform dye distribution is responsible for the increase, although it might be in the case of untreated wool. For these reasons, solvents can be expected to cause a greater increase in dyeing rate on untreated wool than on chlorinated wool.

However, even in the case where no change in dye distribution occurs, a relation between the increase in, and the magnitude of, the dyeing rate in a given system is to be expected from the theory given above. Under conditions where the amount of dye diffusing into the fibre is increased by changing, for example, the fibre properties or temperature of dyeing, without any change in the adsorption of solvent or solubility of dye in solvent, the relative effect of the solvent would be less in increasing the rate of dyeing.

Under the experimental conditions used in chapter 2.4 the increase in the rate of dyeing caused by solvents was about twice as great on untreated wool as on chlorinated wool. This is probably due to both factors described above. The results of dyeing untreated and alkali-treated wool with Cibalanblau BL given in fig. 4 might also be explained by these two factors.

However, the effect of some solvents in causing a more uniform dye distribution might have as much practical importance as an increase in the dyeing rate, although it is more difficult to express this in a quantitative manner. 


\section{INDUSTRIAL EXPERTNENTS ON LOOSE WOOL DYEING}

When loose wool is dyed industrially, care is usually taken to obtain a dyeing rate which is low enough to give level dyeing. The levelness will depend on the properties of the dyestuff and also on the design of the dyeing machinery.

In an ideal loose wool dyeing process all fibres should be subjected to the same concentration of dye liquor at the same time. In a conventional loose wool dyeing machine, however, the dye liquor is circulated through a large plug of wool fibres. If the rate of flow of the liquor is slow compared with the dyeing rate, the concentration of dye in solution may decrease considerably in the initial stages of dyeing, causing an uneven dye distribution. Subsequently, a redistribution will take place from more to less coloured parts of the wool. This is, however, a rather slow process, especially for dye with high affinity for wool.

The more uniform distribution of dye between different wool fibres in the presence of a solvent as described in the previous chapter is a clear advantage in technical dyeing processes. It is, however, important to investigate whether the increased dyeing rate brought about by solvents, can be utilized in technical dyeings.

For this reason experiments were carried out in a Swedish mill; loose wool was dyed by conventional methods and also with butanol or amyl alcohol added to the dyebath. Time and temperature of dyeing were varied, and the following properties were studied: levelness and fastness properties of the dyeing, penetration of dye into the fibre and change in mechanical properties of the wool fibres due to the dyeing process. The result of this investigation has been reported, but a brief summary will be given below (Kärrholm, 1956 and 1958 , in Swedish). 


\subsection{Performance of the experiments}

\section{$\underline{\text { Raw material }}$}

Two types of wool were used. Cape wool, from 8 - 10 months old sheep, and Australian wool $\left(58^{\prime} \mathrm{s}\right)$. The wool was scoured in a textile mill by their usual methods. The Cape wool was used for the main experiments and the results given below refer to this type of wool.

\section{Apparatus}

A stainless steel dyeing machine for loose wool containing $10 \mathrm{~kg}$ wool and 1701 dye liquor was used. The liquor was circulated in only one direction (from bottom to top of the packed wool).

\section{Dyestuff}

All dyeings reported here were performed with Cibalanblau BL (1:2 chrome-complex dye).

\section{$\underline{\text { Procedure }}$}

The wool was packed in a perforated stainless steel container with the addition of cold water, and the container then placed in the dyeing machine. Liquor containing ammonium sulphate ( $3 \%$ on the weight of the wool) and acetic acid, at a pH of $6.2-6.4$ was circulated through the wool. The temperature was adjusted to $40^{\circ} \mathrm{C}$. When an alcohol was used, it was then added to the bath, and some minutes afterwards, the dye ( $2 \%$ on the weight of the wool) dissolved in water, was also added. The temperature was raised to the desired value and dyeing was continued for a fixed time. The bath was then emptied, and the wool rinsed in the machine four times with cold water. Small samples were taken from the top, the middle and the bottom layer in order to compare the colours for levelness. The wool was then centrifuged and dried.

Dyeing was carried out either at $70^{\circ} \mathrm{C}$ for different times in the presence of butanol ( $5 \%$ by volume) or amyl alcohol ( $3 \%$ by volume), 
or at $95^{\circ} \mathrm{C}$ for 5 minutes with butanol in the dyebath. In one series, the wool was dyed at $70^{\circ} \mathrm{C}$ for $20 \mathrm{~min}$. and the temperature then raised to $95^{\circ} \mathrm{C}$ and kept there for about $5 \mathrm{~min}$. A conventional dyeing without the addition of alcohols was made by circulating the dye liquor through the wool at $95^{\circ} \mathrm{C}$ for $45 \mathrm{~min}$. In all cases exhaustion of the dyebath was almost complete. The dyeing conditions are summarized in table 15.

\section{Table 15}

Dyeing conditions used in the industrial dyeing experiments Cibalanblau BL $1.18 \mathrm{~g} / \mathrm{l}$; liquor ratio $17: 1$; $\mathrm{pH} 6.2-6.4$

\begin{tabular}{|c|c|c|c|c|c|c|}
\hline \multirow{2}{*}{$\begin{array}{c}\text { Test } \\
\text { series } \\
\text { nr }\end{array}$} & \multirow{2}{*}{$\begin{array}{c}\text { Addition } \\
\text { to } \\
\text { dyebath }\end{array}$} & \multicolumn{4}{|c|}{$\begin{array}{l}\text { Time in min. } \\
\text { at a temperature of }\end{array}$} & \multirow{2}{*}{$\begin{array}{l}\text { Exhaustion } \\
\text { of dyebath } \\
\% \text { of available } \\
\text { dye }\end{array}$} \\
\hline & & $40-70^{\circ} \mathrm{C}$ & $70^{\circ} \mathrm{C}$ & $70-95^{\circ} \mathrm{C}$ & $95^{\circ} \mathrm{C}$ & \\
\hline 1 & none & $\leftarrow$ & 45 & $\longrightarrow$ & 45 & \\
\hline 2 & $\begin{array}{l}\text { amyl alcohol } \\
3 \% \text { by volume }\end{array}$ & 17 & 20 & & & $\sim 99$ \\
\hline 3 & $\begin{array}{l}\text { butanol } \\
5 \% \text { by volume }\end{array}$ & 16 & 20 & & & $>95$ \\
\hline 4 & - " - & 17 & 40 & & & $\sim 99$ \\
\hline 5 & - " - & 16 & 80 & & & $\sim 99$ \\
\hline 6 & - " - & 17 & 20 & 10 & 6 & $\sim 99$ \\
\hline 7 & - " - & $\leftarrow$ & 30 & $\longrightarrow$ & 5 & $\sim 99$ \\
\hline
\end{tabular}

\subsection{Results and conslusions}

\section{Results}

Levelness

In all test series, where the alcohol was added at $40^{\circ} \mathrm{C}$, only small differences in depth of colour were obtained between the top and bottom layers of the wool. Practical dyers considered that the overall level- 
ness was at least as good as a conventional dyeing.

Penetration of dye into the fibres

The degree of penetration was determined by microscopical examination of cross-sections of the fibres. These were divided into two classes; ring-dyed and completely penetrated fibres (no undyed fibres were detected). The results are given in table 16 and represent the mean values from 500 fibres.

\section{Table 16}

Penetration of dye into wool fibres

at different dyeing conditions

\begin{tabular}{|c|c|c|c|c|}
\hline $\begin{array}{l}\text { Test } \\
\text { se- } \\
\text { ries }\end{array}$ & $\begin{array}{c}\text { Time and temp. } \\
\text { of } \\
\text { dyeing }\end{array}$ & $\begin{array}{l}\text { Addition } \\
\text { to } \\
\text { dyebath }\end{array}$ & $\begin{array}{l}\% \text { completely } \\
\text { penetrated } \\
\text { fibres }\end{array}$ & $\begin{array}{l}\% \text { ring- } \\
\text { dyed } \\
\text { fibres }\end{array}$ \\
\hline 1 & $45 \mathrm{~min}$. at $95^{\circ} \mathrm{C}$ & none & 13 & 87 \\
\hline 2 & $20 \mathrm{~min}$. at $70^{\circ} \mathrm{C}$ & amyl alcohol $3 \%$ & 35 & 65 \\
\hline 3 & $20 \mathrm{~min}$. at $70^{\circ} \mathrm{C}$ & butanol $5 \%$ & 14 & 86 \\
\hline 4 & $40 \mathrm{~min}$. at $70^{\circ} \mathrm{C}$ & butanol $5 \%$ & 23 & 77 \\
\hline 5 & $80 \mathrm{~min}$. at $70^{\circ} \mathrm{C}$ & butanol $5 \%$ & 65 & 35 \\
\hline 6 & $\begin{array}{l}20 \mathrm{~min} \text {. at } 70^{\circ} \mathrm{C}+ \\
+5 \mathrm{~min} \text {. at } 95^{\circ} \mathrm{C}\end{array}$ & butanol $5 \%$ & 85 & 15 \\
\hline 7 & $5 \mathrm{~min}$. at $95^{\circ} \mathrm{C}$ & butanol $5 \%$ & 80 & 20 \\
\hline
\end{tabular}

From the table it is seen that conventional dyeing gives the lowest proportion of completely penetrated fibres. Further, dyeing for a short time at $95^{\circ} \mathrm{C}$ gives a higher percentage of completely penetrated fibres than longer times at $70^{\circ} \mathrm{C}$. Increasing the dyeing time at the same temperature, in the presence of butanol, results in a higher percentage of penetrated fibres. Amyl alcohol gives a higher degree of penetration than does butanol under the same conditions. 
dyed fibres. Cibalanblau BL penetrates the wool fibres as a sharp boundary, slowly moving inwards. After conventional dyeing, the fibres are either completely undyed in the centre, or the whole crosssection has the same strength of colour. When the dyeing was performed in the presence of alcohols, however, complete penetration is rapidly obtained. The cross sections show a pale but uniform distribution of colour growing darker as dyeing proceeds. At the same time a sharp boundary of dye slowly moves inwards.

\section{Fastness properties}

The fastness properties of the dyeings to rubbing, washing and light were tested. Swedish standard methods were used for the determinations: SIS 650014 for the fastness to rubbing, SIS 650017 for the fastness to washing at $40^{\circ} \mathrm{C}$ and SIS 650013 for the fastness to light, using the Fade-Ometer for testing. In table 17 the values obtained are summarized. For fastness to rubbing and washing, the scale runs from 1 to 5, the lowest rating being 1 , and 5 the highest. For light fastness the scale is F 1 to $F 8, F 1$ being the lowest and $F 8$ the highest fastness.

Table 17

Fastness ratings to rubbing, washing and light of wool dyed at different conditions

\begin{tabular}{|c|c|c|c|c|c|c|c|}
\hline \multirow{3}{*}{$\mathrm{Nr}$} & \multirow{3}{*}{$\begin{array}{c}\text { Time and temp. } \\
\text { of } \\
\text { dyeing }\end{array}$} & \multirow{3}{*}{$\begin{array}{l}\text { Addition } \\
\text { to } \\
\text { dyebath }\end{array}$} & \multicolumn{5}{|c|}{ Fastness ratings to } \\
\hline & & & \multirow{2}{*}{\multicolumn{2}{|c|}{\begin{tabular}{|l|}
\multicolumn{2}{|c|}{ rubbing } \\
dry
\end{tabular}}} & \multicolumn{2}{|c|}{$\begin{array}{l}\text { washing at } 400^{\circ} \mathrm{C} \\
\text { staining on }\end{array}$} & \multirow[t]{2}{*}{ light } \\
\hline & & & & & cotton & wool & \\
\hline 1 & $45 \mathrm{~min}$ at $95^{\circ} \mathrm{C}$ & none & 4 & 4 & 5 & $4-5$ & F7 \\
\hline 2 & 20 min. at $70^{\circ} \mathrm{C}$ & amyl alcohol $3 \%$ & 3 & 5 & $4-5$ & 4 & F6 \\
\hline 3 & $20 \mathrm{~min}$ at $70^{\circ} \mathrm{C}$ & butanol $5 \%$ & $3-4$ & $4-5$ & $4-5$ & $4-5$ & F6 \\
\hline 4 & $40 \mathrm{~min}$ at $70^{\circ} \mathrm{C}$ & -"- & 4 & $4-5$ & 5 & $4-5$ & F6 \\
\hline 5 & $80 \mathrm{~min}$ at $70^{\circ} \mathrm{C}$ & $-"$ - & 4 & $4-5$ & 5 & $4-5$ & F6 \\
\hline 6 & $\begin{array}{l}20 \mathrm{~min} \text { et } 70^{\circ} \mathrm{C}+ \\
+5 \mathrm{~min} \text { at } 95^{\circ} \mathrm{C}\end{array}$ & -" - & $4-5$ & 5 & 5 & $4-5$ & F7 \\
\hline 7 & $5 \mathrm{~min}$ at $95^{\circ} \mathrm{C}$ & -"- & $4-5$ & $4-5$ & 5 & $4-5$ & F7 \\
\hline
\end{tabular}


About the same fastness to rubbing as by conventional dyeing is obtained in the presence of butanol, but amyl alcohol in the dyebath causes a lower fastness to rubbing in the dry state, probably due to the lower solubility of the alcohol in water, which makes it more difficult to remove from the wool. The fastness to washing of the dyeings is hardly influenced by using alcohols in the dyebath.

Fastness to light is also unaffected provided the dyeings are performed at $95^{\circ} \mathrm{C}$. Dyeings at $70^{\circ} \mathrm{C}$, however, give a lower fastness rating to light.

\section{Mechanical properties}

The influence of the dyeing process on breaking tenacity and elongation at break of the fibres was determined on an Instron textile testing machine. 30 fibres from each sample were tested and the diameter of each fibre was measured by the resonance frequency method (Gonsalves, 1947). The results are given in table 18 together with the standard deviations. The confidence interval, d, for the difference between two mean values of the breaking tenacity has been calculated from $d=t s \sqrt{1 / n_{1}+1 / n_{2}}$, where $s$ is the standard deviation obtained as the square root of the mean value of $s^{2}$ in table $18, n=$ number of tests. In this case $n_{1}=n_{2}=30$. $t$ is obtained from statistical tables. The $95 \%$ confidence interval obtained $=0.14 \mathrm{~g} /$ den for the breaking tenacity and $7 \%$ for the elongation at break. Thus, there is no change in the breaking tenacity and elongation for dyeings 2,3 and 4 i.e. the batches dyed at $70^{\circ} \mathrm{C}$ for $40 \mathrm{~min}$. or less in the presence of butanol or amyl alcohol. For the other dyeings there may be a tendency for both breaking tenacity and elongation at break to be reduced. The largest loss of tenacity and elongation is, however, given by a conventional dyeing process. 
$\underline{\text { Table } 18}$

Mechanical properties of wool fibres, dyed at different conditions

\begin{tabular}{|c|c|c|c|c|c|c|}
\hline $\begin{array}{l}\text { Test } \\
\text { se- } \\
\text { ries }\end{array}$ & $\begin{array}{c}\text { Time and temp. } \\
\text { of } \\
\text { dyeing. }\end{array}$ & $\begin{array}{l}\text { Addition } \\
\text { to } \\
\text { dyebath }\end{array}$ & $\begin{array}{l}\text { Breaking } \\
\text { tenacity } \\
\text { g/den. }\end{array}$ & $8^{1)}$ & $\begin{array}{c}\text { Elongation } \\
\text { at break } \\
\%\end{array}$ & $\mathrm{~s}^{1)}$ \\
\hline 1 & $45 \min$ at $95^{\circ} \mathrm{C}$ & none & 1.07 & 0.30 & 32.2 & $17 \cdot 3$ \\
\hline 2 & 20 min at $70^{\circ} \mathrm{C}$ & $\begin{array}{l}\text { amyl alco- } \\
\text { hol } 3 \%\end{array}$ & 1.23 & 0.19 & $47 \cdot 5$ & 19.2 \\
\hline 3 & $20 \mathrm{~min}$ at $70^{\circ} \mathrm{C}$ & butanol $5 \%$ & 1.23 & 0.31 & 42.2 & 15.0 \\
\hline 4 & $40 \mathrm{~min}$ at $70^{\circ} \mathrm{C}$ & -" - & 1.29 & 0.21 & 47.7 & 11.4 \\
\hline 5 & $80 \mathrm{~min}$ at $70^{\circ} \mathrm{C}$ & -"- & 1.13 & 0.25 & 38.5 & 15.2 \\
\hline 6 & $\begin{array}{l}20 \mathrm{~min} \text { at } 70^{\circ} \mathrm{C}+ \\
+5 \mathrm{~min} \text { at } 95^{\circ} \mathrm{C}\end{array}$ & -" - & 1.14 & 0.29 & 42.0 & 13.7 \\
\hline \multirow[t]{3}{*}{7} & 5 min at $95^{\circ} \mathrm{C}$ & -" - & 1.14 & 0.27 & 40.8 & $14 \cdot 3$ \\
\hline & undyed & - & 1.24 & 0.27 & $45 \cdot 3$ & 12.2 \\
\hline & \multicolumn{3}{|c|}{ Mean value } & 0.264 & & 13.7 \\
\hline
\end{tabular}

The mean value of the standard deviation determined from the mean value of the variance is $0.26 \mathrm{~g} /$ den for the breaking tenacity; and $13.7 \%$ for the elongation at break.

The $95 \%$ confidence interval for the difference between two mean values is $0.14 \mathrm{~g} /$ den for the breaking tenacity and $7 \%$ for the elongation at break. 


\section{Conclusions}

The increased dyeing rate of wool, brought about by some alcohols, could be technically utilized in two ways, either by lowering the temperature of dyeing with normal dyeing times, or by aecreasing the time of dyeing at normal dyeing temperature. From the above experiments it was found that, when butanol was used in the dyebath, the wool always appeareddarker after dyeing at $95^{\circ} \mathrm{C}$ than at $70^{\circ} \mathrm{C}$, although the amount of dye on the fibres was the same in each case.

This difference is explained by the higher degree of penetration obtained after dyeing at $95^{\circ} \mathrm{C}$. Garrett and Peters, 1956, have shown that an increase in penetration from 10 per cent to 100 per cent has the same effect as a 33 per cent increase in dye concentration. The fastness properties are also slightly better after dyeing at the higher temperature. For these reasons a solventassisted dyeing process performed at about $95^{\circ} \mathrm{C}$ for a short time ( 5 min.) is superior to one at $70^{\circ} \mathrm{C}$ for a longer time ( $40 \mathrm{~min}$ ).

Comparing conventional loose wool dyeing with a process using solvents (e.g. butanol) to increase the rate of dyeing, the latter process gives the same over-all levelness and the same fastness properties after a much shorter time of dyeing and with less fibre degradation. These results justify an interest in the method of solvent-assisted dyeing of wool. 


\section{SUMMARY}

It was previously known that the addition of sparingly soluble alcohols or amines to an aqueous solution of a dye can cause an appreciable increase in the dyeing rate of wool. In this paper such an effect is referred to as "solvent-assisted" dyeing. It was the aim of this investigation to determine under what conditions an effect of solvents was obtained, in order to try the method industrially, and also to obtain some understanding. of the dyeing mechanism.

A preliminary investigation showed, that the increase in dyeing rate is dependent on the degree of sulphonation of the dye. The greatest increase was obtained with an unsulphonated dye and no change in the dyeing rate was observed with a trisulphonated dye.

The dyeing rate increases with the concentration of solvent in the dye liquor, but a maximum is obtained at the saturation concentration. No change in equilibrium exhaustion of a dye was observed when butanol, or amyl alcohol, was added to an aqueous solution in a concentration lower than the saturation concentration. The equilibrium exhaustion of a dye from a solvent solution, saturated with water was, however, found to be much lower than from an aqueous solution.

The "extraction" effect of the solvent is discussed. It was found that the dyeing rate of some acid dyes was increased by pretreatment of the wool with a solvent, which was washed out again before dyeing. However, this effect was not observed with a $1: 2$ chromecomplex dye.

The distribution of dye between different fibres has been studied microscopically. The results indicate that, if the dyeing rate of wool is increased by a solvent, the distribution of dye will be more uniform between different fibres and different parts of the same fibre. 
In addition to this preliminary investigation, more extensive experimental work was carried out on factors of importance to the dyeing mechanism.

The adsorption of alcohols on wool from aqueous solution was measured quantitatively. A special apparatus was designed for this purpose and by means of this it was possible to determine the adsorption of alcohols and dyes on wool in the same experiment. By using a monomolecular dye, it was shown that the uptake of dye on wool after a fixed time is a rectilinear function of the adsorbed amount of benzyl alcohol. The same rectilinear function is valid also for the uptake of dye as a function of the adsorbed amount of some aliphatic alcohols at low adsorption values.

Adsorption isotherms were determined for some aliphatic alcohols, and showed an increase in adsorption with decreasing solubility of the alcohol in water.

The influence of benzyl alcohol on the dyeing rate of an indicator dye, bromphenol blue, was determined at $\mathrm{pH} 1.2$ (acid modification of dye) and at $\mathrm{pH} 7.8$ (basic modification of dye). This alcohol increased the dyeing rate at $\mathrm{pH} 1.2$ but had no effect at $\mathrm{pH} 7.8$. The same amount of alcohol was adsorbed on the wool in both cases. It was shown, however, that the solubility of the acid form in benzyl alcohol is much greater than that of the basic one. By using an amine as solvent, in which the basic form has high solubility, a great increase in the dyeing rate was obtained.

The influence of the surface properties of wool on solvent-assisted dyeings have been investigated. For this purpose, wool was chlorinated to different degrees and dyed with bromphenol blue at $\mathrm{pH} 1.2$ using benzyl alcohol to increase the dyeing rate, and at $\mathrm{pH} 7.8$ using hexylamine for the same purpose. The dyeing rate was described in terms of diffusion coefficients, calculated according to Olofsson's method. It was found that solvents cause a smaller increase in the 
dyeing rate of chlorinated wool than of untreated wool, but there is still a large effect with completely descaled wool.

It has been shown that the stress-relaxation properties of wool fibres in aqueous solution are unchanged by the addition of butanol or amyl alcohol to the dyebath.

Compared with that in water, a small increase in the swelling of wool fibres by benzyl alcohol and hexylamine has been observed.

The mechanism of solvent-assisted dyeing of wool is discussed on the basis of the experimental results obtained.

It was concluded that the solvent acts on the fibre and not on the dye in the dyebath.

The solvent layer theory is treated both as an equilibrium problem and as a kinetic one. It is shown, that this theory cannot explain the observed increase in the dyeing rate.

The experimental results do not contradict the theory of loosening of the fibre structure, which several workers believe to be the main mechanism for carrier-dyeing of hydrophobic fibres. However, this is considered to be of less importance for hydrophilic fibres, and this theory alone cannot account for all experimental data.

A new theory, which assumes a supplementing of normal diffusion in the fibre by diffusion in the adsorbed solvent, or possibly by an increase in the "free" concentration of solute in the fibre, is discussed.

The more uniform dye distribution obtained with solvent-assisted dyeing is considered in relation to the surface properties of wool.

Industrial dyeings on loose wool have been carried out using butanol or amyl alcohol as additions to the dyebath. Two different methods 
were used; dyeing at $70^{\circ} \mathrm{C}$ for normal dyeing times, or dyeing at $95^{\circ} \mathrm{C}$ for very short times. The latter process gave the best result. In both cases, a greater proportion of the fibres were found to be penetrated by the dye than after conventional dyeing. The same fastness properties of the dyeings were obtained with and without solvent in the dyebath. There is, however, less-fibre degradation during a solvent-assisted dyeing. 


\section{ACKNOWLEDGEMENTS}

The author wishes to thank Dr Joel Lindberg for many interesting and stimulating discussions and advice on surface treatment, Dr Bertil Olofsson for valuable collaboration in diffusion problems, and Dr Martin Sandelius for advice regarding statistical questions.

Mr John Holmström helped to design the apparatus. The experimental work was skilfully carried out by Mrs Gunvor Svensson and Miss AnnMarie Andersson, and the microscopy by Mr Rolf Nilsson. The drawings were made by Miss Inga-Lisa Carlström. Miss Linéa Björnsson took great care in typing the manuscript. The English text was revised by Dr Arthur J. Farnworth. To all these persons, I wish to express my appreciation and thanks.

The industrial experiments were carried out at Aktiebolaget Förenade Yllefabrikerna, Norrköping, and the stimulating co-operation with their technical staff is gratefully acknowledged.

I am also much indebted to the head of the institute, Professor Nils Gralén, for his great interest in this investigation.

This work was partly financed by a grant from the International Wool Secretariat, to whom grateful acknowledgement is made. 


\section{BIBLIOGRAPHY}

The following abbreviations are used:

American Association of Textile Chemists

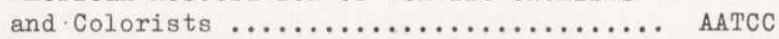

American Dyestuff Reporter ............ Am. Dyestuff Rep.

International Federation of Associations of Textile Chemists and Colourists ....... IFATCC

Journal of the Textile Institute ........ J.Text.Inst. Journal of the Society of Dyers and Colourists ................ J.Soc.Dyers Col.

Philosophical Magazine and Journal of Science .............. Phil.Mag.

Meddelanden från

Svenska Textilforskningsinstitutet ...... Medd.Sv.Textilforskn.inst.

Proceedings of International Wool Textile

Research Conference ................ Proc.Int.Wool Text.Res.Conf

Textile Research Journal ............ Text.Res.J.

AATCC, Delaware Valley Section - Carrier-assisted Dyeing of Hydrophilic Fibers. Am. Dyestuff Rep. 47 (1958), p. P789.

AATCC, Piedmont Section - Accelerant Dyeing of Hydrophobic Fibers Principles and Mechanisms. Am. Dyestuff Rep. 48:22 (1959), p. 23.

Atkinson, J.C., Filson, A. and Speakman, J.B. - Action of Mixed Solvents on Wool. Nature 184 (1959), p. 444.

Baritt, J. and Elsworth, F.F. - The Dyeing Properties of Chlorinated Wool. J.Soc.Dyers Col. 64 (1948), p. 19.

Crank, J. - The Mathematics of Diffusion. Oxford 1956.

Choquette, R.P. - Progress in the Dyeing of the Newer Synthetic Fibers. Text.Res.J. 24 (1954), p. 387.

Delmenico, J. - Melange or Vigoreux Printing of Wool: A Method for Increasing the Rate of Dye Fixation. Text.Res.J. 27 (1957), p. 899.

Fortess, F. and Salvin, V.S. - Factors Influencing the Dyeing of Acetate Fibers with Disperse Nonionic Dyes. Text.Res.J. 28 (1958), p. 1009.

Garrett, D.A. and Peters, R.H. - Effect of Penetration on Reflectance of Dyed Textile Fibres. J.Text.Inst. 47 (1956), p. T166. 
Gokhale, M.K., Peters, L. and Stevens, C.B. - Dyeing Hydrophobic Fibres in Solutions of Solvents. J.Soc.Dyers Col. 74 (1958), p. 236.

Gonsalves, V.E. - Determination of Denier and Strength of Single Filaments by Vibroscope and Heim Tensile Tester. Text. Res.J. 17 (1947), p. 369.

Katz, S.M. and Tobolsky, A.V. - The Relaxation of Stress in Wool Fibers. Text.Res.J. 20 (1950), p. 87.

Kolthoff, I.M. and Rosenblum, C. - Acid-Base Indicators. New York 1937 .

Kramer, B. - Über die Vorgänge beim Färben vollsynthetischer Fasern mit Dispersionsfarbstoffen. Reyon Zellwolle 10 (1955), p. 682 .

Kärrholm, E.M. and Lindberg, J. - The Effect of Solvents on Wool Dyeing. Text.Res.J. 26 (1956), p. 528.

Kärrholm, E.M. - Teknisk färgning av ull i närvaro av butanol och amylalkohol. Medd.Sv. Textilforskn.inst. (1956), nr 11.

Kärrholm, E.M. - Teknisk färgning av lösull i närvaro av butanol och amylalkohol. Textil och Konfektion (1958), nr 6, p. 22.

Lindberg, J. and Gralén, N. - Medd.Sv.Textilforskn.inst. (1949), nr 10 .

Lindberg, J. - Relationship Between Various Surface Properties of Wool Fibers. Part III: Sorption of Dyes and Acids in Wool Fibers. Text.Res.J. 23 (1953), p. 573.

Luck, W.J. - The Mode of Action of Non-Ionic Levelling Agents. J.Soc.Dyers Col. 14 (1958), p. 221.

Medley, J.A. and Andrews, M.W. - The Effect of a Surface Barrier on Uptake Rates of Dye into Wool Fibers. Text.Res.J. 29 (1959), p. 398 .

Millson, H.E. and Turl, L.H. - Studies on Wool Dyeing: The Influence of the Cuticle in the Dyeing of the Wool Fiber. Am. Dyestuff Rep. 29 (1950), p. P647.

Millson, H.E. - The Microdyeoscope, Microscopical Observations on Dyeing. Am. Dyestuff Rep. 44 (1955), p. P417.

Olofsson, B. - A Method of Calculating Diffusion in Fibres Coupled with Irreversible Adsorption or Rapid Reaction. J.Text. Inst. 47 (1956), p. T464.

Peters, L. and Stevens, C.B. - A New Approach to Dyeing. Dyer 115 (1956), p. 327.

Reid, V.W. and Truelove, R.K. - The Colorimetric Determination of Alcohols. Analyst 77 (1952), p. 325.

Rochas, P. and Courmont, M. - The Mechanism of the Action of "Carriers" in the Dyeing of Polyester Fibres with Disperse Dyes. Developments in Dyeing, Printing and Finishing. IFATCC-Congress, London 1959. 
Schetty, G. - The Irgalan Dyes - Neutral-dyeing Metal-Complex Dyes. J.Soc.Dyers Col. 71 (1955), p. 705.

Schuyten, H.A., Weaver, J.W. and Reid, J.D. - An Index of the Water-Repellency of Textiles from the Surface Tension of Aqueous Solutions. Am. Dyestuff Rep. 38 (1949), p. 364 .

Standing, H.A., Warwicker, J.O. and Willis, H.F. - The Diffusion of Direct Dyes in Cellulose. J.Text.Inst. 38 (1947), P. T335.

Stevens, C.B. and Peters, L. - The Effect of Organic Solvents on the Absorption of Dyes by wool from Aqueous Solutions at Low Temperatures. J.Soc. Dyers Col. 72 (1956), p. 100.

Speakman, J.B. and Shah, S.Y. - The Plasticity of Animal Fibres. J.Soc.Dyers Col. 57 (1941), p. 108.

Vickerstaff, Th. - The Physical Chemistry of Dyeing. London 1954.

Wikström, L., Sörvik, E., Cednäs, M. and Olofsson, B. - Chemical Modifications of the Surface Layer of Wool and Their Effect on Wettability and Sorption Properties. Proc.Int. Wool Text.Res.Conf., Australia, 1955, C 257.

Wilson, A.H. - A Diffusion Problem in which the Amount of Diffusing Substance is Finite. Part I. Phil.Mag. 39 (1948), p. 48.

Zimmerman, C.L., Mecco, J.M. and Carlino, A.J. - A Study of Carriers in Dyeing Dacron Polyester Fiber. Am. Dyestuff Rep. 44 (1955), p. P296.

B.P. Patent Specification 546915 (1941). - Process for Imparting to Wool a Gloss similar to that of Natural Silk.

The calculations of confidence limits and confidence intervals have been made according to conventional statistical methods, see for example:

Davies, 0.L. - Statistical Methods in Research and Production With Special Reference to the Chemical Industry, 3rd. ed., London 1957.

The Swedish standard methods for testing textiles referred to in this paper are obtainable from

Sveriges standardiseringskommission, Box 3295, Stockholm 3. 


\section{CHALMERS BIBLIOTEK}

